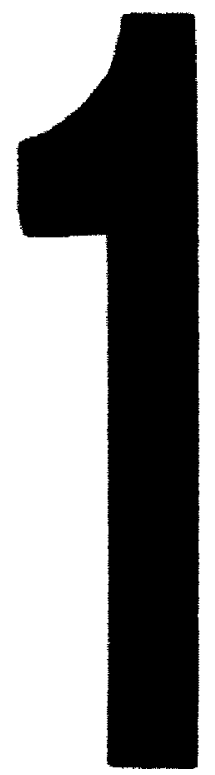

PM-1 31/2"x4" PHOTOCRAPHC MICROCOPY TARCET NBS 10109 AMSI/15O W2 EOUNALENT

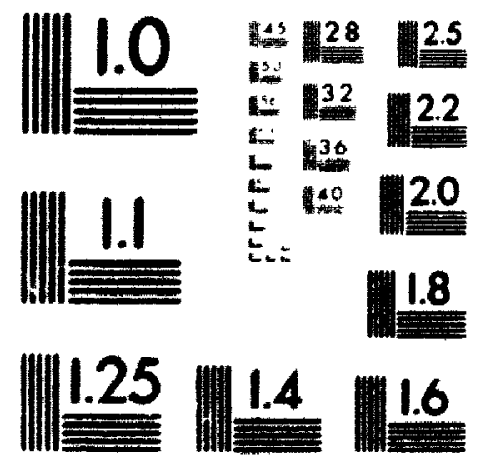


The quality of this microform is heavily dependent upon the quality of the original thesis submitted for microfilming. Every effort has been made to ensure the highest quality of reproduction possible.

If pages are missing, contact the university which granted the degree.

Some pages may have indistinct print especially if the original pages were typed with a poor typewriter ribbon or if the university sent us an inferior photocopy.
La qualité de cette microforme dépend grandement de la qualité de la thèse soumise au microfilmagt. Nous avons tout fait pour assurer une qualité supérieure de reproduction.

S'il manque des pages, veuillez communiquer avec l'université qui a conféré le grade.

La qualité d'impression de certaines pages peut laisser à désirer, surtout si les pages originales ont été dactylographiées à l'aide d'un ruban usé ou si l'université nous a fait parvenir une photocopie de qualité inférieure.

La reproduction, même partielle, de cette microforme est soumise à la Loi canadienne sur le droit d'auteur, SRC 1970, c. C-30, et ses amendements subséquents.
Reproduction in full or in part of this microform is governed by the Canadian Copyright Act, R.S.C. 1970, c. C-30, and subsequent amendments. 


\title{
SIMULATING INDIRECT THRUST MEASUREMENT METHODS AS USED ON MODERN HIGH-BYPASS TURBOFANS
}

\author{
by \\ Jonathan D. Stevenson \\ B.Eng.(Mech.), Memorial University of Newfoundland (1990)
}

A thesis submitted to the Faculty of Graduate Studies and Research in partial fuliiment of the requirements for the degree of

\author{
Master of Engineering \\ Department of Mechanical and Aerospace Engineering \\ Ottawa-Carteton Institute for Mechanical and Aerospace Engineering (OCIMAE) \\ Carleton University \\ Ottawa, Ontario \\ Canada \\ December, 1992 \\ (1) copyright \\ 1993, Jonathan D. Stevenson
}


Acquisitions and

Bibliographic Services Branch

395 Welinglon Street

Ottawa. Ontano

KIA ON4

\section{Bibliotheque nationale}

du Canada

Direction des acquisitions et

des services bibliographiques

395. rue Wellinglon

Otrawa (Ontario)

KIA ON4
The author has granted an irrevocable non-exclusive licence allowing the National Library of Canada to reproduce, loan, distribute or sell copies of his/her thesis by any means and in any form or format, making this thesis available to interested persons.
L'auteur a accordé une licence irrévocable et non exclusive permettant à la Bibliothèque nationale du Canada de reproduire, prêter, distribuer ou vendre des copies de sa thèse de quelque manière et sous quelque forme que ce soit pour mettre des exemplaires de cette thèse a la disposition des personnes intéressées.

L'auteur conserve la propriété du droit d'auteur qui protège sa thèse. Ni la thèse ni des extraits substantiels de celle-ci ne doivent être imprimés ou autrement reproduits sans son autorisation. 
The undersigned hereby recommend to the Faculty of Graduate Studies and Research, acceptance of the thesis: "Simulating Indirect Thrust Measurement methods as Used on Modern High-Bypass Turbofans" submitted by J.D. Stevenson, in partial fulfilment of the requirements for the degree of Master of Engineering.

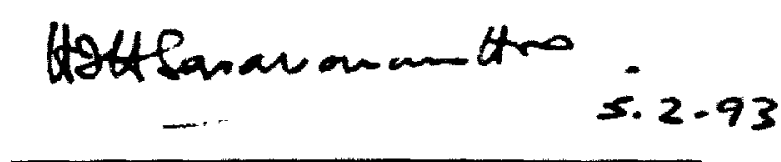

Thesis Supervisor

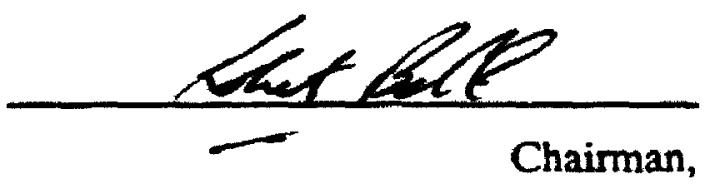

Department of Mechanical and Aerospace Engineering 


\begin{abstract}
As yet, there is no known reliable method for directly measuring the thrust of a turbofan in flight. Manufacturers of civil turbofans use various indirect thrust measurements to indicate performance of an engine to the flight deck. Included among these are: Engine Pressure Ratio (EPR), Integrated Engine Pressure Ratio (IEPR), Fan Mechanical Speed as a percentage of its uesign speed $\left(\mathrm{N}_{1}\right)$, and various Turbine Gas Temperatures. Of key concern is whether these thrust indicators give an accurate account of the actual engine thrust. The accuracy of trose methods, which are crucial at take-off, may be compromised by various types of common engine deterioration, to the point where a thrust indicator rnay give a false indication of the health and thrust of the engine.

A study was undertaken to determine the effect of advanced engine cycles on typical values of the most popular thrust setting parameters, using a generic computer model of a twin-spool high BPR turbofan. A preliminary investigation was conducted to determine the effects of various kinds of engine deterioration on the engine performance and the indirect thrust indicators.
\end{abstract}


To Michelle, for her support and patience 


\section{Acknowledgements}

I wish to recognize the following for their assistance during this project:

Professor H.I.H. Saravanamuttoo, whose wisdom and guidance helped me throughout this research, keeping me from "staying off course" on a number of occasions.

My wife Michelle, who (along with Prof. Saravanamuttoo) helped proof-read the numerous manuscripts for this thesis.

Kevin Williams, who was extremely helpful in providing the computer source conle for the twin-spool matching procedures for an RB211 industrial gas turhine simulattor. This formed the basis of the off-design core simulation section of the luribofan simulator presented in this thesis.

The Natural Science and Engineering Research Council (NSERC), whose linancial support helped make this research financially viable. 


\section{Table of Contents}

Chapter 1 Introduction 1

1.1 Objectives 1

1.2 Indirect Thrust Indicators 1

1.3 Origin of EPR and IEPR 4

$\begin{array}{lll}1.4 & \text { Scope of Study } & 7\end{array}$

Chapter 2 Choice of Design Point $\quad 9$

2.1 Definitions of Turbofan Design Points 9

2.2 Matching Different Design Points 10

2.2 Comparison of Different Choices of Primary Design Point 12

Chapter 3 On-Design Simulation Methods 16

3.1 Need for Accurate Design Point Performance 16

3.2 Basic Assumptions 16

3.3 Calculation Methods 17

Chapter 4 Off-Design Simulation Methods

4.1 Assumptions 27

4.2 Twin-Spool Matching Procedure $\quad 30$

4.3 Component Modelling Methods 34

Chapter 5 Turbofan Simulator Program Overview 43

S.1 Overall Program Structure 43

5.2 On-Design Module 44

5.3 Off-Design Module $\quad 47$

5.4 Miscellaneous Program Features $\quad 56$ 
Chapter 6 Nominal Simulation Results

6.1 Baseline On-Design Performance $\quad 58$

6.1.1 Specific Fuel Consumption and Specific Thrust 59

6.1.2 Thrust Splits

6.1.3 EPR and IEPR Variations $\quad 62$

6.2 Advanced Cycle Design Choice 65

6.3 Off-Design Performance Estimates $\quad 67$

6.3.1 Climb Performance 67

6.3.2 Cruise Performance 73

6.3.3 Take-off Performance 78

6.4.1 Simulation of the JT9D-7A 86

6.4.2 Simulation of the JT15D-4 91

Chapter 7 Deteriorated Engine Performance Simulation 9.4

$\begin{array}{ll}7.1 \text { Fault Simulation Methods } & 94\end{array}$

7.2 Take-off Performance with Faults
(10)

7.2.1 Take-off Thrust for Different Ambient Conditions 100

7.2.2 HDTO Thrust without Temperature Limiting 102

7.2.3 HDTO Thrust when Temperature Limiting is Applied 106

7.3 Cruise Performance with Faults 110

Chapter 8 Selection of Thrust Indicators $\quad 116$

8.1 Observations Concerning Thrust Indicators 116

8.2 Effect of Faults on Thrust Indication Accuracy 117 
$\begin{array}{ll}\text { Chapter } 9 \text { Conclusions and Recommendations } & 119\end{array}$

9.1 Conclusions 119

9.2 Recommendations for Further Work 121

9.2.1 Simulation of Other Faults 121

9.2.2 Enhancements to the Computer Model 121

References

123

Additional Readings

127 


\section{List of Tables}

Table 2.1 TOC and SLS Engine Cycle Matches

Table 2.2 Comparison of Nozzle Areas for Different Designs

Table 2.3 Comparison of Engine Cycle Parameters and Performance

Table 3.1 Constant Gas Properties Assumed

Table 6.1 Range of Engine Cycles used for On-Design Estimattes

Table 6.2 Design Data for Advanced Cycle Twin-Spool Turbofan

Table 6.3 Summary of Cruise Thrust Setting Parameters

Table 6.4 Summary of Take-off Thrust Setting Parameters

Table 6.5 JT9D-7A Cycle and Operation Dara

Table 6.6 Simulation of the JT9D-7A

Table 6.7 TOC Design Point Data used to Simulate the JT151).4

Table 6.8 Predicted JT15D-4 Take-off Performance and Engine Cycle

Table 7.1 Probable Turbofan Faults

Table 7.2 Setting HDTO Thrust (No Temperature Limits)

Table 7.3 Mean ITT Increases with Faults at HDTO Conditions

106

Table 7.4 Maximum HDTO Thrust with ITT Temperature Limiting

$10 \mathrm{x}$

Table 7.5 Effect of Faults on Cruise Fuel Flow 


\section{List of Figures}

Figure 1.1 Turbine Inlet Temperature and Cooling Trends 3

Figure 1.2 Turbofan Schematic $\quad 7$

Figure 2.1 Variation of Net Thrusts during Climb for Different Cycle Designs 15

Figure 2.2 Variation of EPR during Climb for Advanced Cycle Designs 15

Figure 3.1 IIP Turbine Cooling Bleed Schematic 20

$\begin{array}{lll}\text { Figure } 4.1 \text { Typical Turbine Characteristics } & 29\end{array}$

Figure 4.2 Gencralized Fan Characteristic $\quad 34$

Figure 4.3 Generalized L.PC Characteristic 36

IFigure 4.4 Generalized HPC Characteristic 37

Figure 4.5 Flow Compatibility for Two Turbines and a Nozzle In Series 40

Figure 5.1 Overall TURBOFN4 Program Structure 43

Figure 5.2 On-Design Module Structure $\quad 45$

Figure 5.3 Off-Design Module Structure $\quad 48$

Figure 5.4 Diagram Showing Fan Speed Line Iteration Procedure 50

Figure 5.5 Diagram of LPC Match Procedures $\quad 52$

Figure 5.6 Diagram of HPC Match Procedures $\quad 54$

Figure 6.1 Specific Thrust and SFC for Different Advanced Cycle Designs 59

Figure 6.2 Net Thrust Split for Advanced Cycles at SLS 61

Figure 6.3 Net Thrust Split for Advanced Cycles at TOC 61

Figure 6.4 EPR Trend for Advanced Cycles at ISA SLS Design Point 63

Higure 6.5 EPR Trend for Advanced Cycles at TOC Design Point 63

Figure 6.6 IEPR Trend for Advanced Cycles at ISA SLS Design Point 64

Figure 6.7 IEPR Trend for Advanced Cycles at TOC Design Point 64

Figure 6.8 Typical Climb Profitc for Modern Airliners $\quad 66$

Figure 6.9 Thrust Trend during Climb 70

Figure 6.10 Variation of Fuel Flow during Climb 70

Figure 6.11 Variation of EPR during Climb 71

Figure 6.12 Variation of IEPR during Climb $\quad 71$ 
Figure 6.13 Variation of Spool Speeds during Climb

Figure 6.14 Change in Cycle Temperatures during Climb 72

Figure 6.15 Cruise Thrust vs. $\mathrm{N}_{1}$

Figure 6.16 Cruise Thrust vs. Fuel Flow 70

Figure 6.17 Cruise Thrust vs. EPR 77

Figure 6.18 Cruise Thrust vs. IEPR $7 \%$

Figure 6.19 Take-off Thnist Variation vs. $N_{1}$ 82

Figure 6.20 Take-off Thrust Variation vs. Fuel Flow

Figure 6.21 Take-off Thrust with EPR as Thrust Sctting

Figure 6.22 Take-off Thrust with IFPR as Thrust Setting Si

Figure 6.23 Variation of HDTO Cycle Temperatures vs. $N_{1}$

Figure 6.24 Variation of HDTO Cycle Temperatures vs. N,

Figure 6.25 Variation of HD'TO Cycle Temperatures vs. I:PR

Figure 6.26 Variation of Spool Speeds at Cruise (JT)D and $(\mathrm{T} \%(3-80)$

Figure 6.27 Variation of Criise EPR (IFPR) for Several lingines

Figure 6.28 JT15D-4 Climb Thrust

Figure 6.29 JT15D-4 Climb Fuel Flow 93

Figure 6.30 JT15D-4 Take-off Thrust

Figure 7.1 Take-off Thrust with Fan Fault using $N_{1}$ as Sciting 111

Figure 7.2 Take-off Thrust with Fan Fault using EPR as Setling

Figure 7.3 HDTO Thrust Variation with $N_{1}$ for Different Faulis

Figure 7.4 HDTO Thrust Variation with Fuel llow for Different Fallts $\quad 10.4$

Figure 7.5 HDTO Thrust Variation with EPR for Different Faults 105

Figure 7.6 HDTO Thrust Variation with IFPR for Different I Faults 105

Figure 7.7 Increases in HDTO ITT with Faults when $N_{1}$ is Thrust Setting $1(6)$

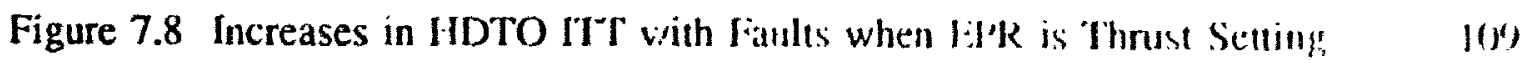

Figure 7.9 Cruise Thrust vs. $N_{1}$ for Faulty Engine 114

Figure 7.10 Cruise Thrust vs. Fuel Flow for Faulty lingine 114

Figure 7.11 Cruise Thrust vs. EPR for Faulty Engine 115

Figure 7.12 Cruise Thrust vs. IEPR for Faulty Engine 115 


\section{Nomenclature}

List of Symbols:
A
Exit area of nozzle
bl
HP Turbine cooling bleed (\% core mass flow)
C
Air flow velocity
$c_{p}$
Specific heat (at constant pressure)
F, Fs
Thrust, specific thrust
M, Mach
Mach number
m
Mass flow
$N_{1}, N_{2}$
Mechanical LP and HP spool speeds
$(n-1) / n$
Polytropic index
nr
Corrected relative spool speed
p. $T$
Static pressure, temperature
P. $T$.
Ambient pressure, temperature
$\Delta \mathrm{p}_{\mathrm{h}}$
Combustion pressure drop (\% CDP)
$P_{N}, T_{N}$
Nozzle plane static pressure, temperature
$p_{0}, T_{0}$
Total pressure, temperature
Q
Non-dimensional or corrected mass flow parameter
$\delta$
Corrected pressure $\left(p_{d} / 1.01325, p_{o}\right.$ in Bars)
Specific heat ratio
7.
Polytropic efficiency
Isentropic efficiency
Corrected temperature $\left(T_{0} / 288.16, T_{0}\right.$ in $\left.K\right)$

$\gamma$

$\eta$

$\Theta$

Acronyms:

BPR

Bypass ratio

CDP

HP Compressor delivery total pressure

CDTO

Cold day take-off (ISA $-15^{\circ} \mathrm{C}$ at SLS) 
EGT LP Turbine exhaust gas total temperature

EPR Engine pressure ratio

FADEC Full authority digital engine control

FF Fuel flow

FPR Fan pressure ratio

GG Gas generator (core of turbofan)

HDTO Hot day take-off (ISA $+15^{\circ} \mathrm{C}$ at SLS)

HP, LP High pressure, low pressure

HPC, HPT High pressure compressor, turbine

IEPR Integrated engine pressure ratio

IFSD In flight shutdown

ISA International standard atmosphere

ITT Inter-turbine total temperature (gas generator EGT;

LPC, LPT Low pressure compressor (Boosters), turbine

OPR Overall pressure ratio

PR Pressure ratio

RPR Ram pressure ratio

SFC Specific fuel consumption

SLS Sea level static

TIT HP turbine inlet total temperature

TOC Top of climb

UHB Ultra high bypass (turbofans)

\section{Subscripts:}

$\begin{array}{ll}\text { a } & \text { Air } \\ \text { c } & \text { Cold (fan or bypass) } \\ \text { cc } & \text { Combustion chamber } \\ \text { fan } & \text { Fan } \\ \text { hpc, hpt } & \text { High pressure compressor, turbine } \\ \text { g } & \text { Gas }\end{array}$


h

i

j

Ipc, Ipt

mech, $\mathrm{m}$

N

Hot (core)

Intake

jet

Low pressure compressor, turbine

Mechanical

Nozzle plane 


\section{Chapter 1 Introduction}

\subsection{Objectives}

The primary goal of this study was to analyze various indirect thrust measurement methous with the aim of determining the relative usefulness and reliability of some of the more popular methods on modern turbofans. This objective required fairly accurate simulation of internal engine conditions, especially the exhaust gas temperatures and pressures for the gas generator, and both nozzles of the turbofan. In addition, since the LP and HP spool speed relationships were required, accurate simulation of the iwin-spoul match was also necessary. This final requirement necessitated the use of some kind of component characteristics.

Thus, there was a need to develop a generic twin spool turbofan simulator which could accurately predict the overall performance of a typical modern high-bypass turbofan. This was complicated by the fact that most information required to accurately simulate a specific engine design is highly proprietary and available only to the manufacturer. However, it has been shown that fairly good simulation can be achicved using reasonable assumptions of component performance behaviour based on the current state-of-the-art and openly published engine data.

\subsection{Indirect Thrust Indicators}

Although jet engines have been used commercially for 40 years, there is still no direct method of measuring thrust in flight. Indirect methods of indicating thrust are used, based on pressure measurements or rotational speeds. The use of engine pressure ratio (EPR), which is defined as the ratio of total exhaust pressure over total inlet pressure, became dominant in early turbojet engines where there was a direct relationship between EPR and thrust. A problem arose with the introduction of high bypass turlefians, where a substantial portion of the total net thrust is provided by the cold or bypass 
stream; EPR considered only the core engine pressure ratio and hence the thrust contribution from the hot stream. One alternative was to use integrated engine pressure ratio (IEPR) which is based on an area weighted average of the bypass and core nozzle pressure ratios. Another approach was to use fan rotational speed $\left(\mathbf{N}_{\mathbf{1}}\right)$ to indicate thrust.

In addition to pressure ratios and spool speeds, modern high bypass engines must use temperature measurements to monitor and control engine performance. The key issue is that there is a thermal limit in all gas turbine engines. The most critical temperature is the Turbine Inlet Temperature (TIT) which in addition to determining the overall thermal efficiency of the engine, influences the maximum rotational speed that the engine can withstand safely. Higher TrT generally results in increased power in a given engine and higher specific thrust, and this has led to the need for gradual increases in TIT since the commercial jet engine was first introduced.

In a given engine, the maximum permissible TIT is influenced chiefly by the matcrial limits and the desired overhaul life, especially in the HP Turbine rotor components. The gradual increases in TIT since the 1960 s were made possible largely through improvements in turbine materials and the increased use of various turbine cooling techniques. The general trend for increased TIT and greater use of turbine cooling technologies can be seen in Figure 1.1. It has been estimated that the theoretical limit for cruise TIT is of the order of $2400 \mathrm{~K}$, which will theoretically give a maximum overall efficiency of approximately $50 \%$ assuming the same type of fuel and reasonable values of OPR. The theoretical limit to TIT corresponds to the stoichiometric limit of the fuel. (Pickerell, 1984) 

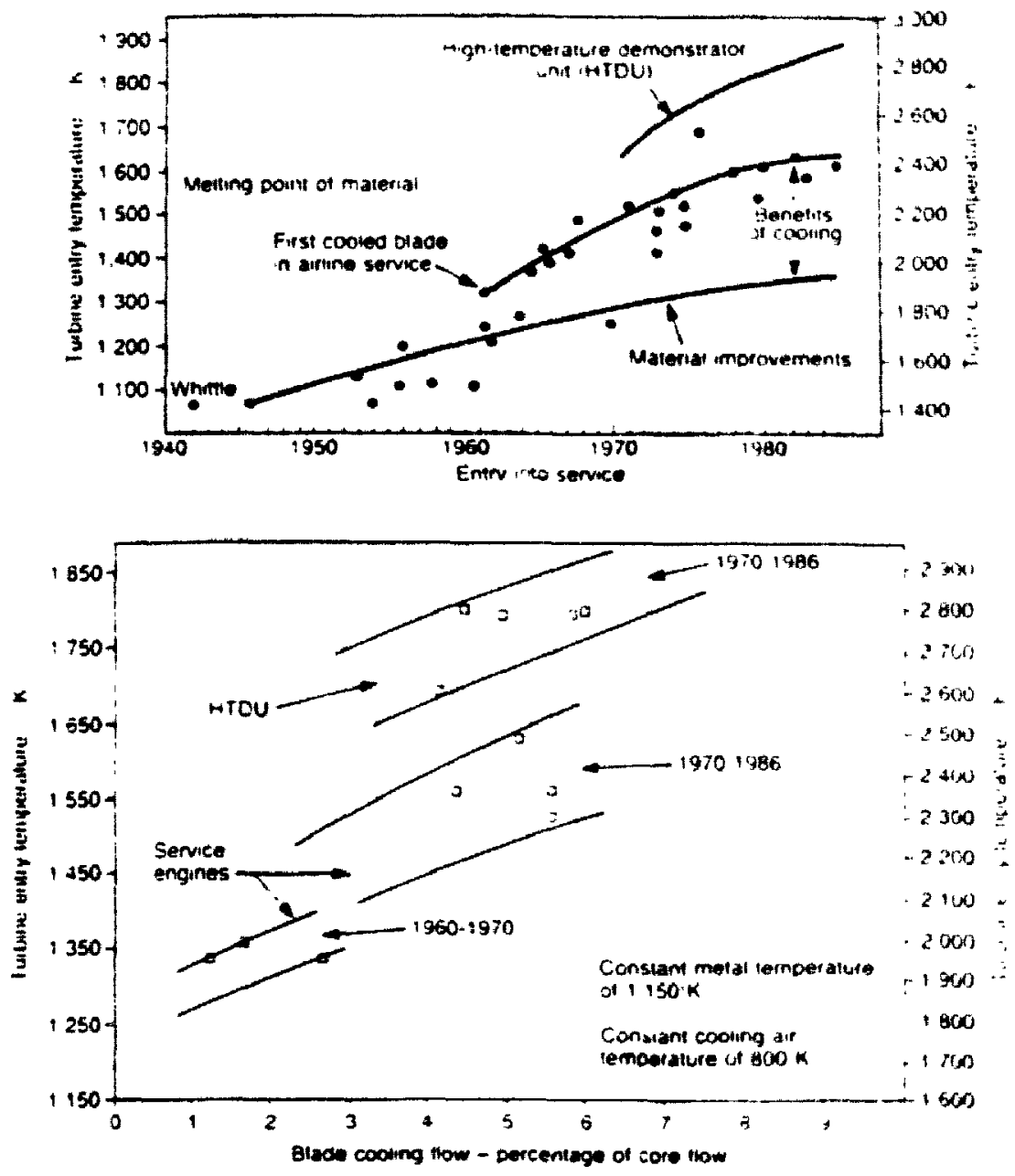

Figure 1.1 Turbine Inlet Temperature and Cooling Trends (Byworth, S., 1987) 
It is important to realise that TIT is rarely measured due to the difficulties with measuring such high ternperatures. Instead, most high bypass engines have temperature probes located between the HP Turbine exhaust and the LP Turbine inlet which measure the Inter-Turbine Temperature (ITT). Some engine manufacturers call this quantity the Exhaust Gas Temperature, but Gas Generator EGT would be more precise. For the remainder of this thesis ITT will be used to describe this quantity, while EGT will be used to denote the LP Turbine Exhaust Gas Temperature (EGT). It can be shown that the relaive value of TIT can be inferred fairly accurately from ITT.

Another indirect way of estimating the performance is by monitoring the Fuel Flow (FF). This is of primary concern to commercial airliner operators in that FF dictates the range and relative economy in operating an aircraft with a specific engine. In modern engines, such as those equipped with FADEC (Full Authority Digital Engine Control), FF is automatically controlled by an on-board computer system such that a pilot selects a specific throttle setting corresponding to take-off, climb or cruise thrust. The automatic control system then adjusts fuel flow to prevent engine overheat and to sarisfy a desired fuel schedule. An example is the need for minimum fuel burn during climb, which is particularly important for short range flights when the climb to cruise altitude may bum a significant portion of fuel. On long haul flights, minimum fuel flow at cruise is more critical for good range.

\subsection{Origin of EPR and IEPR}

The use of Engine Pressure Ratio (EPR) as an indirect thrust measurement originates from the use of such ratios in pure turbojet engines. EPR can be shown to be directly proportional to net thrust in the case of a simple, fixed nozzle turbojet in the following manner:

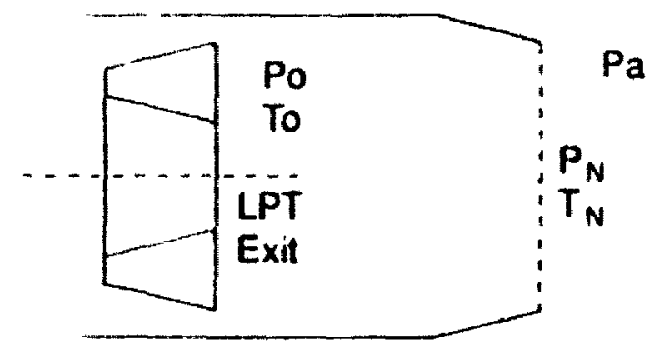

$P_{0}, T_{0}$ - stagnation

$P_{N}, T_{N}$ - static, nozzle plane

P. - ambient 
For a choked nozzle,

$$
F=m C_{N}+A\left(p_{N}-p_{a}\right) \text {, and } \frac{p_{N}}{p_{0}}=\left(\frac{2}{\gamma+1}\right)^{\frac{\gamma}{\gamma-1}}
$$

Also, $\quad m=\rho_{N} A C_{N} ; \quad \rho_{N}=\frac{p_{N}}{R T_{N}} ; \quad C_{N}^{2}=2 C_{p}\left(T_{o}-T_{N}\right)$

Hence, $\quad F=\rho_{N} A C_{N}^{2}+A\left(p_{N}-p_{a}\right)$

$$
\begin{aligned}
& =\frac{p_{N}}{R T_{N}} A \cdot 2 C_{p}\left(T_{o}-T_{N}\right)+A\left(p_{n}-p_{a}\right) \\
& =2 \frac{\gamma}{\gamma-1} A\left(\frac{p_{N}}{p_{0}}\right)\left(\frac{p_{a}}{p_{a}}\right) p_{a}\left(\frac{T_{0}}{T_{N}}-1\right)+A p_{a}\left(\frac{p_{N}}{p_{a}} \cdot \frac{p_{o}}{p_{a}}-1\right)
\end{aligned}
$$

Substituting the value of $\left(\frac{p_{N}}{p_{0}}\right)$ :

$$
\therefore \frac{F}{A p_{a}}=\left[2 \frac{\gamma}{\gamma-1} \cdot\left(\frac{2}{\gamma+1}\right)^{\gamma-1}\left(\frac{p_{o}}{p_{a}}\right)\left(\frac{\gamma+1}{2}-1\right)\right]+\left[\left(\frac{2}{\gamma+1}\right)^{\gamma} \frac{p_{o}}{p_{a}}-1\right]
$$

This gives,

$$
\frac{F}{A p_{a}}=\frac{p_{0}}{p_{a}}\left\{\left(\frac{2}{\gamma+1}\right)^{\frac{\gamma}{\gamma-1}}(\gamma+1)\right\}-1
$$

It follows that

$$
\frac{F}{A p_{a}}=K\left[\frac{p_{0}}{p_{a}}\right]-1 \quad \text { where } K=f(\gamma)
$$


This can be extended to work with EPR instead, and noting that

$$
\frac{p_{o r}}{p_{a}}=\frac{p_{o t}}{p_{o t}} \cdot \frac{p_{o l}}{p_{a}} \quad \text { i.e. nozzle } P R=E P R \times R P R
$$

Then,

$$
\frac{\left(\frac{F}{A p_{a}}+1\right)}{R P R}=K(E P R)
$$

Where $\mathrm{K}=1.2594$ for $\gamma=1.333$

A similar derivation can be determined for the case of an unchoked nozzle; however, in most cases the hot nozzle is likely to be choked over the useful operational range of a jet engine. Thus, for a fixed nozzle turbojet, the thrust can readily be found from the EPR.

In the case of a turbotan, the EPR will depend on both the bypass ratio and fan pressure ratio since both of these have an effect on the total pressure of the LP Turbine exhaust. Because of this there is no longer a direct relationship between total net thrust and EPR. Also, in high bypass engines a majority of the net thrust is generated by the cold stream, but the cold nozzle conditions are not measured in any way. The concept of IEPR, pioneered by Rolls-Royce in the late 1960s, attempts to include the substantial thrust contribution from the fan or bypass nozzle through an area-weighted average defined as follows:

$$
I E P R=\frac{P_{o z} \cdot A_{c}+P_{o 7} \cdot A_{k}}{P_{o I}\left(A_{c}+A_{b}\right)}
$$

This requires extensive pressure measurements in the fan duct, involving the use of sophisticated pressure probe "racks" and data acquisition systems. However, IEPR does appear to be a more logical way to indicate the thrust of a high bypass turbofan. 


\subsection{Scope of Study}

This study was limited to the simulation of high bypass turbofan engines as are commonly used in modem civil transport aircraft. The configuration assumed was a twinspool type with separate nozzles. This excludes the simulation of low bypass military type turbofans which almost always incorporate some kind of mixer and afterburner assembly. There are a few high bypass engines which use a mixed nozzle, but in general such a configuration is rarely seen, as the slight thrust or SFC advantage from using such a scheme is limited to a very restricted range of fan and LP Turbine exit conditions.

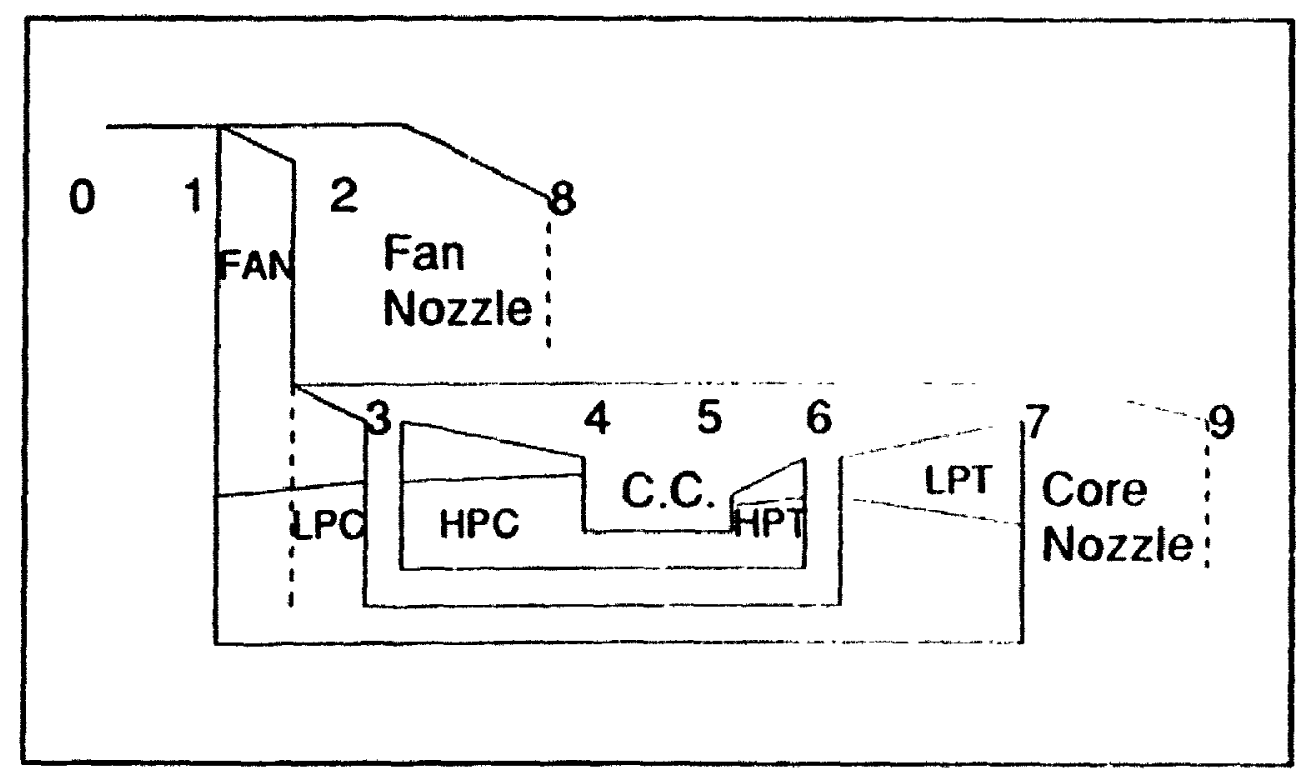

Figure 1.2 Turbofan Schematic

Figure 1.2 illustrates the basic twin-spool configuration that was used in this study. The high bypass Fan is driven by the LP Turbine, while the IIP Compressor is driven by the HP Turbine on another shaft. Note the station numbering used in ligure 1. ?, which includes the presence of a portion of the low pressure compression system (Fan+I.PC) in the core flow. These so-called "booster" stages are common in modern turbofans. While the inclusion of these booster stages has almost no effect on the on-design performance (assuming similar efficiencies in the LPC and HPC), they do have an effect on the 1.1\% spool power balance and consequently affect the twin spool matching calculation at offdesign operating points. 
Since the requirement of this study was to establish generic engine performance, the accurate modelling of a specific engine was not of paramount importance except for verification purposes. In particular, the modelling of three-spool turbofans such as the RB211 was not considered. Other details such as variable geometry stators were ignored, and a generalized HPT cooling method was assumed even though specific engine designs have different turbine cooling details. A reasonable cooling system, which is described in detail in Chapters 3 and 4, was modelled by a certain fixed percentage of core air being bled off at the HP Compressor exit location, bypassing the combustion chamber, and being introduced back at the HPT stators and rotors. This cooling air was assumed to be split more or less equally between the HPT stator and rotor stages. This is roughly equivalent to current twin-spool turbofan designs. (Collins and Hill, 1991)

The off-design operation of the generic turbofan was restricted to high rotational speeds, as the assumption of LP Turbine choking (see Chapter 4) would not be valid at very low speed settings such as idle or descent power. Restricting the simulation to high speeds is necessary given the restricted speed range on available component characteristic maps. Such a restriction is not considered to be a major problem, since the issues of aciequate thrust and good efficiency are usually only critical at take-off, climb and cruise operating conditions. 


\section{Chapter 2 Choice of Design Point}

\subsection{Definitions of Turbofan Design Points}

Modern high-bypass turbofans are designed around several flight conditions or design points, and not just the Sea Level Static (SLS) condition as was perhaps the common design point in early engines when adequate take-off thrust was the primary concern. The most common flight conditions for which modern designs are optimized are (Philpot, 1992):

1) Sea Level Static (SLS) Takeoff: Usually at ISA $+15^{\circ} \mathrm{C}$, to allow a flat rated take-off thrust up to a hot ambient temperature condition (Iot Day Take-off, or IIDTO). Most modern engines automatically controi the take-off fuel flow to prevent the TTY from exceeding a specified safety limit. In practical terms, the Inter-turbine Temperature (IT'T) is used as the limiter due to difficulties with directly measuring the high IITs common in modern turbofans. The HDTO condition is important, limiting the maximum allowable TIT and hence influencing the ultimate thermodynamic cycle choice. Note that the l1\% is sometimes called the gas generator Exhaust Gas Temperature (EGT) by many engine manufacturers. In this thesis, EGT will be used to denote the LP Turbine exhaust temperature.

2) Cruise: A majority of the fuel burned during a typical civil airliner hight will be during cruise, especially for long range. It is essential to have an excellent Specific Fuel Consumption (SFC) while allowing high cruising speed (i.e. maxinizing (j/sf(). The choice of engine cycle conditions (FPR, BPR, OPR, and cruise TIT) is optimized around this goal. Aircraft may have different optimum cruise conditions owing to differing flight characteristics, but the most common standard cruise conditions used are Mach 0.8 or 0.85 and $35000 \mathrm{ft}$ altitude. The Mach 0.8 cruise condition has been used in this study. 
3) Top-of-Climb (TOC): This condition is also called Maximum Climb, and for high bypass engines it is the point of maximum pressure ratio within the engine. For this reason, the TOC condition sets the maximum Overall Pressure Ratio, and also the fan conditions (FPR, corrected mass flow $Q_{1}$, and corrected LP spool speed). This point is commonly used as the Aerodynamic Design Point of the engine. (Philpot, 1992)

\subsection{Matching Different Design Points}

For fixed geometry nozzles, which will be the case with modern high-bypass turbofans, the choice of design point has a marked effect on off-design performance. This is especially true when the TOC and SLS conditions are compared, since both nozzles (Fan and Core) will be choked at the TOC, but will normally be unchoked at SLS. The off-design calculation method based on twin-spool matching is highly dependent on an accurate estimate of the fixed nozzle areas, as well as accurate determinations of the design point aerodynamic characteristics of the Fan, Compressor and Turbines.

A brief study was conducted to study the possibility of "matching" the three design points discussed earlier in the same engine. The objective was to model a known engine that was very similar to the generic turbofan design that will be used later in this study. The primary focus was to match known TOC performance with known SLS (take-off) performance of the same engine, and thus determine the design point engine parameters at each discrete design point.

A simplified method was used which utilized the on-design calculation subroutines to specify the first on-design point (usually the TOC) in terms of BPR, OPR, TIT, FPR and cycle efficiencies. The specific thrust and actual thrust (from a known engine) were used to calculate the required mass flow and then the cold and hot nozzle areas. These latter two were expressed as a fixed ratio $A_{d} / A_{k}$. Then, the second design point was defined, as were a second set of cycle parameters except for the BPR. An iterative approach was conducted (with the second set of TIT, OPR and FPR fixed) by varying 
BPR until the same $A_{d} / A_{b}$ ratio was obtained. Then, the actual mass tlow and thrust obtained at this second design point was calculated by scaling the per unit mass now areas by the nozzle areas found at the first design point.

It was noted that during the BPR iteration, some combinations of TOC and SIS cycles were invalid, resulting in an unsuccessful search for a BPR which gave the correct A J $A_{h}$ ratio. Also, for some combinations of TIT, FPR and OPR at seal level conditions, it was possible for there to be more than one solution and hence two valid BPRs. In this case, the BPR match which yielded the closest mass flow and SI S thrust (as complared with known engine data) was taken as the solution.' The important results from the analysis are summarized in Table 2.1 .

The TOC-SLS matching process was conducted for two discrete take-off conditions, ISA SLS and ISA $+15^{\circ} \mathrm{C}$. It was noted that for reasonable BPR matches, the TIT for the ISA+15 $\mathrm{C}$ case had to be increased from the equivalent ISA SI SS value. This is reasonable when compared with known quoted hot day TITs for an actual engine. The corresponding FPRs for successful matches on hot days had to he lower. In general, high TOC TITs made it difficult (or impossible) for reasonable cycle mathes al SI.S conditions.

Obviously, there is great flexibility in selecting TOC cycle conditions that will yield reasonable SLS engine conditions, as evident from Table 2.1. However, the solutions closest to actual engine data are fairly difficult to obtain, requiring extensive iterations to "fine-tune" the match until a satisfactory solution is found. The highlighted $(*)$ values denote the solutions that were found which matched available engilie datia and also approximate the generic engine performance modelled during this study. This similarity to actual off-design performance is notable since the effeci of different mechanical spool speeds at the different design points was ignored.

\footnotetext{
1. During this analysis, a TOC thrust of $28.6 \mathrm{kN}$ and a SLS Take-off thrust of $1335 \mathrm{kN}$ iwith 427.6 $\mathrm{kg} / \mathrm{s}$ mass flow) were the target engine values. These correspond to data for the CFM $56-5 \mathrm{~B} 1$ engune which is very similar to the hypothetical advanced cycle engine used in this study. The CFMSK,-SB] has a BHIR of 5.5 at SLS conditions and a TIT of approximatcly $1610 \mathrm{~K}$ at HDTO. $1530 \mathrm{~K}$ at standard SIS Comditions. (CFM56 Family Engine Brochure, 1990)
} 
Table 2.1 TOC and SLS Engine Cycle Matches

\begin{tabular}{|c|c|c|c|c|c|c|c|c|}
\hline \multicolumn{9}{|c|}{ Engine Cycle Parameters for: } \\
\hline & TOC & \multicolumn{3}{|c|}{ ISA SLS } & \multicolumn{4}{|c|}{ HDTO (ISA +15 C) } \\
\hline $\begin{array}{l}\text { BPR } \\
\mathrm{FPR} \\
\text { OPR } \\
\mathrm{THT}(\mathrm{K}) \\
\mathrm{m}_{4}(\mathrm{~kg} / \mathrm{s}) \\
\text { Fnet(kN) }\end{array}$ & $\begin{array}{l}5.5 \\
1.65 \\
35 \\
1400 \\
175 \\
28.6\end{array}$ & $\begin{array}{l}3.75 \\
1.58 \\
32.6 \\
1572 \\
459 \\
165\end{array}$ & $\begin{array}{l}5.58 \\
1.61 \\
32.6 \\
1572 \\
434 \\
137 \\
\end{array}$ & $\begin{array}{l}6.25 \\
1.58 \\
32.6 \\
1572 \\
420 \\
126 \\
\end{array}$ & $\begin{array}{l}4.4 \\
1.55 \\
33 \\
1597 \\
425 \\
142 \\
\end{array}$ & $\begin{array}{l}5.3 \\
1.55 \\
33 \\
1597 \\
410 \\
130 \\
\end{array}$ & $\begin{array}{l}5.5 \\
1.54 \\
33 \\
1597 \\
406 \\
125 \\
\end{array}$ & $\begin{array}{l}5.7 \\
1.54 \\
33 \\
1597 \\
400 \\
123 \\
\end{array}$ \\
\hline $\begin{array}{l}\text { BPR * } \\
\text { FPR } \\
\text { OIPR } \\
\text { TIT(K) } \\
\mathbf{m}_{\mathbf{2}}(\mathbf{k g} / \mathbf{s}) \\
\text { Fnet(kN) }\end{array}$ & $\begin{array}{l}5.5^{*} \\
1.70 \\
35 \\
1400 \\
176.5 \\
28.6\end{array}$ & $\begin{array}{l}3.2 \\
1.58 \\
32 \\
1550 \\
400.5 \\
120\end{array}$ & $\begin{array}{l}5.5 * \\
1.61 \\
32.6 \\
1550 \\
429 \\
132.6\end{array}$ & $\begin{array}{l}5.6 \\
1.61 \\
32 \\
1550 \\
429.5 \\
133.1 \\
\end{array}$ & $\begin{array}{l}4.8 \\
1.55 \\
32 \\
1550 \\
409.5 \\
127.6\end{array}$ & $\begin{array}{l}5.3 \\
1.55 \\
32 \\
1565 \\
402.9 \\
122.5\end{array}$ & $\begin{array}{l}5.5 * \\
1.54 \\
33 \\
1597 \\
406 \\
130\end{array}$ & $\begin{array}{l}5.7 \\
1.54 \\
33 \\
1597 \\
400 \\
125 \\
\end{array}$ \\
\hline $\begin{array}{l}\text { BPR } \\
\text { FPR } \\
\text { OPR } \\
\text { TITr(K) } \\
\mathrm{m}_{\text {_l }}(\mathrm{kg} / \mathrm{s}) \\
\text { Fnet(kN) }\end{array}$ & $\begin{array}{l}5.5 \\
1.65 \\
35 \\
1450 \\
168.8 \\
28.6\end{array}$ & $\begin{array}{l}4.6 \\
1.53 \\
33 \\
1550 \\
408.3 \\
132.4\end{array}$ & $\begin{array}{l}4.8 \\
1.54 \\
31 \\
1550 \\
408 \\
131.8\end{array}$ & $\begin{array}{l}5.9 \\
1.53 \\
32 \\
1550 \\
393 \\
119 \\
\end{array}$ & $\begin{array}{l}4.8 \\
1.47 \\
32 \\
1550 \\
375.3 \\
115.2 \\
\end{array}$ & $\begin{array}{l}4.8 \\
1.5 \\
32 \\
1590 \\
385 \\
123 \\
\end{array}$ & $\begin{array}{l}.4 \\
1.47 \\
32 \\
1550 \\
368.1 \\
108.4\end{array}$ & $\begin{array}{l}5.5 \\
1.5 \\
33 \\
1590 \\
376.9 \\
113.9\end{array}$ \\
\hline $\begin{array}{l}\text { BPR } \\
\text { FI'R } \\
\text { OI'R } \\
\text { TIT(K) } \\
\mathrm{m}_{\text {, }}(\mathrm{kg} / \mathrm{s}) \\
\text { Fnet(kN) }\end{array}$ & $\begin{array}{l}6.0 \\
1.70 \\
35 \\
1425 \\
178.2 \\
28.6\end{array}$ & $\begin{array}{l}5.25 \\
1.62 \\
32 \\
1550 \\
440 \\
140\end{array}$ & $\begin{array}{l}5.5 \\
1.61 \\
32 \\
1550 \\
437 \\
135\end{array}$ & $\begin{array}{l}5.6 \\
1.6 \\
32 \\
1550 \\
434 \\
136.9\end{array}$ & $\begin{array}{l}4.75 \\
1.56 \\
33 \\
1575 \\
425 \\
138\end{array}$ & $\begin{array}{l}5.25 \\
1.55 \\
33 \\
1575 \\
412 \\
127\end{array}$ & $\begin{array}{l}5.6 \\
1.54 \\
33 \\
1575 \\
406 \\
123\end{array}$ & \\
\hline
\end{tabular}

\subsection{Comparison of Different Choices of Primary Design Point}

A brief analysis was conducted to show the sensitivity of the overall performance of a bypass engine to the choice of design point. The nature of the three commonly quoted "design points" and a simplified method for matching such design points has been described. It is believed that many modern designs use the TOC as the aerodynamic design poiat and this is imponant to consider since at this location both nozzles are likely 
to be choked. The areas that would therefore be calculated will he quite different from the sea level static or take-off case when one or both of the nozzles are likely to be unchoked.

Using a known engine ${ }^{2}$, four designs were created corresponding to ISA SL.S take-off, HDTO, TOC and Cruise designs. These designs were matched to known engine performance (Net thrust) and cycle parameters at these different conditions. In most cases a number of iterations were needed to match the engine cycle with known design parameters such as TIT and BPR. Table 2.2 details the nozzle areas found for each of the different designs and Table 2.3 shows the variation of cycles for these designs.

\begin{tabular}{|l|c|c|c|c|c|}
\hline \multicolumn{6}{|c|}{ Table 2.2 Comparison of Nozzle Areas for Differen Designs } \\
\hline Engine Design & Known Data & ISA SLS & HDTO & 1OC & Cruise \\
\hline Bypass $\left(\mathrm{m}_{2}\right)$ & 0.999 & 0.979 & 1.011 & 1.001 & 1.049 \\
\hline Core $\left(\mathrm{m}_{2}\right)$ & 0.310 & 0.331 & 0.376 & 0.312 & 0.246 \\
\hline
\end{tabular}

\begin{tabular}{|c||c|c|c|c|}
\hline \multicolumn{4}{|c|}{ Table 2.3 Comparison of Engine Cycle Parameters and Performance } \\
\hline Design Type: & ISA SLS & HDTO & TOC & Cruise \\
\hline BPR & 6.0 & 6.0 & 5.2 & 6.0 \\
\hline OPR & 28.5 & 28.5 & 31.3 & 26.0 \\
\hline FPR & 1.56 & 1.55 & 1.75 & 1.50 \\
\hline TIT (K) & 1485 & 1536.7 & 1375 & 1300 \\
\hline $\mathrm{m}_{\mathbf{t}}(\mathrm{Kg} / \mathrm{s})$ & 386.8 & 386.8 & 177 & 159 \\
\hline Net Thrust $(\mathrm{kN})$ & 111.3 & 111.4 & 25 & 22.3 \\
\hline
\end{tabular}

2. In this case, fairly complete information was available for a related engine, the CFMS6, $5 \mathrm{~A}$ I cngine. Accurate values for the fan and core nozale areas were obtained. (D. Hovey. Air Canadd Mantenance. Montreal, August 1992) 
It is clear from Table 2.2 that using the TOC flight condition to calculate required nozzle areas provides the most accurate prediction. The performance of these designs over the same set of flight conditions corresponding to a typical climb profile for a modern airliner was simulated using the twin-spool turbofan simulation program detailed in Chapter 5. A number of iterations were needed to obtain the most reasonable climb performance profiles for most of the designs, particularly for finding the most appropriate design spool mechanical speeds for the Fan and HP Spool. The mechanical design speeds will not necessarily be $100 \%$, especially at the TOC and cruise flight conditions.

Figures 2.1 and 2.2 show the variation of Net Thrust and EPR respectively. It is notable that the two SLS designs both appear to accurately predict take-off thrust while they tend to under-predict net thrust at TOC and cruise conditions. Also, whereas these designs give reasonable values for EPR at take-off, during climb it can be seen that the EPR drops to a very low value, even dropping below 1.0. The primary cause seems to be that the core nozzle in both designs has been sized for unchoked conditions and is thus too large. The cruise and TOC designs appear to predict both the take-off and high altitude thrusts more reasonat.'y. The same is true for EPR, though in the case of the cruise design (which has an abnormally large fan nozzle, and small core nozzle) the EPR predicted appears to be rather high overall. The TOC design seems to provide both an accurate prediction of net thrust during climb, and a reasonable prediction for EPR variation. It also has the most accurate combination of nozzle areas, with a maximum error of less than $1 \%$ for both nozzles. The TOC condition will be used during the remainder of this study as the main design point for fixing nozzle areas and the design point parameters for the aerodynamic components (Fan, LPC, HPC and turbines). 
Net Thrust (kN)

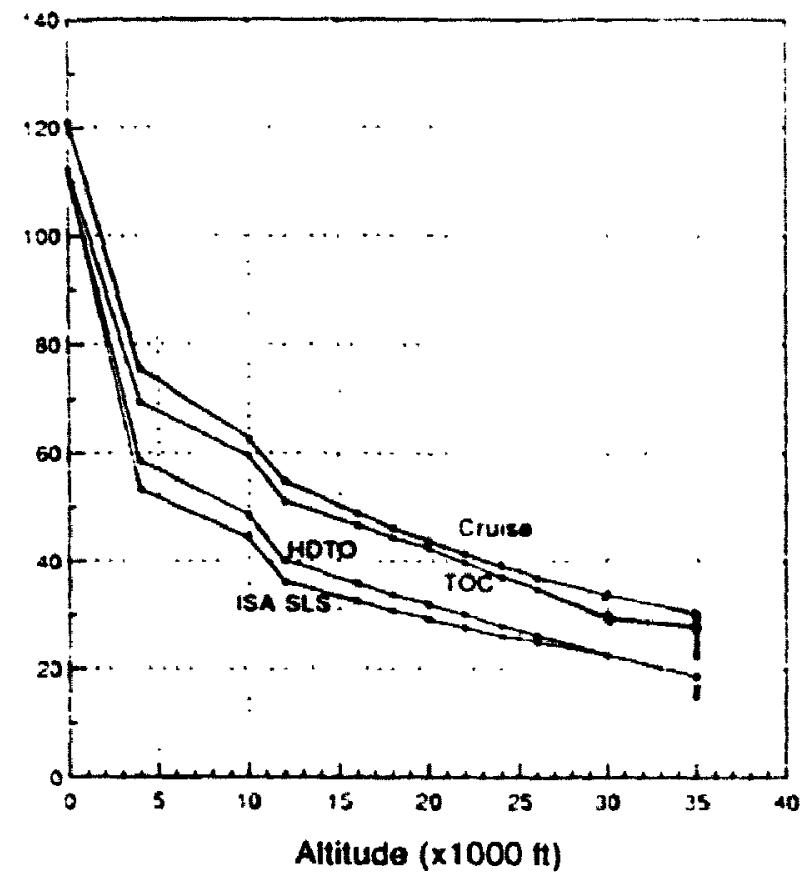

Figure 2.1 Variation of Net Thrusts during Climb for Different Cycle Designs EPR (Po7/PO1)

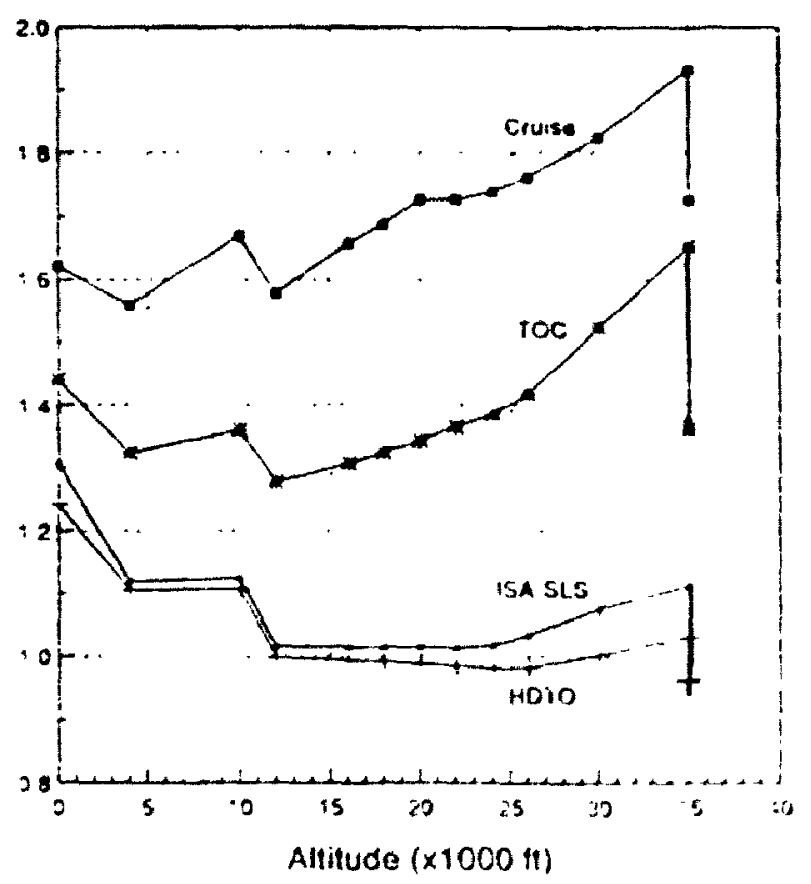

Figure 2.2 Variation of EPR during Climb for Different Advanced Cycle Designs 


\section{Chapter 3 On-Design Simulation Methods}

\subsection{Need for Accurate Design Point Performance}

Before the performance of a turbofan can be predicted over its operational range. an accurate determination of its design point (hereafter called on-design) performance must be accomplished. In practise, the overall design point performance will be known, along with some of the corresponding design point parameters such as BPR and OPR. Unfortunately, the more obscure parameters such as TIT, FPR and component efficiencies are seldom available. Therefore, it is usually necessary to iterate, using reasonable assumptions for the unknown quantities, to achieve the same performance as is known. Of course, this procedure would not be necessary to simulate a hypothetical design.

Of major importance, the off-design calculation procedure which will be described later required certain on-design performance parameters at a fairly detailed level. These included the design values of PR, non-dimensional mass flow and efficiency for the aerodynamic components (fan, compressors and turbines), to allow off-design simulation based on scaled component characteristics. The twin-spool matching procedure made extensive use of the fan and core nozzle exit areas; indeed the latter area was used during the off-design matching calculation to check the error in successive match trials. Obviously, incorrect nozzle areas would not yield the correct off-design performance trends.

\subsection{Basic Assumptions}

The on-design calculation procedure followed in this study used several simplifying assumptions. The first assumption concerns gas properties. Throughout the simulation constant gas properties were assumed for the air before the combustion chamber, and for the expansion gases in the hot end (turbines and core nozzle). These fixed gas properties are shown in Table 3.1. 
Table 3.1 Constant Gas Properties Assumed

\begin{tabular}{|l|c|c|}
\hline & Compressor Air & Hot Gases \\
\hline$\gamma$ (specific heat ratio) & 1.400 & 1.333 \\
\hline $\begin{array}{l}c_{p e} \text { (specific heat at } \\
\text { constant pressure, } \mathrm{kJ} / \mathrm{kg})\end{array}$ & 1.005 & 1.149 \\
\hline Gas Constant $\left(\mathrm{kJ} / \mathrm{kg}^{*} \mathrm{~K}\right)$ & & 0.287 \\
\hline
\end{tabular}

The turbofan modelled was assumed to use standard hydrociarbon jet fuel with standard properties as detailed in (Cockshutt and Chappell, 1974) hereafter referred to as the Cockshutt-Chapell Tables. The addition of this fuel in the combustion chamber was assumed to have a negligible effect on the net mass flow through the turbines.

Another assumption was that the bypass and core nozzles are separate, such that no mixing of the streams occurs. This simplifies both the on-design and off-design calculations. The use of mixed exhaust nozzles, while very common in low-hypass engines (older turbofans and modem military engines), is rare in high bypass civil engines due to the restricted range of cycle conditions when they are beneficial. $\Lambda$ s implied by the off-design performance calculations, both nozzles are assumed to be converging nozzles of fixed geometry.

Other assumptions will be noted in the next section which oullines the calculation procedures followed for the on-design performance calculations.

\subsection{Calculation Methods}

The on-design calculation procedure followed a slightly modified version of the turbofan design point calculation methods as outlined in the text Gas Turbine Theory 3rd Edition (Cohen, Rogers and Saravanamuttoo, 1987). The fundamental therinodynamic principle used was that the compression and expansion processes were polytropic. The details of the solution methods used follow. Note that the station numbering used 
throughout this discussion is as shown in Figure 1.2.

First, on-design parameters values are specified for the design point flight condition desired, including:

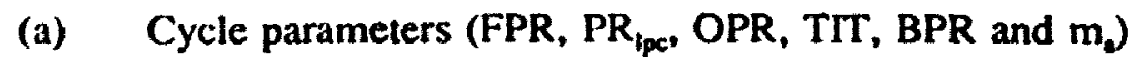

(b) Component efficiencies (Polytropic)

(c) Mechanical efficiencies, cooling bleed and CC pressure drop

(d) Ambient conditions and flight Mach number, and design values for the mechanical speeds of the LP and HP spools.

\section{Internal Pressures and Temperatures for Specified Cycle}

The compression and expansion processes are assumed to be polytropic processes, hence the values of the polytropic indexes $(n-1) / n$ are calculated as:

for compressors,

$$
\frac{n-1}{n}=\frac{1}{\eta_{\infty}}\left(\frac{\gamma_{a}-1}{\gamma_{a}}\right)
$$

for turbines.

$$
\frac{n-1}{n}=\eta_{-1}\left(\frac{\gamma_{g}-1}{\gamma_{g}}\right)
$$

Where $\eta_{-c}$ is the design point polytropic efficiency of the fan, LPC or HPC as appropriate and $\eta_{-t}$ is the design point polytropic efficiency of the appropriate turbine.

Using the ambient conditions and Mach number, the conditions at the fan entry may be calculated from compressible flow relations and the specified intake efficiency:

$$
T_{o t}=T_{a}+\frac{C_{a}^{2}}{2 c_{p a}} \text {, and } p_{o t}=p_{a}\left(1+\eta_{d} \frac{C_{a}^{2}}{2 c_{p} T_{a}}\right)^{\frac{\gamma_{o}}{\left(\gamma_{o}-1\right)}}
$$

The change in conditions through the fan can be calculated by using the polytropic compression process expression and the specified FPR: 


$$
\frac{T_{o 2}}{T_{o l}}=(F P R)^{\frac{n-1}{n}} \text {, and } P_{o 2}=P_{o l} \times F P R
$$

The compression processes for the booster stages (LPC) and the IIP Compressor are simulated in the same manner, using the exit conditions from the previous component as the entry conditions for the next:

For the LPC: $\frac{T_{o 3}}{T_{02}}=\left(P R_{i p c}\right)^{\frac{n-1}{n}}$, and $P_{o 3}=P_{o 2} \times P R_{t p c}$

For the HPC: $\frac{T_{o t}}{T_{o 3}}=\left(P R_{h p c}\right)^{\frac{n-1}{n}}$, and $P_{o t}=P_{o 3} \times P R_{h p c}$

Note that with FPR, OPR and $P_{R_{l p c}}$ specified, $P_{R_{\text {tpp }}}$ is fixed. The exil conditions at the HPC exit could be calculated directly using OPR, assuming the same polytropic efficiencies in each compression component. $p_{\alpha 4}$ would be correct regardless since this is how OPR is defined; $T_{\infty}$ would not be the same if the three compressors have different polytropic efficiencies.

The total mass flow through the engine is split after the fan into a bypass and core mass flow. The core mass flow is modified by the incorporation of a basic IIPT coxoling model in the simulation. There are many different cooling strategies incorporated in current turbofan designs, making simulation of a specific engine fairly difficult. $\Lambda$ simplified cooling system was assumed as follows: high pressure cooling air is bled off at the HPC exit as a fixed percentage of the total core mass flow. This bleed, designated bl, bypasses the combustion chamber and is added back at the IIP Turbine staturs and rotors, with $50 \%$ going to each. The cooling system that is simulated is shown in ligure 3.1.

The change in HP Turbine mass flow affects the HP Turbine inlet mass flow parameter, $Q_{s}$, and hence the HP Spool match. Thus, for calculation of $Q_{s,}$ the mass flow 


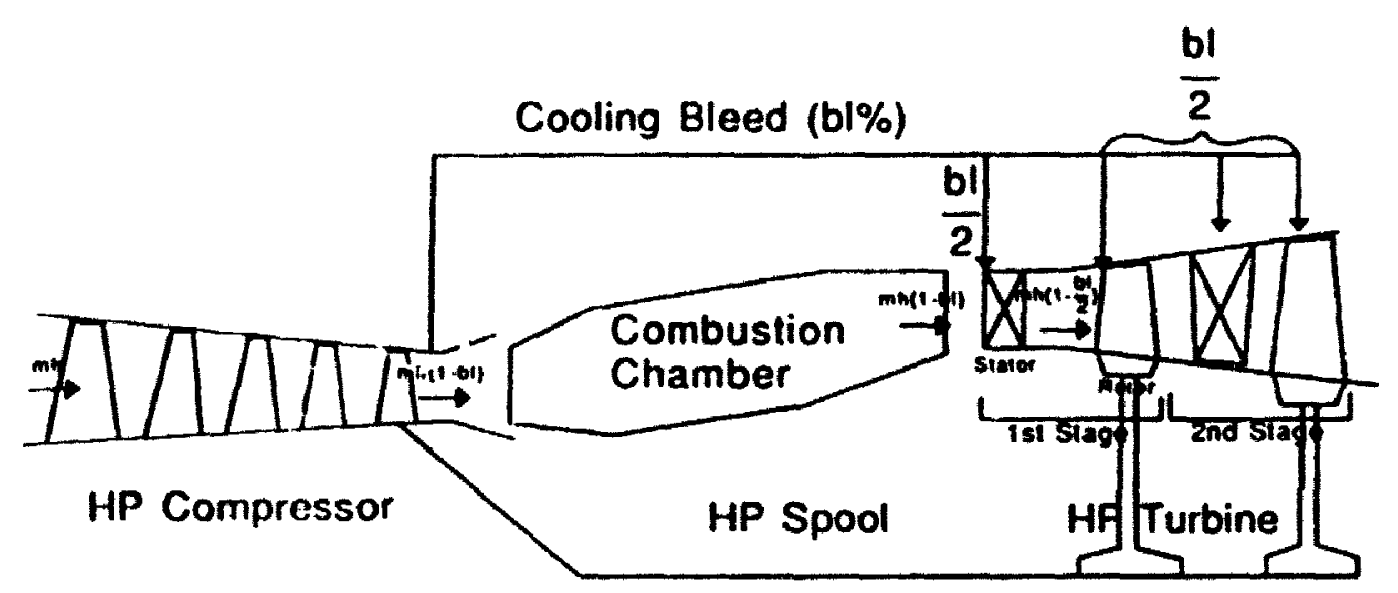

Figure 3.1 HP Turbine Cooling Bleed Schematic

through the combustion chamber is used, $m_{21}(1-b)$. The cooling air added at the rotor is not considered in the HP spool work balance, but at this point about $50 \%$ of the bleed air is assumed to have been returned, so the mass flow used for calculating HP turbine work is $m_{\infty}(1-b / / 2)$. No attempt is made to determine the effect of these cooling bleeds on the gas properties or conditions (total pressure or temperature). These would be very minor if the cooling system is designed correctly. By the time the core flow reaches the I.P Turbine entrance, the bleed is considered to be completely returned.

Using the specified total mass flow $\mathrm{m}_{\mathrm{v}}$ BPR and bleed, the mass flows throughout the turbofan are calculated as follows:

$$
\begin{gathered}
m_{c}=m_{a} \frac{B P R}{B P R+1} ; \quad m_{h}=m_{a} \frac{1}{B P R+1} \\
m_{1}=m_{s} ; \quad m_{2}=m_{3}=m_{h} ; \quad m_{c c}=m_{h}(1-b l) \\
m_{(\text {urPTsators })}=m_{c c}: m_{(u P T, \text { otors })}=m_{s}=m_{h}\left(1-\frac{b l}{2}\right)
\end{gathered}
$$


The two definitions for the mass flow through the HP Turbine are required to allow separate calculations of the HPT inlet mass flow function $\left(Q_{s}\right)$ and the rotor work calculation.

The small fraction of mass added as fuel in the combustion chamber is neglected; in practise, an additional amount of HP Compressor bleed is used to cool the spools and pressurize bearings and is then dumped overboard. This small negative loss is assumed to be countered by addition of the fuel mass at the combustion chamber.

The expansion processes are simulated using power balances for each speol, which can be used to find the total temperature drops. Polytropic expansion processes are then used to calculate the resulting pressure drops, starting with the total pressure at the III' Turbine entrance. The procedures used are as follows:

The total temperature and pressure at HPT entry are:

$$
T_{a s}=T I T ; \quad p_{o s}=p_{o s}\left(1-\Delta p_{b}\right)
$$

where $\Delta \mathrm{p}_{\mathrm{b}}$ is the drop in total pressure in the combustion chamber, expressed as a percentage of the CDP. The power balance for the L.P spools is:

$$
m_{c} c_{p o}\left(T_{o 2}-T_{o 1}\right)+m_{2} c_{p o}\left(T_{o 3}-T_{o 2}\right)=m_{h} c_{p g}\left(T_{o b}-T_{o 1}\right) \eta_{\text {math }}
$$

And for the HP Spool:

$$
m_{3} c_{p a}\left(T_{o t}-T_{o s}\right)=m_{s} c_{p g}\left(T_{o s}-T_{o b}\right) \eta_{m e c h}
$$

Solving the LP and HP power balances yields the temperatures at the hot end of the engine (i.e. the ITT and EGT). Note that if boosters are not desired, the $\mathrm{P}_{\mathrm{fqx}}$ can $\mathrm{l}_{\mathrm{x}}$ set to 1.0 which will yield the same total pressures and temperatures at stations 2 and 3 . The second term in the LP power balance (left hand side) would likewise disappear. Omitting the LPC by essentially "lumping" the booster contribution to the OPR into the HPC pressure ratio has no effect on the on-design performance provided the same polytropic efficiencies are used. Boosters do, however, have an effect on the off-design performance of a turbofan by modifying the LP and HP spool matching. 
Total pressures at each of the stations downstream of the HPT entry can now be solved using the TIT, ITT and EGT and polytropic expansion processes:

$$
\begin{aligned}
& \frac{p_{o s}}{p_{o b}}=\left(\frac{T_{o s}}{T_{o \sigma}}\right)^{n \cdot \pi}=\left(\frac{T I T}{I T T}\right)^{\frac{n}{(n-1)}} \\
& \frac{P_{o 6}}{P_{07}}=\left(\frac{T_{06}}{T_{07}}\right)^{\frac{n}{(a-1)}}=\left(\frac{I T T}{E G T}\right)^{n-\pi}
\end{aligned}
$$

All temperatures and pressures within the engine are now known. What remains is the determination of fuel flow, nozzle conditions and areas and the resulting thrust gencrated with the choice of cycle.

\section{Fund Filow}

The fuel flow is calculated using the approach outlined in the Cockshutt-Chapell Tables. The first step is to calculate the fuel/air mixture ratio, $f$, which can be calculated using the equivalent caloric value (ECV) of the fuel and enthalpy of the combustion air $\left(h_{4}\right)$ at the entrance and exit of the combustion chamber:

$$
f=\frac{h_{s}-h_{o f}}{E C V_{s}+\left(h_{f F}-h_{f R}\right)}
$$

The values of ECV and $h_{\mathbb{\alpha}}$ can be determined from the total temperature at the relevant station; polynomial relations provided by the Cockshutt-Chapell Tables are used to calculate these values at the appropriate combustion chamber inlet and exit temperature conditions. The second term in the denominator accounts for the sensible enthalpy of the liquid fuel at injection above that at a reference temperature; this term is generally very small in comparison with ECV and has been neglected. Once the fuelair ratio is known, the actual fuel flow $\left(m_{l}\right)$ may be calculated using the air mass flow through the combustor 
$\left(m_{e c}\right)$ and the combustor efficiency:

$$
m_{f}=\frac{f x m_{c c}}{\eta_{c c}}
$$

\section{Determining Nozzle Sizes and Thnusts}

The conditions at the entrances of the cold (bypass) and hot (core) nozales have been calculated previously, and are the stagnation properties at Stations 2 and 7 respectively. These, in combination with the known ambiem conditions, Hight condition and nozzle mass flows, allow the two nozzles to be sized and thrust to he calculated. Recall that an accurate estimate of both (fixed) nozzle areas is essential to the off-dexign calculation procedures.

Apart from the difference in the hot and cold gas properies, the procedure is identical for the two nozzles. Using the hot nozzle as an example, since $p_{u}$ is known, the nozzle pressure ratio is also known $\left(p_{0} / p_{2}\right)$. This ratio must he checked against the critical pressure ratio to determine if the nozzle is choked:

$$
\frac{p_{o t}}{p_{c}}=\left[1-\frac{1}{\eta_{j h}}\left(\frac{\gamma_{g}-1}{\gamma_{g}+1}\right)\right] \frac{\gamma_{t}}{\left.\gamma_{c}-1\right)}
$$

If the nozzle pressure ratio is greater than the critical pressure ratio, the norde is choked and the exit static conditions are calculated in the following manner:

$$
\begin{gathered}
T_{9}=T_{c}=\left(\frac{2}{\gamma_{h}+1}\right) ; \quad p_{9}=p_{c}=p_{c h}\left(\frac{p_{c}}{p_{c, 7}}\right) \\
\rho_{9}=\frac{p_{c}}{R T_{c}} ; \quad C_{j h}=\sqrt{\gamma_{h} R T_{c}}
\end{gathered}
$$


If the pressure ratio is equal to or less than the critical pressure ratic, the nozzle is unchoked. In this case, the static pressure at the nozzle exit plane is the ambient pressure. The other static conditions are calculated as follows:

$$
\begin{aligned}
& T_{9}=T_{o \gamma}-\eta_{j h} T_{a 7}\left[1-\left(\frac{p_{a}}{p_{o 7}}\right)^{\frac{\left(y_{g}-1\right)}{\gamma_{q}}}\right] \\
& \rho_{9}=\frac{p_{9}}{R T_{9}} ; \quad C_{j k}=\sqrt{2 c_{p q}\left(T_{o 7}-T_{9}\right)}
\end{aligned}
$$

The required nozzle area can now be calculated using the known mass flow and continuity:

$$
A_{h}=\frac{m_{h}}{\rho_{9} C_{j h}}
$$

Finally, the net thrust generated by this nozzle may be calculated:

$$
F_{h}=m_{h}\left(C_{j h}-C_{a}\right)+A_{j h}\left(p_{g}-p_{a}\right)
$$

The nozzle conditions, area and thrust for the cold (bypass) nozzle are calculated in precisely the same manner, with inlet conditions at station $\mathbf{2}$ and cold gas properties. The total net thrust generated by the turbofan is the sum: of the hot and cold nozzle thrusts. Note that if a nozzle is choked, the re will be a piessure thrust contribution, while the pressure contribution will disappear in the case of an unchoked nozzle.

\section{Calculating Specific Values and Thrust Indicators}

With the overall engine performance and internal cycle conditions calculated, the detemination of the indirect thrust indicators, monitoring temperatures and specific performance parameters are straight forward. They are calculated as follows: 


$$
\begin{aligned}
& F_{\text {nes }}=\left(F_{c}+F_{n}\right) ; F_{\text {spec }}=\frac{F_{\text {net }}}{m_{a}} ; S F C=\frac{F F}{F_{n e s}} \\
& I T T=T_{o b} ; \quad E G T=T_{o 7} ; \quad E P R=\frac{P_{0 \%}}{p_{0 y}} \\
& I E P R=\frac{\left(p_{o z} A_{c}+p_{o r} A_{h}\right)}{p_{o j}\left(A_{c}+A_{h}\right)}
\end{aligned}
$$

\section{Determining Non-Dimensional Performance Vilues}

During on-design calculations, the design spool speeds are not used. however, the non-dimensionalized on-design LP and HP spool speeds are important since they all used during the off-design performance calculations. Simtlarly, the design values of the isentropic efficiencies and non-dimensional mass flows (Q) are reguired for cath wit the aerodynamic components, to allow scaling of generalized component charactensices. The non-dimensional mass flows are calculated as:

For aerodynamic components: $\quad Q=\frac{m \sqrt{T / T_{s t d}}}{p_{1} / p_{s u d}}$

And for nozzles: $\quad Q=\frac{m \sqrt{R T_{\omega}}}{A p_{o}}$

$\mathbf{T}_{\text {std }}$ and $\mathbf{p}_{\text {std }}$ are the standard ambient conditions sea level $28816, K$ and 1101325 Bars respectively). Care is needed when calculating Q, since this must th: the mas blow parameter at the stator entrance of the HPT, and not the flow parameter at the lirst stige

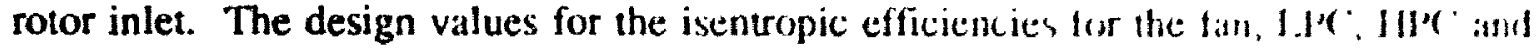
turbines are calculated using the polytropic efficiency and PR for eachenument. The conversion formulas 'ised are: 
Iior compressions: $\quad \eta_{1}=\frac{P R^{\frac{(y-1)}{y}}-1}{P R^{\frac{(y-1)}{\eta_{-}}-1}}$

For expansions:

$$
\eta_{1}=\frac{1-\left(\frac{1}{P R}\right)^{\frac{(\gamma-1) \eta_{-}}{\gamma}}}{1-\left(\frac{1}{P R}\right)^{\frac{(\gamma-1)}{\gamma}}}
$$

Iinally, the design point values for the LP and HP spool speeds are calculated using the specified values of mechanical speed (expressed as a percentage of the maximum spool design speed) and local corrected temperatures. Due to the flexibility in selecting the design point of a turbofan the design mechanical speeds are not necessarily $100 \%$. The design values for non-dimensional spool speed are required for cach compressor component; namely the fan, booster, and HP Compressor. Normally, the boosters and Fan will have the same mechanical spool speeds, but in smaller engines it is possible to have a gearbox between these. However, since percentage speed is used for $\mathbf{N}_{\mathbf{1}}$, the distinction between the fan and booster mechanical speeds is not necessary. The non-dimensionalized values of spool speed for each component, $\mathbf{n r}$, is thus:

$$
n r_{i, 2 n}=\frac{N_{1}}{\sqrt{\frac{T_{o 1}}{T_{s i d}}}} ; n r_{t p i}=\frac{N_{1}}{\sqrt{\frac{T_{o 2}}{T_{s t d}}}} ; n r_{h p c}=\frac{N_{2}}{\sqrt{\frac{T_{o 3}}{T_{s t d}}}}
$$

Calculation of the turbine thermodynamic speeds is not necessary, as will be discussed in Chapter 4, since the assumption of LP Turbine choking limits the operation of hoth turbines such that spool speed effects are minimal. 


\section{Chapter 4 Off-Design Simulation Methods}

\subsection{Assumptions}

A number of assumptions have been used during the off-design perfinmance simulations to simplify the solution. Several of these assumptions are the same as those previously described for the on-design simulation methods, while some are distinct to the twin-spool matching procedure used for the off-design calculations. The assumptions that were applied are:

\section{(a) Consiant Fluid Properties}

As with the on-design simulation, fixed specific heats are assumed lin the

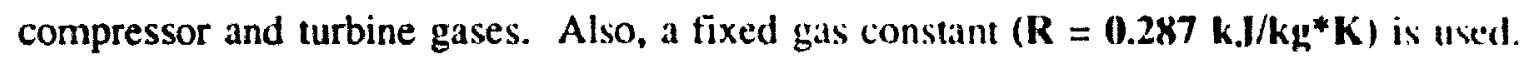

\section{(b) Ambient Conditions are I.S.A. Standard}

The ambient conditions are assumed to be International Standard Atmosplicere (ISA) values for a specified flight altitude. Some flexibility exists in the case of ambiom temperature, which can be defined to be different from the IS $\Lambda$ by some ammum, such as ISA $+15^{\circ} \mathrm{C}$ which is commonly used to simulate a hot day take-off condition.

\section{(c) Fixed HPT Turbine Cooling Method}

The advanced cycle turbofan simulation includes a fixed HIP cooling model which was described in detail in Section 3.3. Basically, this method is smulated by a fixed percentage of compressor delivery air being bled off, bypassing the combustion chamber and being r':-introduced at the HPT. Included in this model is the assumplion that this bleed air does not contribute to HPT work output, and that the conleng air is divided approximately evenly for stator and rotor cooling. 
d) Fixed Geometry Unmixed Nozzles

The high bypass turbofans simulated in this study are assumed to have separate bypass and core nozzles of fixed geometry (area).

\section{e) Definition of Spool Speeds}

One of the more difficult concepts to reconcile with actual engine data is the concept of percentage mechanical speed. It has been assumed in this thesis that $100 \%$ mechanical speed is the maximum speed that a spool has been designed to withstand safely; this is intimately related to the stress levels and material limits in the fan, compressor and turbine rotors and these are themselves influenced by thermodynamic considerations, especially the TIT. In other words, $100 \% \mathrm{~N}_{1}$ or $\mathrm{N}_{2}$ has NOT been assumed to be the design speed of the rotor but rather the design limit. Owing to the flexibility in selecting the design point of a turbofan (as discussed in Chapter 2) it is probable that at the TOC design point, $\mathrm{N}_{1}$ and $\mathrm{N}_{2}$ will be somewhere in the range of $92-$ 98\%. In this thesis, the generic engine simulated has been assumed to have mechanical speeds of $100 \% \mathrm{~N}_{1}$ for Ilot Day Take-offs (when TIT is maximum), 97\% $\mathrm{N}_{1}$ for standard day take-offs (ISA SLS), $95 \% \mathrm{~N}_{1}$ during climb, and $90 \% \mathrm{~N}_{1}$ at cruise. $\mathrm{N}_{2}$ is calculated as a result of the off-design matching methods, but a design point value is needed. In general, a value of $\mathrm{N}_{2}$ at TOC will be selected with the aim of achieving $100 \% \mathrm{~N}_{2}$ at HDTO conditions.

\section{(f) Fixed Duct Pressure Losses and Efficiencies}

No attempt has been made to simulate variable pressure losses in the turbofan ducting. intake or nozzles. Thus, a fixed pressure drop is used for the combustion chamber. defined as a percentage of the compressor delivery pressure. The pressure losses in the intake and nozzles are simulated by fixed isentropic efficiencies. There are methods that can be used to estimate variable pressure losses in ducts, but these are essentially secondary effects and not considered important in this study since determining general performance trends was the main focus of the simulations. (Gas Turbine Theory, 3rd Folition. pp.342-343) 


\section{g) Simplified Turbine Characteristics}

Figure 4.1 shows a typical turbine characteristic. At low speeds, it has been suggested that there is some dependence on corrected speed, but this can he approximated fairly accurately by a single line. A similar observation can be made tor the etficiency of a turbine, which is essentially constant above the choking PR, but does exhibit some speed dependence at low PR. If high turbine speeds are assumed. a turbine characteristic may be modelled successfully by a single curve, making it essentially identical to a nomzle characteristic cure. The assumption that LP Turbine stators are choked, which is reasonable for the high speeds under consideration in this thesis, simplifies the situatlon further such that the LP Turbine operates in a region where the PR is high enough for both the non-dimensional mass flow (Q) and efficiency to be constant. Due to how compatibility and the fact that the HP and LP turbines are in series, this causes the IPT operating point to be fixed. The details of this LPT choking concept will lxe shown later in this Chapter, but the imporant conclusion is that if LP'T choking is a valid assumption. there is no longer a need to use actual characteristics for either turhine during off-design calculations.
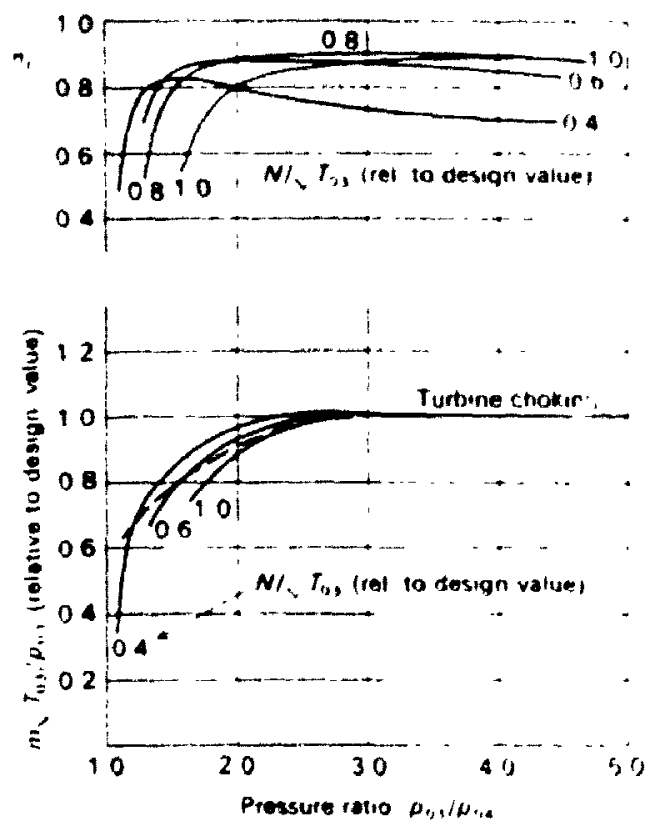

Figure 4.1 Typical Turbine Characteristics (Gas Turbine Theory 3rd Ed., p.293) 


\subsection{Twin-Spool Matching Procedure}

What follows is an overview of the twin-spool matching procedure used to simulate off-design performance of an advanced cycle turbofan. It is essentially identical to the procedure described in Chapter 9 of the text Gas Turbine Theory, 3rd Edition (Cohen, Rogers and Saravanamuttoo, 1986), but with modifications added to include the simulation of LPC (booster) stages downstream of the fan. It is presented here in simplified form; the detailed mathematics and procedures for component modelling are described in Section 4.3 .

The assumption of LP Turbine choking results in fixing the operating point of the HP Turbine. This has the effect of limiting the operation of the HP Compressor to a single operating line. Once design point performance is determined, this operating line may be solved before starting the matching procedire, by finding the unique operating point for each corrected speed of the HP Compressor. This solution procedure is shown in Section 4.3. The pre-determination of this operating line simplifies the matching calculations for the HP Compressor, resulting in faster solutions.

(a) For the specified flight condition (Mach, $T_{2}$ and $p_{2}$ at given altitude) the conditions at fan inlet $\left(T_{01}\right.$ and $\left.p_{01}\right)$ may be calculated.

(b) Fron the spacified fan mechanical speed $\left(\mathrm{N}_{1}\right)$ the corrected speed can be calculated as $n r_{1}=N_{1} / N T_{o 1}$. A point on this speed line (on the fan characteristic) is selected, giving $Q_{1}, F P R$ and efficiency. From these three operating fan parameters $m_{1}$ can therefore be calculated, as can the fan exit conditions: $T_{01}, P_{02}$ and $Q_{2}$.

(c) Tic $2, \ldots \ldots$... non-dimensional mass flow that can be passed $\left(Q_{c}\right)$ is calculated. From this $Q_{c}$, the cold nozzle mass flow $\left(m_{c}\right)$ may be found from the known fixed cold nozzle area. The core mass flow and BPR are then calculated from $m_{h}=m_{a}-m_{c}$ and BPR $=m_{d} / m_{h}$. This defines the gas ge $\bullet r$ inlet conditions. 
(d) The non-dimensional mass flow and corrected speed of the booster are now determined as follows:

$$
Q_{2}=\frac{m_{h} \sqrt{T_{o z}}}{P_{o 2}} ; n r_{b}=\frac{N_{1}}{\sqrt{T_{o 2}}}
$$

The value of $\mathrm{nr}_{\mathrm{b}}$ defines the appropriate speed line on the LP Compressor map. and using the calculated value of $Q_{2}$, the corresponding values of PR and efficiency cin be determined. Exit conditions are then calculated $\left(T_{03}, P_{03}\right.$, and $\left.Q_{3}\right)$ which are the entry conditions for the HP Compressor. ${ }^{3}$

(e) The HP Compressor operating line due to LPT Choking is already known. The inlet flow conditions $\left(Q_{3}\right)$ are used to find the exact point on the operating line that corresponds to this mass flow. this will be a unique point, providing $\mathrm{PR}_{\mathrm{hpr}}$. compressor efficiency and the corrected HP spool speed $\left(\mathrm{nr}_{2}\right)$. The temperature rato $\left(\mathrm{T}_{\mathrm{a}_{4}} / \mathrm{I}_{\mathrm{e}}\right)$ and rise $\left(\Delta T_{034}\right)$ through the HP Compressor can now he calculated.

(f) The HP Spool mechanical speed $\left(\mathrm{N}_{2}\right)$ and OPR are now calculated:

$$
N_{2}=n r_{2} \sqrt{T_{o 3}} ;\left(\frac{p_{o 4}}{p_{o l}}\right)=\left(\frac{p_{o 2}}{p_{o l}}\right) \times\left(\frac{p_{o 3}}{p_{o 2}}\right) \times\left(\frac{p_{o s}}{p_{o 3}}\right)
$$

(g) The HP Turbine inlet pressure and mass flow can be calculated based on the defined pressure drop and HPT cooling bleed:

$$
p_{o s}=p_{o s}\left(1-\Delta p_{b}\right) ; \quad m_{c c}=m_{h}(1-b l) ; \quad m_{s}=m_{h}\left(1-\frac{b l}{2}\right)
$$

3. Step (d) is required if booster stages are to be simulated, otherwise conditions at HPC inlet (station 3) are identical to those calculated at Fan exit (station 2). 
where $\Delta p_{b}$ is the combustion chamber pressure drop as a percentage of the CDP, and bl is the percentage of HP Compressor air bleed used for HP Turbine cooling, as described in Chapter 3.

(h) The value of $Q_{5}$ is a fixed quantity if LP Turbine choking is assumed, and is the design value $Q_{5 d}$ calculated during on-design calculations. $T_{05}$, the Turbine Inlet Temperature (TIT), is now calculated:

$$
T_{o s}=\left(Q_{s d} \times \frac{p_{o s}}{m_{c c}}\right)^{2}
$$

(i) The HP Turbine is operating at a fixed operating point due to LP Choking, which fixes the values of $\mathrm{P}_{0} / \mathrm{p}_{06}$ and $\Delta \mathrm{T}_{\mathrm{os} 6} / \mathrm{To}_{5}$, which were calculated during on-design performance determination. The conditions at the LP Turbine entrance are then calculated as:

$$
p_{o b}=p_{o s} x\left(\frac{p_{o b}}{p_{o s}}\right) ; \text { and } T_{o b}=T_{o s}-\Delta T_{o s 6}
$$

The mass flow at LP Turbine entrance is $\mathrm{m}_{\mathrm{n}}$, with the assumption that all cooling bleed has been returned to the core flow. The conditions at the HP Turbine exit could also be calculated by doing a power balance for the HP Spool.

(j) The inlet conditions are known for the LP turbine, and the temperature drop can now be calculated by calculating the power balance for the LP Spool. The LP Turbine polytropic efficiency (assumed to be constant) is then used to calculate the pressure ratio for the LPY. The power balance for the LP Spool is the same as used for the on-design calculations:

$$
m_{c} c_{p a}\left(T_{o 2}-T_{o 1}\right)+m_{2} c_{p a}\left(T_{o 3}-T_{o 2}\right)=m_{k} c_{p q}\left(T_{o b}-T_{o 7}\right) \eta_{\text {meck }}
$$


The second term on the LHS disappears if booster stages are not present since in that case $T_{03}=T_{02}$. The conditions at the LP Turbine exit are now determined $\left(T_{0}, P_{0,1}\right)$.

k) The LPT exit conditions are used to calculate the hot nozzle PR. The nondimensional mass flow parameter $\left(Q_{n}\right)$ can be calculated using this PR and the hot norzle isentropic efficiency using compressible flow relations (Wittenterg. 1976). From the corc mass flow and $Q_{n}$ the required nozzle area $\left(A_{k}\right)$ can be found since the non-dimensionil mass flow parameter for a nozzle is defined:

$$
Q_{h}=\frac{m_{h} \sqrt{R T_{o 7}}}{A_{h} p_{o 7}} ; \quad \therefore \quad A_{h}=\frac{m_{h} \sqrt{R T_{o 7}}}{Q_{h} p_{o 7}}
$$

1) The calculated area $\left(A_{h}\right)$ is compared with the fixed hot nozzle area as determined during the on-design calculations $\left(A_{b d}\right)$. In general $A_{b}$ will not agree with the design area $A_{b a}$. In this case, a different point is selected on the fan speed line and the process is repeated starting at step (b), until the calculated hot notzle area agrees with the design value.

Once agreement is obtained between the calculated and fixed hot norzle areas, the cycle conditions for the turbofan are known. Calculation of the fuel flow, nozzle thrusts and thrust indicators is then straight forward, following the identical precelures as done for the on-design performance.

For practical computer solutions, the above procedure must be modified slightly to provide some logic for the fan speed line search pattern; the main concern is 10 avoid impossible bypass ratios which result in unsolvable L.P Spool power balances. The details of this logic will be discussed in Chapter 5. The source of the various componem characteristics will be shown in the next section. 


\subsection{Component Modelling Methods}

\section{(a) Fan}

Ti) allow simulation of spool speed effects, it was necessary to use fan characteristic data. Detailed data on an exact fan or compressor is very difficult to obtain, being highly proprietary to a turbofan inanufacturer. Since the objective of this study was to simulate typical high-bypass curbofan behaviour, a generic fan map was needed that would be representative of the high efficiency wide-chord type fans now common in turbofans. Fortunately, such a map was found for the JT15D-4 turbofan. The map was modified slightly by adjusting the positions of the speed lines. This fan map should provide a fair degree of accuracy for turbofans with design FPRs of between 1.4 and 1.8, and with polytropic efficiencies the same as the current state-of-the-art (88-92\%). The modificd fan map can be seen in Figure 4.2.
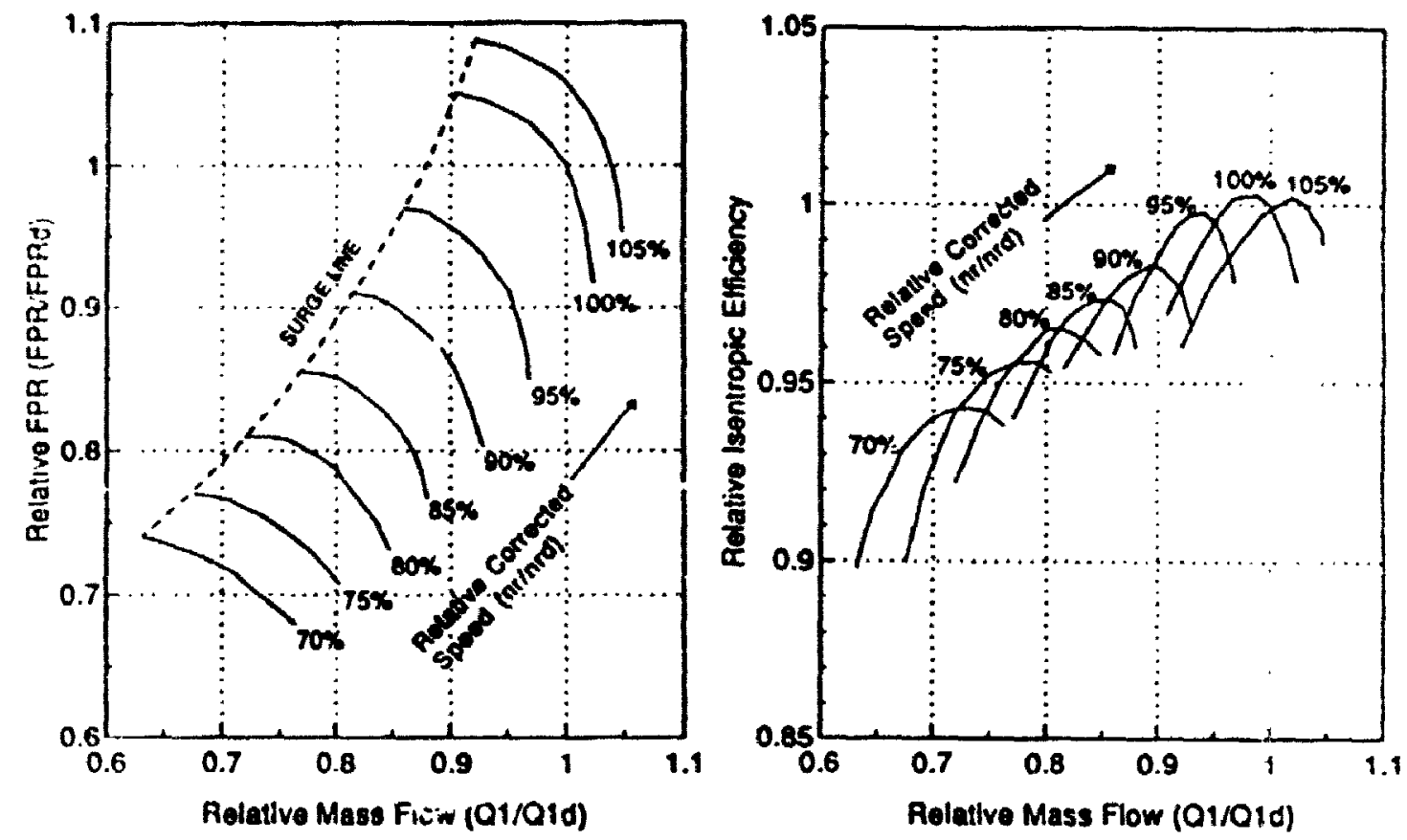

Figure 4.2 (ieneralized Fan Characteristic (Boyd, D.I., 1987)

Fur practical computer use of this characteristic, each speed line was divided into 10 points with the top point assunied to be on the surge line. The relative values of $\mathrm{nr}_{1}$. $Q_{1}$, FPR and efficiency for each point were determined and this information was stored in a data file in tabular form. Interpolation was used to define a speed line or operating 
point between these known points. For a given off-design matching calculation, the fan speed line has to be defined once, before the start of the iterative process. This is accomplished by using the corrected fan spool speed (found from the specified thight conditions, Mach number, $T_{o t}$ and $N_{1}$ ) and converting the relative performance parameters for the 10 points making up this line to actual fan performance values. Actual fan performance parameters are calculated by multiplying the design point perfonnance values by the relative values obtained from the generalized fan map.

The computerized twin-spool matching procedure alters the choice of fan opkerating point by choosing a different speed line data point depending on the outcome of the hot nozzle area estimate (see step (b) in the previous section) calculated in the previous iteration. If the calculated nozzle is too big, a point further down the speed line laway from the surge line) is used; if the calculated hot nozzle area is tor small, the opposite choice is made.(Gas Turbine Theory, pp.354-355)

\section{(b) Boosters}

The booster stages (LPC) were simulated in a manner similar to that descrilxed for the fan. A generalized LPC map was constructed using perfonmance curves that were available from the literature for a high efficiency L.P compressor. (Reynolds, et.al.. $\mid \mathcal{W})$ ) In this case the available LPC map data was in dimensional form but fortunattely the design point values for this unit were available from the map. A generalized I.P(' Map) was constructed by dividing the actual map values by the design point parameters. In the case of $\mathbf{P R}_{\mathrm{ppc}}$, care was needed to allow future scaling of the relative map PR. Values for PR relative to the design $\mathrm{PR}_{\mathrm{d}}$ were calculated by using the formula:

$$
\text { Rel } P R=\frac{(P R-1)}{\left(P R_{d}-1\right)}
$$

The resulting relative L.PC Map used in the simulation can be seen in Figure 4.3. 


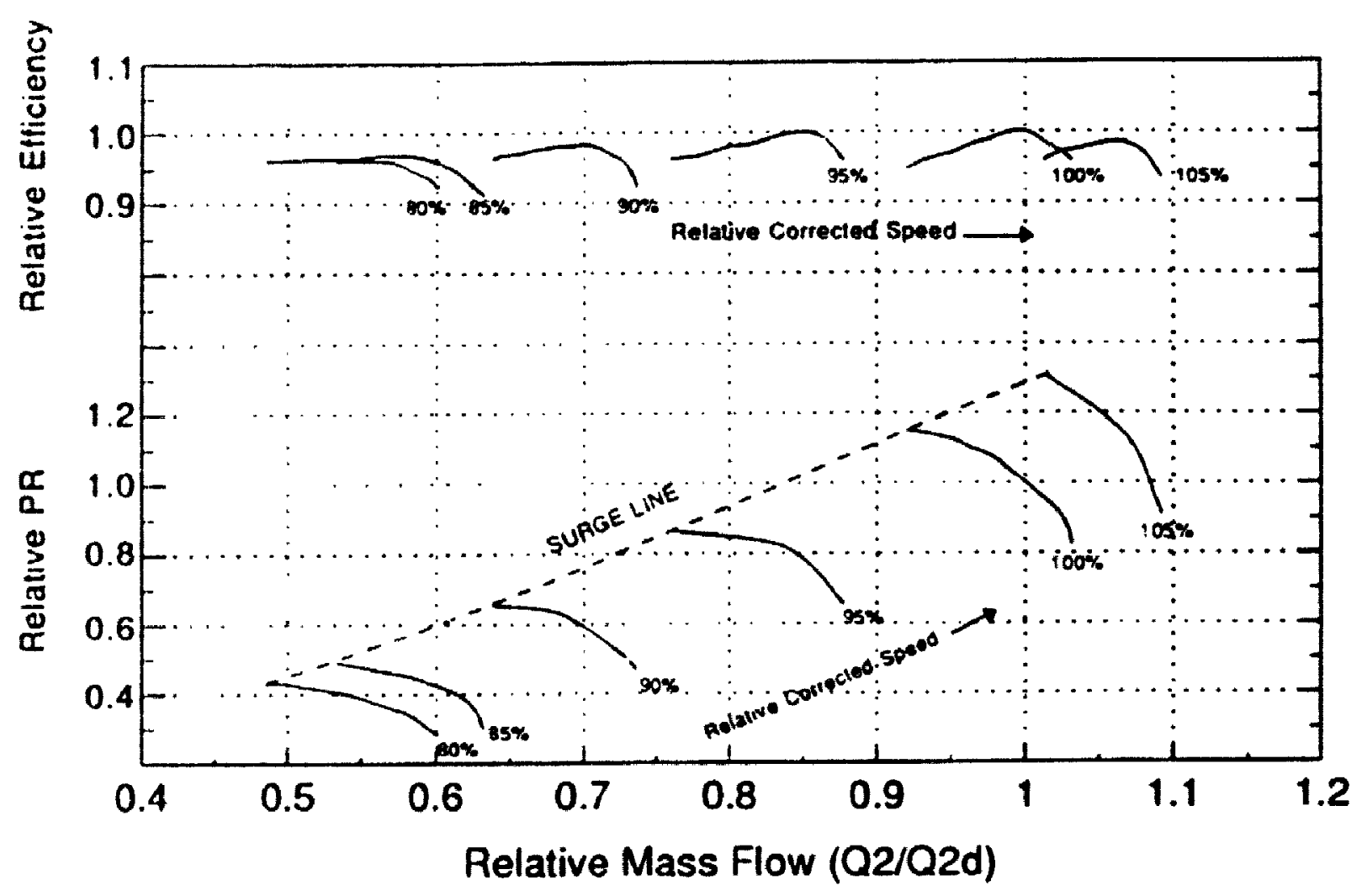

Figure 4.3 Generalized LPC Characteristic (Reynolds, et.al., 1991)

The generalized LPC Map was used during the simulation in a manner similar to that for the fan. Each of the relative speed lines were defined by dividing them into 10 regularly spaced points, and the relative performance parameters were determined for each point and saved in a tabular form. During the off-design calculations, the calculated conditions after the fan were used in combination with the known LP mechanical speed to define the LPC corrected speed. The corresponding LPC speed line on Figure 4.3 is then constructed, interpolating between known speed lines as necessary and scaling the speed line to the design point operation of the LPC. Since the non-dimensional mass flow $Q_{2}$ is defined from the fan exit conditions and the previously solved BPR, a unique operating point on the LPC non-dimensional speed line can be determined, which will yield the corresponding values of $\mathrm{PR}_{1 \mathrm{pe}}$ and efficiency for the iteration. Additional logic is necessary in the computerized search procedure to avoid LPC operating points that are beyond the limits imposed by the constructed speed line. 


\section{(c) HP Compressor}

The HP Compressor was simulated using a generie map that was derived from the HPC characteristic for the LM-2500 (AN, GE Product Brochure, I9S(1). The IIIC characteristic, combined with knowledge of the design point characteristics of this unit, allowed the construction of a generalized map in a manner similar to that described for ihe booster stages. The LM-2500 HPC was chosen as representative of the high performance HP Compressors required in turbofans with $\mathrm{OPR}=35$ or greater. It can ine shown that given a modest FPR and booster PR, the high pressurc compressor ratio in such an engine would be approximately the same as the LM-25(0) HIPC pressure ratio. Figure 4.4 shows the generalized HPC Map that was derived. A proxess identical to that described for the LPC was used to convert the dimensional information on the L.M .25(0) map into relative (generalized) information usable by the computer simulation. liach relative speed line was defined by dividing it into ten equally spaced mints, and saving the information for each point in a formatted data file.

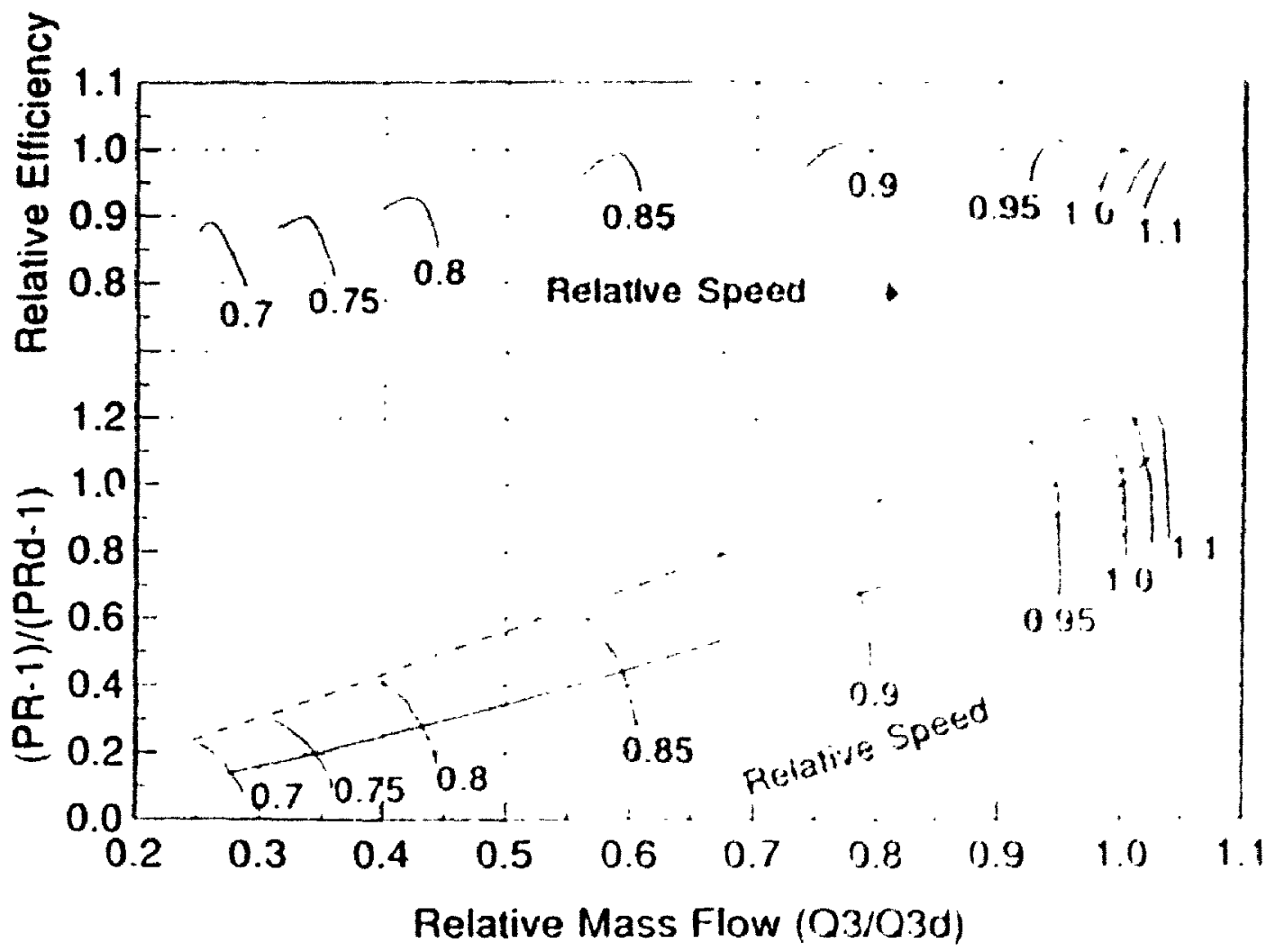

Figure 4.4 Generalized HPC; Characteristic 
The computer simulation of the HPC was simplified by determining the operating line on the HPC characteristic. This operating line could be calculated ahead of time by using the assumption that the LP Turbine stators are choked, which restricts HPC opcration to a single line on its characteristic. This simplification becomes invalid at low IIP spool speeds when the LPT may become unchoked, but such speeds were not considered in this study. The HPC operating line is calculated using an iterative approach, from now and work compatibility for the core:

$$
\begin{gathered}
\frac{m_{s} \sqrt{T_{o s}}}{p_{o s}}=\frac{m_{3} \sqrt{T_{o 3}}}{p_{o 3}} \times \frac{p_{o 3}}{p_{o s}} \times \frac{m_{5}}{m_{3}} \times \frac{p_{o s}}{p_{o t}} \times \sqrt{\frac{T_{o s}}{T_{o 3}}} \\
\frac{\Delta T_{o s 6}}{T_{o s}}=\frac{\Delta T_{o 34}}{T_{o 3}} \times \frac{T_{o 3}}{T_{o S}} \times \frac{c_{p a}}{c_{p s} \eta_{\text {mech }}} \times \frac{m_{3}}{m_{5}}
\end{gathered}
$$

The solution for each speed line is calculated by choosing points up and down each IIPC speed line until both equations give the same temperature ratio $\left(T_{00} \delta T_{03}\right)$, thus defining the HPC parameters for the point. This is done for each speed line in turn, defining the operating line through these points. An example of such an operating line can the seen in Figure 4.4. The operating line is solved in dimensional form; that is, the points on each speed line are defined in terms of actual HPC performance values as used in the matching procedure. These dimensional parameters are determined by multiplying the infurmation on the generalized HPC Map information by known design point operation values for the HPC during the operation line solution procedure. The solution of the two cequations given for $T_{n s} T_{\mathrm{e} 3}$ is greatly facilitated by LP Turbine choking since

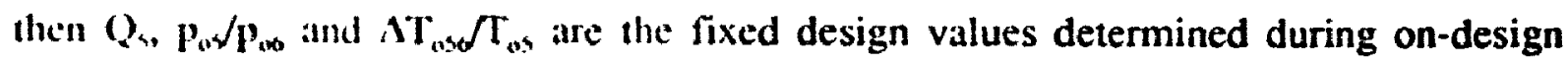
pertomance calculations.

During the off-design matching procedure, the HPC operating line is used to solve the IIPC pressure ratio and efficiency for a given non-dimensional mass flow $Q_{3}$ which is known from the LPC exit conditions. The solution point is found by interpolating 
between known points on the operating line as necessary; additional logic is used w ensure that impossible matches (such as too high or too low $Q_{3}$ ) are avidided.

\section{(d) Combustion Chamber}

The combustion chamber is simulated using Cockshutt- Chapell tables to calculate the fuel flow as for the on-design calculations. The pressure drop and mass flow through the chamber $\left(\mathrm{m}_{\mathrm{rc}}\right)$ are both calculated under the assumption that there is a constiant percentage of HPC delivery air being bled to the HPT for cooling, and that the pressure drop is a constant percentage of the CDP.

\section{(e) Turbines}

It has been mentioned that the perfornance of axial flow hurbines can be simulatted through the use of turbine characteristic curves which can be approximaled by a single line showing the non-dimensional flow rate $Q$ for a given turhine pressure ratio. This implies that there is little dependency on rotational speed, as detailed turbme characteristics attempt to indicate, for the range of rotational speeds heing comsindred. With this simplification, the turbine characteristics are identical to those for tixed areat nozzles. This assumption is seen to be generally applicable, especially when the effect of having two turbines and a nozzle in series is considered.

In the case of turbines, downstream compone. (another turbine or a mor/le lave a direct influence on performance due to the requirement of flow compatibility homblh the components. If the LP furbine is assumed on be choked, which is a valid assumption for most of the practical operating range of modern turbefians, then the simulatum of the two turbines is greatly simplified. Figure 4.5 shows the effect of two wrbines in serres. 


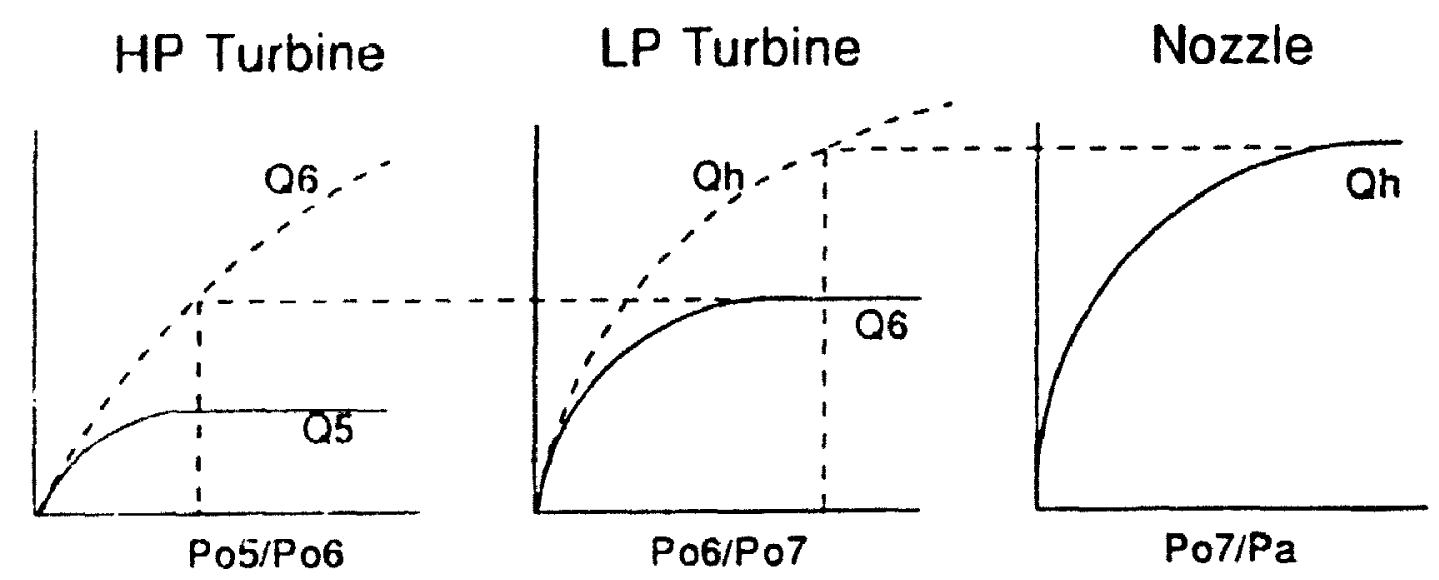

Figure 4.5 Flow Compatibility for Two Turbines and a Nozzle In Series

It can be seen that LP Turbine choking restricts the operation of the HP Turbine to a fixed pressure ratio and non-dimensional flow rate. The non-dimensional flow rate of the LP Turbine would also be constant for PRs above the critical (choking) !imit. Once the design point values of these viriables are calculated, the need for using actual turbine characteristics is eliminated. This is the method that has been used during this study. As was described in the section on HP Compressor modelling, LP Turbine choking facilitates the determination of a u:ique operating line on the HP Compressor characteristic, simplifying the off-design calculation procedure.

\section{(n) Norrles}

It has teen mentioned that simplified turbine characteristics resemble the graphical representation of fixed geometry converging nozzle operating characteristics (charateristics). A sypical nozzle characteristic will be as shown in Figure 4.5, with a horizontal (constant (Q) porion above some pressure rutio, called the critical pressure ratio or choking limit of the nozzle. For ideat nozzles, this PR is constant depending only on the nature of the gas being passed through. For normal air (with $\gamma=14$ ) this critical 
pressure ratio is 1.893 , while for turbine gases (with $\gamma=1.333$ ) it is 1.853 . For less than ideal nozzles, these critical pressure ratios will be slightly higher. The calculation of critical pressure ratio is derived from compressible flow relations. corrected for a specified isentropic nozzle efficiency.

It can be shown that the precise nature of nozzle characteristics (usually a line representing the non-dimensional mass flow with nozzle PR) can be descriled quite adequately by using compressible flow relations (Wittenberg. 1976). The only unique problem is if a particular nozzle is not $100 \%$ efficient, which modifies the shape of the curve. However, the effect of a less than perfect nozzle can still to simulated through use of compressible flow relations; the nozzle equations will then have to take into account the efficiency of the nozzle. Usually, the efficiency of a nozzle is stated as an isentropic efficiency which is assumed constant. The derivation of the relevant noske equations, which are based on isentropic flow relations for compressible flows is shown in detail in the report by Wittenburg (Wittenberg, 1976). The resulting noz/le eyuations are shown below for an unchoked nozzle,

$$
\frac{m \sqrt{R T_{0}}}{A p_{0}}=\frac{p_{a}}{p_{0}} \sqrt{\frac{2 \gamma}{\gamma-1} \eta\left(1-\left(\frac{p_{a}}{p_{0}}\right)^{\frac{\gamma-1}{\gamma}}\right)} \cdot \frac{1}{1-\eta_{1}\left(1-\left(\frac{p_{0}}{p_{0}}\right)^{\frac{\gamma^{1}}{\gamma}}\right)}
$$

and for the case of a choked nozzle (when the noczle PR is above the critical ratio vilue),

$$
\frac{m \sqrt{R T_{o}}}{A p_{o}}=\left(1-\frac{1}{\eta} \frac{\gamma-1}{\gamma+1}\right)^{\gamma} \cdot \sqrt{\gamma \frac{\gamma+1}{2}}
$$

Thus, all that is needed is the PR of the nozzle (and knowledge of the type of fluid), and the non-dimensional mass flow of the nozzle may be calculated directly. If the 
inlet conditions and actual mass flow are known, the required area can be calculated from Q. The opposite calculation is also possible, where area can be specified and then the mass flow that the nozzle can handle could be found. Using these nozzle formulae results in highly accurate nozzle simulations, and eliminates the need to solve the nozzle performance graphically through the use of characteristics.

The nozzle exit plane properties (static temperature and pressure) are calculated using the approach followed in the on-design simulation procedures. The calculation of fuel flow, thrusts and thrust indicators is then a straight forward procedure since a successful twin-spool matching calculation results in all internal cycle conditions being known for the engine. Once these conditions are known, the solution process is identical to that used for the on-design calculations. 


\section{Chapter 5 Turbofan Simulator Program Overview}

\subsection{Overall Program Structure}

The turbofan simulation software was developed using a recent version of MicroSoft Fortran (Version 5), though in most respects this follows the Fortrin 77 standard. Once compiled, it will run on an IBM PC or compatible computer with reasonable speed. The program was designed in modular format, with most of the basic computations conducted by individual subroutines and linked together during the compiling process. Additional comments and details on the programming aspects of this program may be found in the Operators Manual which has been prepared for the program. What follows is a description of the major features of the program, including the menu structure.

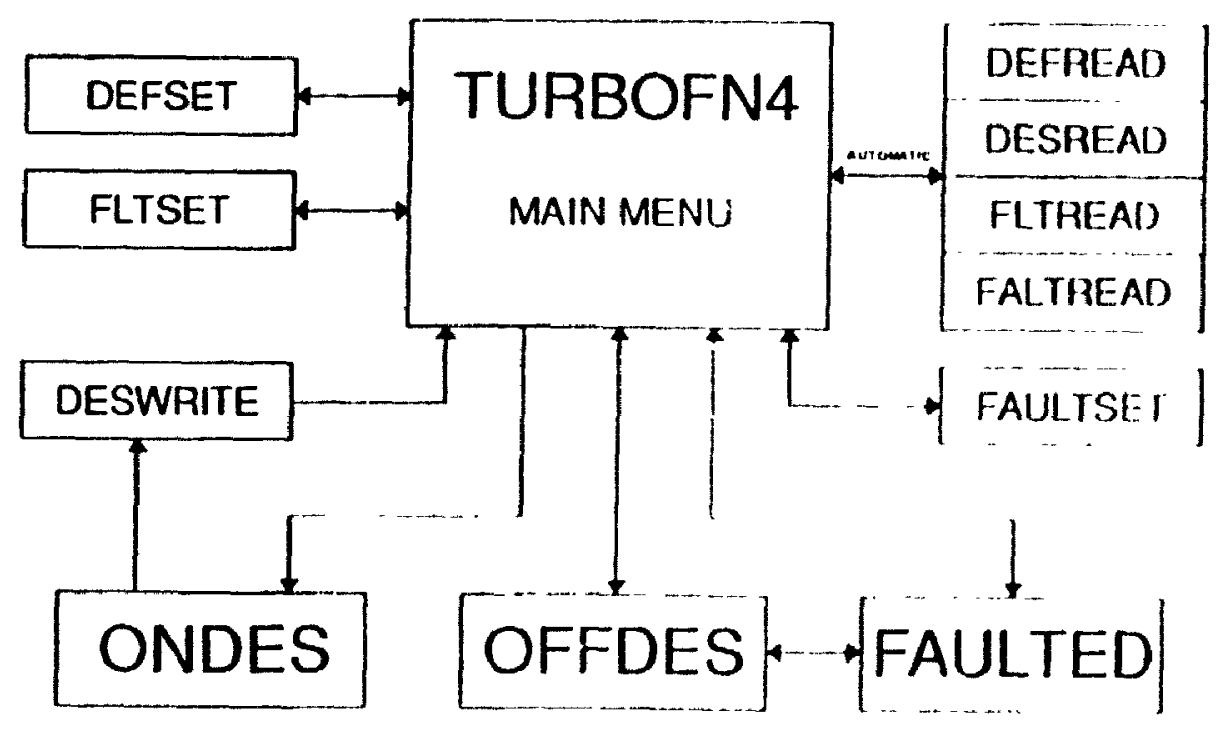

Figure 5.1 Overall TLRBOFNA Program Structure 


\section{TURBOFN4 Main Program}

Figure 5.1 shows the overall organisation of the turbofan simulation package. As evident from this schematic, the simulator is organised around a menu-style structure, with the main program called TURBOFN4. This is the fourth version of the TURBOFAN simulation package developed by the author, abbreviated to conform to the filename length limits in DOS. TURBOFN4 contains the Main Menu which calls all other subroutines. Besides controlling the main menu, TURBOFN4 does all initialization functions for the simulation program, such as defining variables and loading in default program settings. The three main functions of the simulator, on-design, off-design and faulted engine simulations, are conducted in separate subroutines of the same name, and called from the TURBOFN4 main menu as Options 1 through 3 respectively. Other subroutines are called as needed, which set the flight conditions, faulted engine conditions and program defaults.

\subsection{On-Design Module}

The on-design calculation module is responsible for defining, editing, saving and retrieving the turbofan design parameters. The module itself is called ONDES.FOR, and it is a menu driven program which ealls several sub-processes as shown in Figure 5.2. The menu display also shows the current engine design that is under consideration, complete with an abbreviated output of the design point cycle and the estimated perfomance of the design. The major features of the on-design calculation module will he described in the sections which follow. 


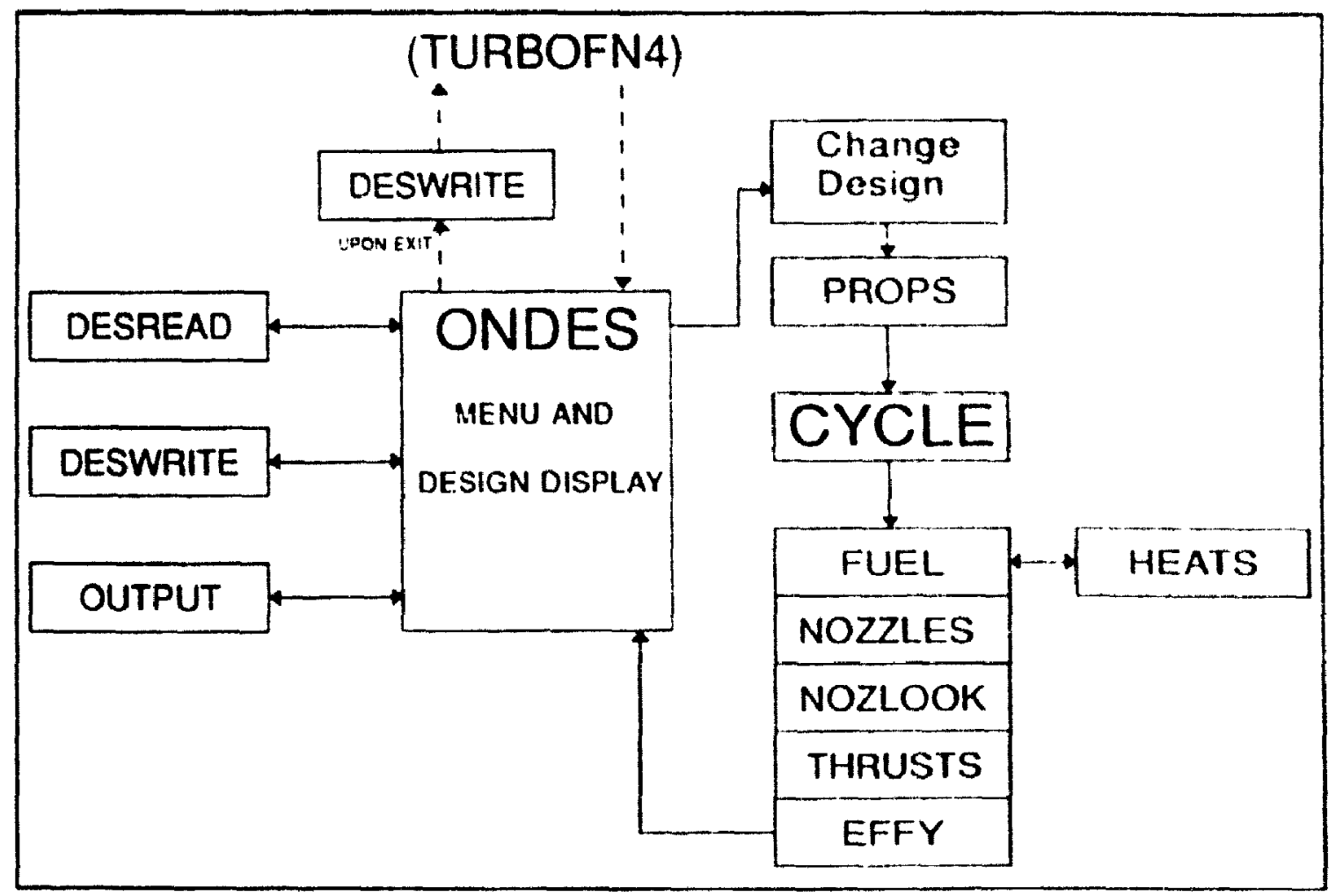

Figure 5.2 On-Design Module Structure

\section{CYCLE}

The "heart" of the on-design calculation procedure, this subroutine does a single on-design calculation based on the current design point parameters. CYCI.J uses the design point calculation methods described in detail in Chapter 3 to estimate the turbotan design performance, the indirect thrust indicators, and various design point parameters required by the off-design calculations. CYCLE itself calls several shon subroumes (some are common subroutines shared by other programs) which are used to conduct the more frequent on-design calculations such as the converson of polytropic to isentropte efficiency and determination of fuel flow. The results of the analyss are passed back to the calling program.

\section{DESREAD, DESWRITE}

These two subroutines are used to read in a previously saved design (IDI:SKI:AD) or to write the current design for latter use (DESWRITE). IDESREAI) is automatically 
used when TURBOFN4 is started, reading in the last design that was defined, whose design parameters are stored in a file called DESSET.DAT. Within the ONDES subroutine, designs may be read or written using user-defined names as desired. When ONDES or TURBOFN4 are exited, the current design is automatically written to DESSET.DAT by DESWRITE. This backup is done in case there is a program crash, and to speed up initialization of the main program.

\section{IHFY, FUFL, HEATS, PROPS}

These are small subroutines which conduct calculations repeated often by the turbofan modelling program. EIFY is used to convert a polytropic efficiency to the equivalent design point isentropic efficiency based on pressure ratio and whether a component is a compressor or turbine. FUEL calculates fuel flow by finding the fuel/air ratio based on the combustion chamber inlet and exit temperatures, the enthalpies at these temperatures, and the IECV of the fuel. HEATS is the subroutine which calculates these cuthalpies and ECVs based on polynomial fits as given by (Cockshutt-Chapell, 1974). PROPS calculates the ambient temperature and pressure conditions at a specified altitude, based on standard conditions at 0 meters, and a linear variation in temperature up to the tropopause. Ambient pressure is calculated by using algebraic expressions based on hydrostatic type pressure variation with atmosphere depth. A change in ambient temperature from standard values may also be used (eg. ISA $+15^{\circ} \mathrm{C}$ ) which is applied after the standard temperature is calculated. This is assumed to have no effect on the ambient pressure.

\section{NOYZIIES, NOZIOOOK, THRUSTS}

NOZZIIES is used to calculate the nozzle conditions in the manner described in Chapter 3. while NOZI.OOK is used to determine the design nozzle area as discussed in Chapter 4. THRUSTS uses the nozzle areas and flow conditions to calculate the thrusts from each nozzle, overall net thrust and various thrust indicators. 
OUTPUT

This outputs a detailed description of the turbofan design and design print perfomance behaviour. This may be used to match the performance of all existing engine if such details as design point internal cycle conditions or nozzle areas are hnown.

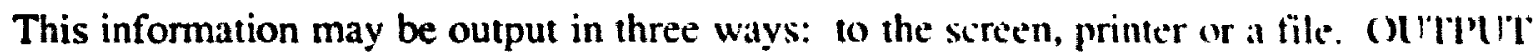
is a "shared" subroutine, as it is used in a similar fashion during off-design calculations.

\subsection{Off-Design Module}

The off-design calculations are initiated from the Main Menu in TURB()INA. either for an unfaulted engine (Option 2) or faulty engine (Option 3). The olf alesign module is not menu driven, but instead performs an automated off-design analysis of the current design with or without certain faults. The procedure is essentially identical to the methods detailed in Chapter 4, with the initialization procedures (mosily the pre. determination of the fixed HP Compressor operating line) accomplished at the stant of the run. Off-design then cycles through the current set of flight condition data points (defined in the subroutine FLTSET, called from the Main Menu of TURB(OINA), determinimg the appropriate fan speed line and then passing control to the sub-routine MATCII which conducts the twin spool matching procedure. Upon a successful match result, MAICII returns the solved engine cycle conditions (total temperatures and pressures al all stations) to OFFDES which then calculates the overall performance at the flight condition. This is accomplished by calling NOZZLES, FUEL, and TIIRUSTS, which were descrited in the previous section. The subroutine OUTPUT then outputs the results of the Iwill ipexil match to one of three destinations; screen, printer or file. The structure of the ()I.1-1)1:S module may be seen in Figure 5.3, which also shows the program execution precedure. The individual subroutines are detailed in the following paragraphs.

\section{FANLIM (LPCLIM). FANSPIED, FANIOOK}

These subroutines are responsible for assembling the required fan speed line for each flight condition. FANLIM reads the speed iimit ranges from the first line fan map 
data file. A similar routine called LPCLIM is used to define the speed limits for the LPC (booster) stages, if these are to be included. FANSPEED calculates the corrected fan speed based on the flight conditions for the run, which include the mechanical speed, aircraft altitude and Mach number. Using this corrected speed, FANLOOK selects two sets of speed line data from the fan map data file and then determines the required fan speed line by interpolation. The output of this procedure is a set of 10 data points defining the fan speed line for the current off-design operating point.

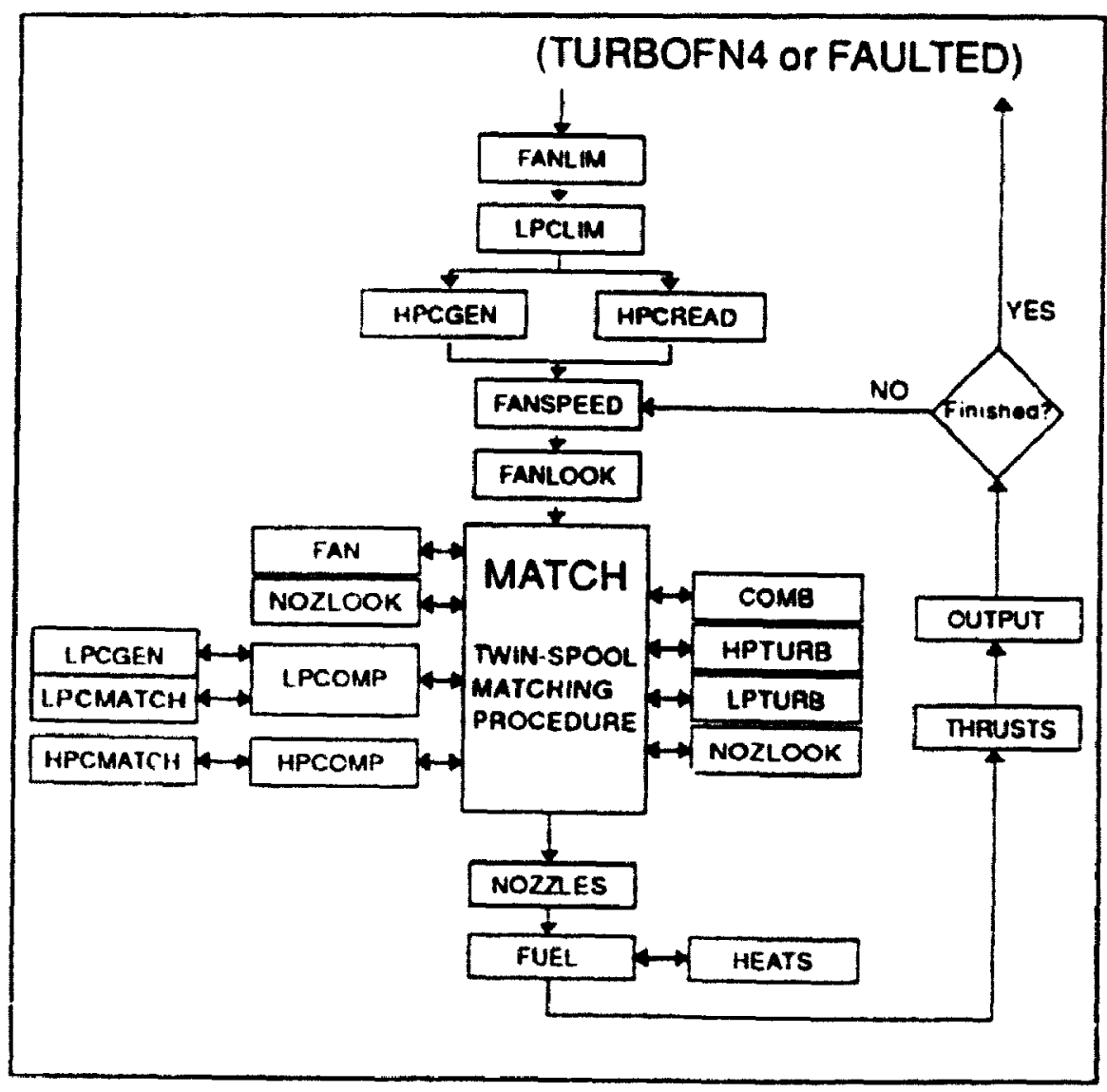

Figure 5.3 Orf-Design Module Structure

\section{HPCGEN and HPCREAD}

These subroutines are used at the start of all oti-design calculations to determine the fixed HPC operating line defined by the LP Turbine choking assumption. The procedure used is an iterative one. following the mathematical matching process that was 
outlined in Section 4.3(c). HPCGEN is used to calculate the set of operating points located on each HPC corrected speed line, which define this line. TURBOIFN4 keeps track of whether or not changes to the HPC, HPT or LPT have occurred since the last offdesign procedure. If they have not, then the HPC operating line should not have changed. In this case HPCREAD reads the operating line data from a small data file called HPCLINE.DAT. This data file is automatically created at the completion of the calculation procedures in HPCGEN, defining sach of the HPC speed line operating prints for later use and manual error checking.

\section{MATCH}

This subroutine conducts the twin spool matching calculation, based on the procedures outlined in Chapter 4. The subroutine makes extensive use of small subroutines to perform calculations for each of the individual components. This was dome for two reasons. Each separate subroutine could be tested and debugged without having to compile and run the entire TURBOFN4 program. Secondly, due to the nxolular nature of the program, individual component modelling procedures may be allered and/or improved without changing MATCH itself. All that is required is the same orgamsation for the variable listing in the CALL statement to the subroutine. Most subroutines are quite straightforward, conducting component modelling procedures as was outlined in Chapter 4. Only those involving complex or important procedures will be detailed here.

Extensive logic is required to make MATCH find the correct twin-sp(x)l match in an optimum fashion. The procedure starts by choosing the top point (i-10) of the pe generated fan speed line. The coarse search pattern then proceeds. with the olf design performance calculated at this chosen point. The default search pattern is to decrement the search index (i.e. $i=i-1$ ) as long as the calculated hot morele area $\Lambda_{b}$ is greater than the design area $A_{b d}$. This search pattern is illustraied in ligure 5.4 . 


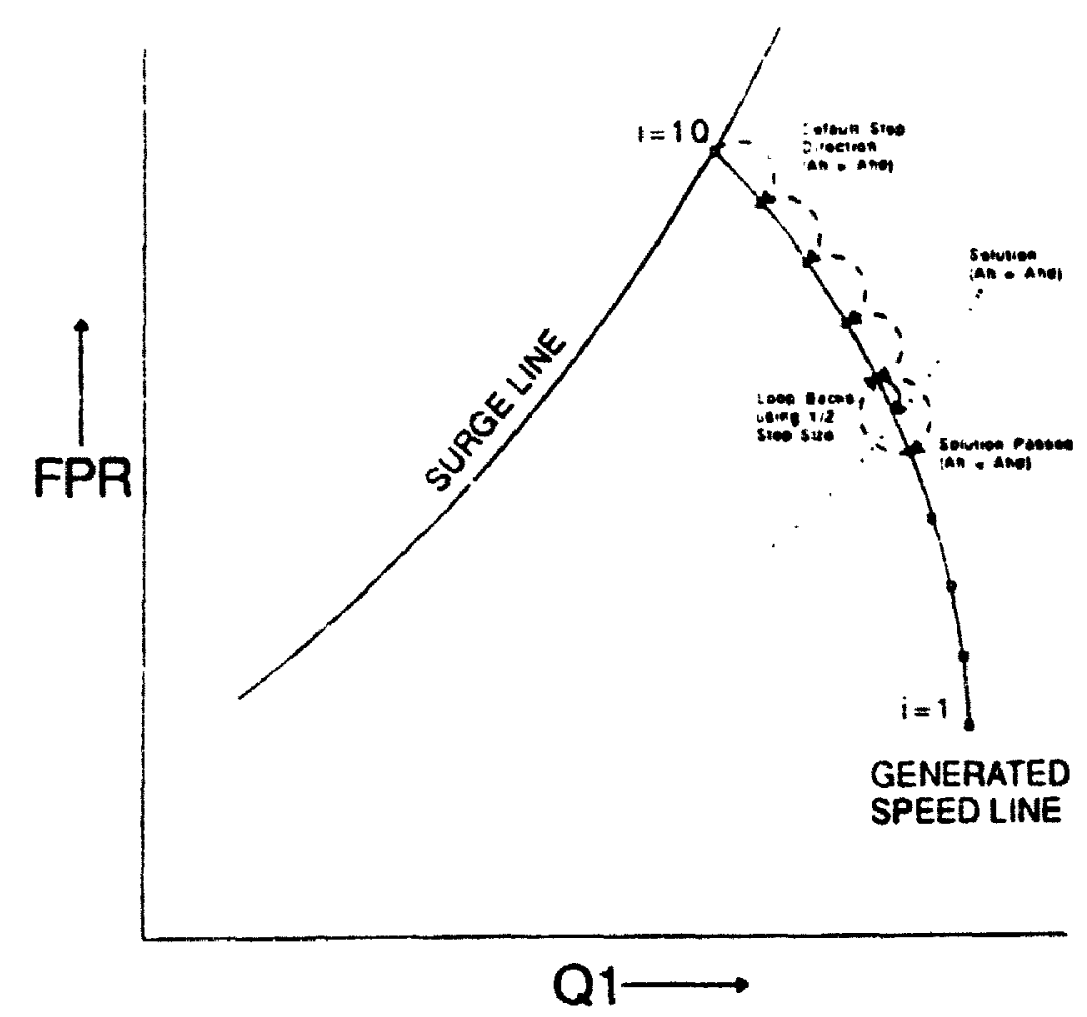

Figure 5.4 Diagram Showing Fan Speed Line Iteration Procedure

The coarse search continues until one of the following conditions are met:

(a) The calculated hot nozzle area is too small (Ah $<$ Ahd) which means that the solution has just been passed. In this case, the search backs up to the previous pattern, and a fine search procedure is staried.

(b) The calculated area equals the design value or is within the error range desired. This results in a successful match, and control is passed back to OFFDES to find the overall performance at this operating condition.

(c) The last point $(i=1)$ is reached without passing the solution. Decrementing the search pattern is not possible, and so a legitimate fan match cannot be found. The search procedure is terminated. and control is passed to OFFDES, which alerts the operator to this problem. In practical terms, an unsuccessful match such as this must be due to a severe fan operating condition being specified. If option (a) is true for the first 
search point $(i=10)$ then moving up the fan speed line puts it into surge, which is not allowed by the simulator. This generates an unsuccessful search result.

The fine search pattern uses a binary search procedure, initially using the two known operating points $(i$ and $i+1)$ as the low and higa data points. Then, one-half of the spacing between these is used, stepping down the fan speed line as thefore until the solution point is found or passed. Fan speed line points are determined by interpolation where necessary. The search loops backs to the last point and the step is divided in half again. This procedure continues, resulting in successively finer scarch stejs, until the solution is found or the search increment becomes smalker than the desired error range parameter. A typical core area error range was $0.005 \mathrm{~m}^{2}$, which corresponds to an overall error of approximately $1.5 \%$ for the size of engine simulated (core area of $0.32 \mathrm{~m}^{2}$ or approximately $500 \mathrm{in}^{2}$ ).

Additional logic is required to allow selection of the appropriate I.PC aperating point and the match point on the HPC operating line. MATCH controls access to the subroutines used to find the LPC and IIPC operating conditions, filteriag atlempls all matching points in either case which are out of range or which would result in a tatal program crash. The main purpose of the logic is to augment the selection of the fim speed lines, since some choices (especially for high FPR) result in inlet conditions at the LPC or HPC which are impossible for them to handle within the range imposed by the LPC and HPC map data. During both kinds of searches (coarse and fine) legical sections immediately after the LPC and HPC calculations are used "1, when necessary, shont circuit the nomal fan speed line point selection.

In the case of the LPC (boosters) the logic is used to atvoid problems with litter calculations. Figure 5.5 shows the types of logic used for the L.PC match, as detailed below:

(a) Any I/O Errors are flagged, indicating a problem with the format of the LPC map data file. The matching procedure is terminated.

(b) A successful LPC match causes MATCll to proceed immediately of the HPC calculations. 
(c) If the mass flow $Q_{2}$ into the LPC is too low, it cannot be found on the specified LPC speed line. In this case, a point further DOWN the fan speed line is selected $(i=i+1)$.

(d) If the mass flow $Q_{2}$ into the LPC is too high, a match on the LPC speed line will not be possible. Another fan speed line point must be selected closer to the surge line. This triggers a fine search in the event that this is flagged during the coarse search. If already within a fine search, this triggers a loop back in the procedure with a finer increment.

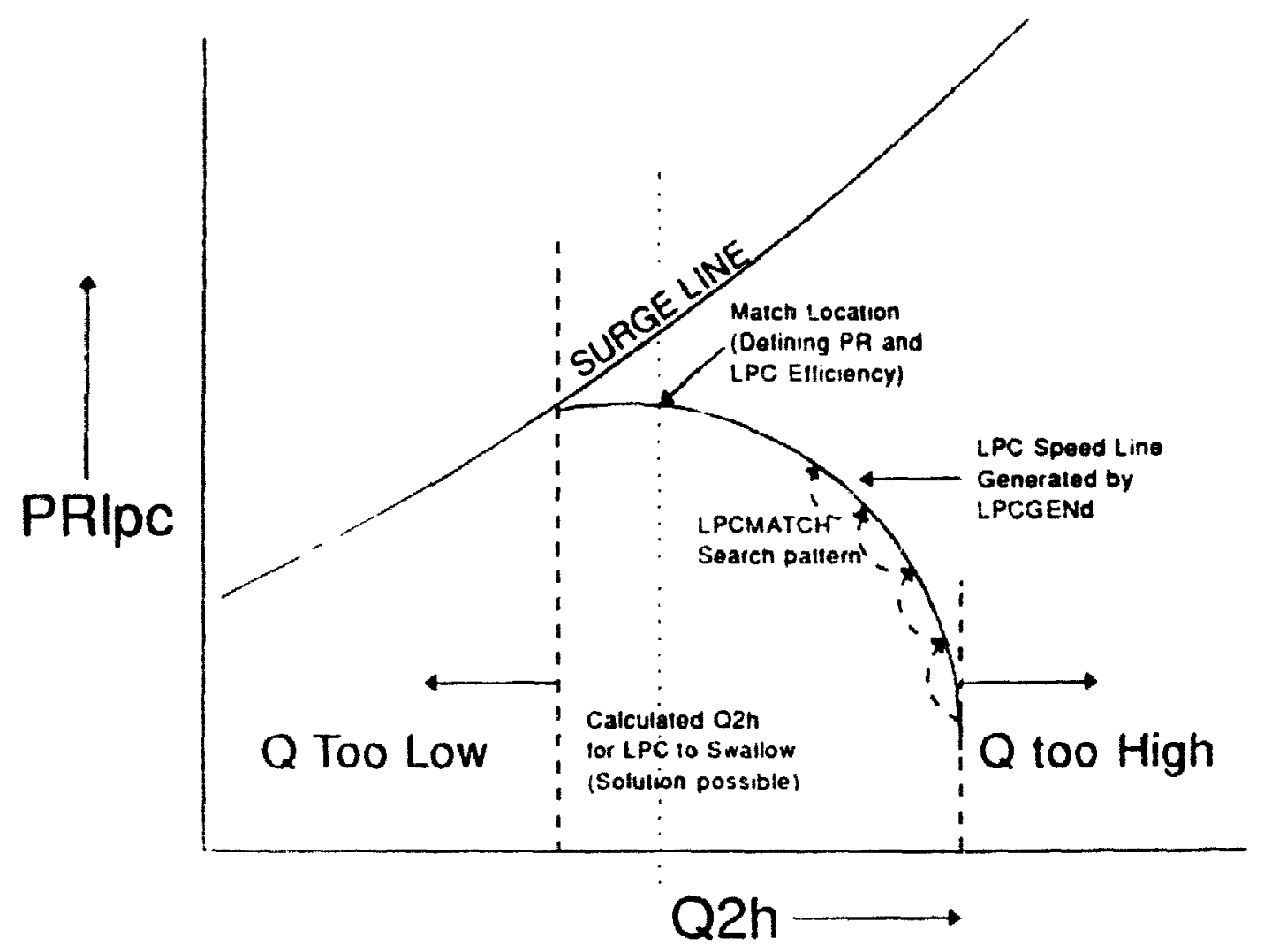

Figure 5.5 Diagram of L.PC Match Procedures

The search/match logic followed in the case of the HP Compressor is similar to the LPC logic. but this time is simplified by the presence of a pre-determined operating 
line. With a $Q_{3}$ specified for the HPC to swallow, a match should be found on the linc unless this mass flow is excessively low or high. The logic followed for the HPC math can be seen in Figure 5.6. The details of this logic are:

(a) If the HPCMATCH procedure encounters problems with using the IIIC map data, an $1 / O$ error is flagged which terminates $11 \mathrm{NTC} / 1$ in a non-fit..l mammer. Such an error indicates a problem with the data file; cither the format is wrong: ar perhalps it is missing.

(b) If $\mathrm{Q}_{3}$ is too small, a match on the operating line mat mot be possible since this would put it at a speed outside the lower limit of Ill' spects. In this atse, another fan speed line point further down is needed.

(c) If $Q_{3}$ is too large, a match will not be ferund since the required mass flow is greater than the highest value on the operating line. In this catse a fan spered line puint closer to the surge line (with lower overall mass flow) is nceded. It lhis accums during: a coarse search, a fine search is initiated. If already within a fine scarch procedure, this triggers a loop-back to the previous point and a finer increment being chosen.

During the initial iterations of the coarse and sine seaches impmsible fort end conditions could be generated, especially when the calculated Bypa,s Ratio is significanly higher from the design Bypass Ratio. This can lead a implobable: $\mid f^{\prime}$ Spmel woik balances and impossible pressure or temperature conditions at the 1.P Tubine exit. The principle cause for this stuation is excessive Fan Pressure Ratio. To avoid calculating, negative total temperatures or pressures below ambicnt (both of which will result in a fatal math error in the LPTURB or NOWLOOK sibroutines) MATCH amtonmatically executes a fan speed line point decrement away from the surge line fant circuiting the hot nozzle area estimate calculation. 


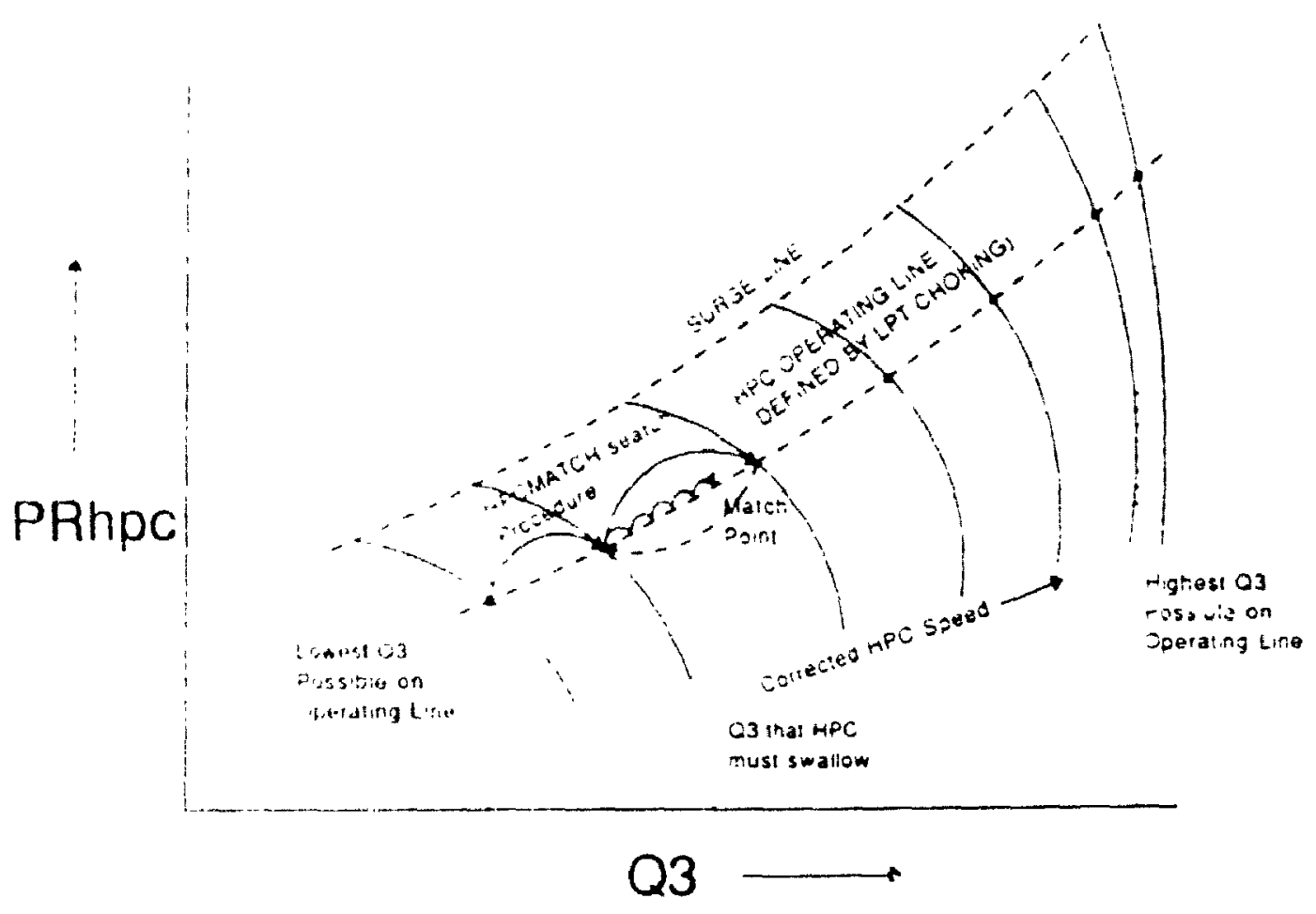

Figure 5.6 Diagram of HPC Match Procedures

B.AN

This subroutine calculates the exit temperature and pressure conditions based on fectied refirmance parameters defined by the current choice of fan operating point Hong the speed line.

\section{N() 71.0() $\mathrm{K}$}

Thus subroutine uses analytical expressions based on compressible flow relations 6) colculate the non-dimensional now $Q$ for a convergent nozzle for a given pressure 1.atw. From $Q$, the mass flow utich may be passed may be determined if the area of the norste is known (Mode 1). If the mass flow is known, the opposite calculation Wetcmmatuon of required nozzle area) may be conducted instead (Mode 2). Following the tan calculation. Mode 1 is used to tind the cold mass flow that can be passed by the byass nuzzle which has a known (fixed) area. Following the LP Turbine caiculations, Mode 2 is used to calculate the hot rozzle area required for the known core mass flow. 


\section{LPCOMIP, LPCGEN, LPCMATCH}

LPCOMP is the subroutine called from MATCH which deismines the operatm! point and the resulting perfomance for the booster stages (if used) 1. 'Po.Ml' itself salls other subroutines which are used to find the L.PC operation point. I.PC iliv uses the corrected spool speed determined from fan exit conditions we senerate the correat $1 . \mathrm{f}^{\circ}$ corrected speed line. LPCMATCH then uses the $Q_{\text {in }}$ that the L.P' must suallow on tind the appropriate point on the generated LPC spers line. Following a stacentul muth. LPCOMP calculates the overall performance of the boster sages, in particular the (Null temperature and pressure conditions for the $H^{\circ}$ Compressor. An unsuccesviul match is

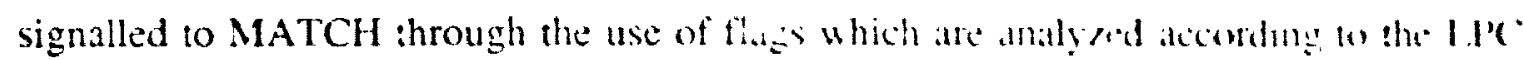
match logic protocol described prevounly.

\section{HPCOMP, HPCMATCH}

These subroutines model the performance of the III' (ompressor. III' (onll' is called from MATCH, and controls the determination of HPC pertomance. Mre MAT II uses an iterative search procedure along the known llle operatimg line umbl a mathe is found between the required $Q_{3}$ to be suallowed, and the $Q_{3}$ possible an the aperatme lane.

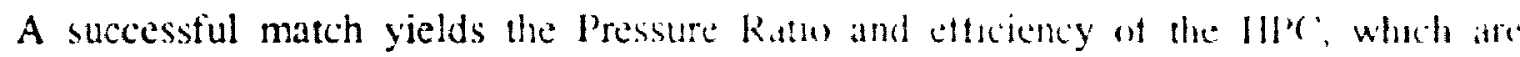
returned to HPCOMP. An unsucerstul match results an a premature commanm, and return to MATCH which interprets the reason by we of error fligs following it

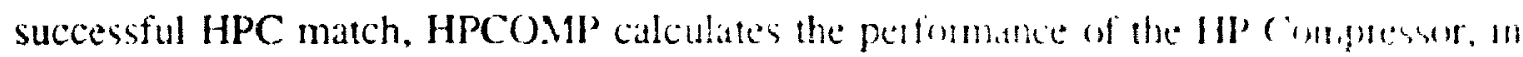
particular the exit temperature and presuace conditions.

\section{COMB. HPTLRB. IPTI:RB}

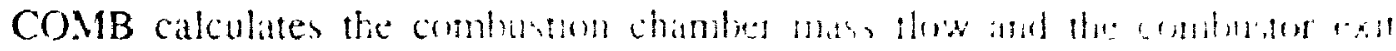

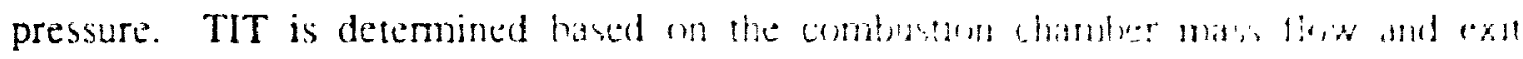

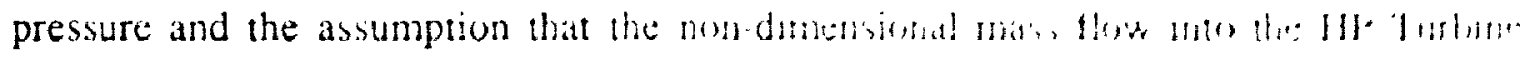

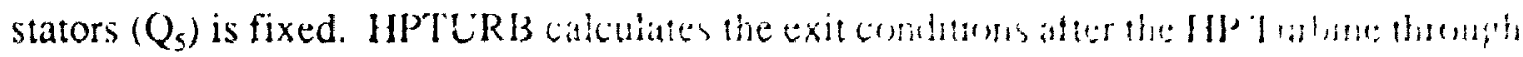
the use of the known (fixed) HPT pressure rato and isentropic efficiency LPTIRls calculates the conditions after the LP Turbine by conducung a I.P spoul werk balanes: 


\subsection{Miscellaneous Program Features}

Severa! additional features of the program are called from TURBOFN4 itself. These subroutines are used to define the operating parameters for the simulator. Arvitier major feature is the simulation of various kinds of discrete faults (detailed description uf the methods used for fault simulations are be contained in Chapter 7). A brief description of the miscellaneous subroutines called from TURBOFN4 will be given here.

\section{DI:I:SF:T, DI:IFRFAD}

These routines are used to set the default values used by the simulation. DEFSET is a menu driven routine for editing the current set of defaults. These include whether or mot boosker (LPC) stages are to be used, the level of detail desired for OUTPUT, the names of the component characteristic map data files, the default values to be used for the various gas properties, the values for standard sea level temperature and pressure, and the level of accuracy used during l'se twin spool matching calculation. Upon completion of DI:ISSEY. These values are atomatically saved by writing to a file called DI:IAULT.I)AT. 'This file is read by the subroutine DEFREAD when TURBOFN4 is initialized. Henct, the progran maimains a record of the most recent default settings.

\section{IILISIE, FITRISAD, FLTWVRITE}

These subroutines are used to set the flight conditions to be used during off-design calculations. The default flight conditions are stored in a file called FLIGHT.DAT which is automatically read in when TURBOFN4 is begun, by the subroutine FLTREAD. II.TSEI is the subroutine used to edit the number of flight conditions to be used, and the prameters tiur each. To define a flight condition, the altitude, Mach number, change in temperature fom ISA and the fan mechanical speed (as a percentage for the design specd) is repuired. The program then automatically determines the ambient conditions and actual thight speed for each point. It is possible to edit the design point flight condition within ILTSET (this is by default the first condition in the list), but this requires that ONDES be run to properly calculate the new design operation conditions 
before any off-design calculations are conducted. Also, HLTSET can sive and retrieve alternative sets of flight conditions using FLTIVRITI: and HLTRI:AD respectively, which may have any name provided they are of the proper format. The precise format repuired is discussed in Appendix A. FLTWRITE saves the tlight condition informatum in the correct format, automatically upon exiting FLTSET (in the file FI.I(iHT.J)AT) or when requested within FLTSET (in which case a different lile name can be uscil).

\section{FAULTSET, FALTREAD, FAUITTED}

These subroutines are used to set various component fiults to simulate the effect of engine deterioration on performance. FAULTSI:T is used to edit the current set of fault conditions by defining a percentage change in some component perfinmance parameter. Currently, deterioration in one of the major alerodymamic eompunents (fan, Compressors or Turbines) may be simulated by specitying a change in design poimt polytropic efficiency or non-dimensional mass flow (Q). Other lypes of deternoution such as problems with mechanical components (combustion chamber, lxarings, hleced valve's, nozzles or intake) have not been implemented in this version of IURIBUN.N. FALTREAD is used to load in fault settings from a data file as repunited. When TURBOFN4 is started, the last set of fault settings are automatically read in from the default file FAULT.DAT. The contents of this file ane atumatically updated each time that the subroutine FAULTSET is terminated. Within I:AUI ISI:I, famlt information can be saved and retrieved using user-defined filemames. When a finted tumbetan is to be

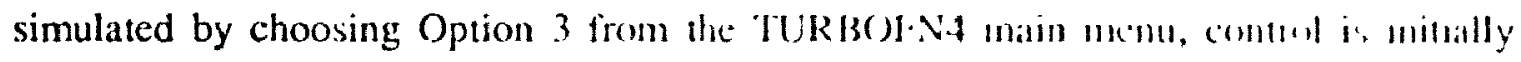
passed to FAULTED. This subroutine performs several initialiation prexeress which essentially save the unfaulted design-point component paramegers betore they an - moxhlied

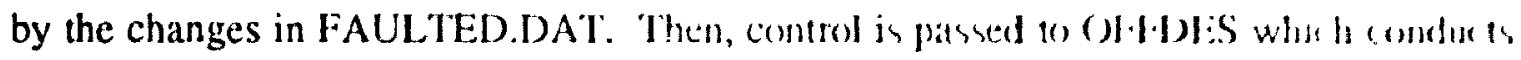
a full set of off-design performance calculations using modified values of the component

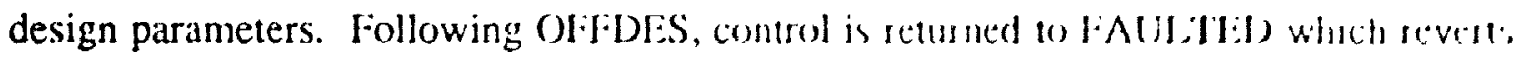
all design parameters back to unfauled form before returnmg to the main menu of TURBOFN4. 


\section{Chapter 6 Nominal Simulation Results}

\subsection{Baseline On-Design Performance}

Before focusing on a particular advanced cycle, it is interesting to note the effect of the design point engine cycle on overall performance and indirect thrust indicators. A serics of on-design calculations were conducted for a range of cycles at two design points, defined as shown in Table 6.1. Essentially, OPR and TIT were held constant while BPR and FPR were changed. The TIT and OPR at each location are typical for modern high bypass engines with BPRs of 5 to 6 . The TIT/OPR combinations at SLS and TOC are roughly equivalent, representing typical variation in these two parameters from take-off to TOC for modern turbofans.

Table 6.1 Range of Engine Cycles used for On-Design Estimates

\begin{tabular}{|l|c|c|}
\hline Cycle Paramcier & Sea Level Static (ISA) & TOC (Mach 0.8 @ 35000 ft) \\
\hline BPR & 2.0 to 9.0 & 2.0 to 9.0 \\
\hline IFR & 1.2101 .8 & 1.2 to 1.8 \\
\hline OPR & 32 & 35 \\
\hline TlT $(K)$ & $1550^{4}$ & 1400 \\
\hline
\end{tabular}

Constant polytropic efficiencies of $90 \%$ were assumed for the main components (1:an, I.PC. IIPC, Turbines) at both design points. Other mechanical details were also kept constant: nozzle, combustion and spool efficiencies were assumed to be $99 \%$, while

4. Thermodynamically equivalent to $1630 \mathrm{~K}$ for IDTO $\left(\right.$ ISA $\left.+15^{\circ} \mathrm{C}\right)$. 
the intake efficiency was assumed to be $95 \%$. The combustion chan'? er pressure drop was taken to be $5 \%$ of the CDP, and 10\% HP Turhine cooling bleed was used. simulated by the simplified cooling model described in Chapter 3.

\subsubsection{Specific Fuel Consumption and Specific Thrust}

The variation of specific thrust and SFC for the two design points can be seen in Figure 6.1. The TOC conditions are equivalent to typical cruise conditions for the purposes of on-design calculations. It can be seen that high BPR engines have reduced specific thrust (for the same TIT and OPR) and thus larger engines are needed for the same net thrust, and more thrust is derived from the bypass nozzle. High BPRs also have a beneficial effect on SFC at both design points. Higher FPRs give increased specific thrust and reduced SFC for a given BPR, though there is a limit to IPPR due to the energy extraction limit for the LP Turbine, when the amount of net thrust obtained from the bypass nozzle approaches $100 \%$. This accounts for the nature of the high lif' lines at high BPR in Figure 6.1, with specific thrust rapidly dropping off. The I:PR is also

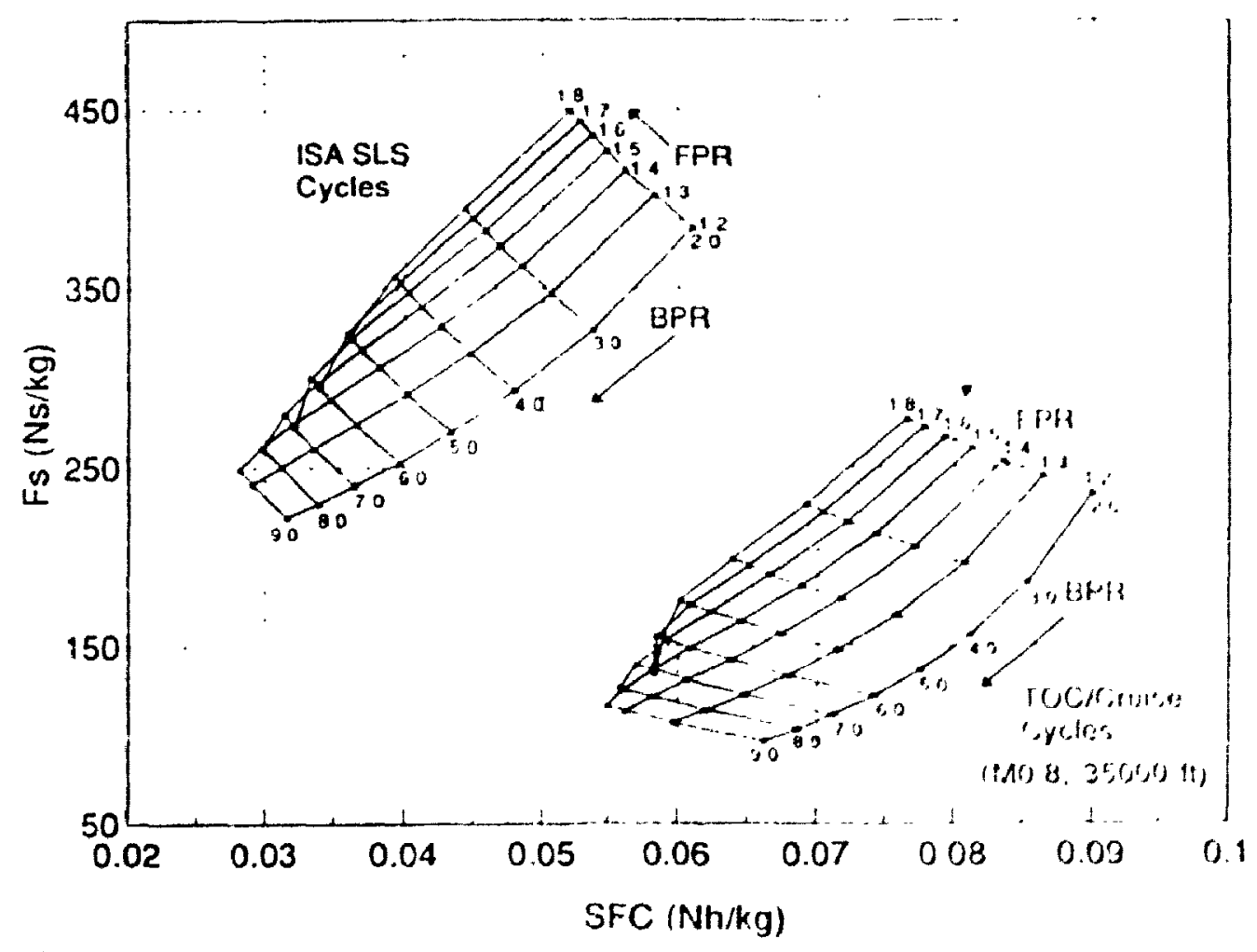

Figure 6.1 Specific Thrust and SFC for Different Advanced Cycle Designs 
limited for reasons of minimizing weight and noise, for which a single stage fan is considered essential. In practical terms, this limits the FPR to a maximum value of about 1.X. (Philpor, 19\%2) Lower values of FPR would only be used for ultra high BPR engines as the optimum FPR would be lower than the current 1.6 to 1.8 range most common in urloffituns with BPRs of 5 to 6 .

The effect of equivalent engine cycles moving from the take-off condition to the cruise/fOC design point is also evident from Figure 6.1. In general, the bypass ratio of a given engine deres not change much from the take-off to cruise condition. FPR (and OPR) will in general he maximum at TOC, but less again after throttling back to the cruise condition. The drop in TIT ( $1550 \mathrm{~K}$ to $1400 \mathrm{~K})$ is typical for this class of turbofan $(B P R=5$ and ()$P R=35)$ and cruise TIT would most likely be somewhat lower, in the range of $13(0)-1350 \mathrm{~K}$. These variations in cycle parameters will be confirmed in later sections of this Chapter. Figure 6.1 shows that in moving from take-off to TOC/cruise, the SFC increases significantly while specific thrust decreases, even when major changes in cycle parameters are considered. However, at both design points, higher FPR and BPR result in improved specific fuel consumption, which explains the current trend towards higher BPR, especially at cruise.

\subsubsection{Thrust Splits}

The thrust splits at the two design points are shown in Figures 6.2 and 6.3 , expressed as the percentage of total net thrust contributed by the cold (bypass) nozzle. It can le seen that the engine cycle choice has a major effect on the portion of thrust derived from the fan. Current high bypass turbofans have take-off BPRs of around 5. The percentage of thrust derived from the cold stream is approximately 70-88\% at standiard SLS conditions. For the same BPR but at TOC/cruise (when the FPR will be semewhill higher) the percentage of cold thrust is slightly lower, ranging from 60-82\%. Both figurcs show that as BPR and FPR are increased, the portion of net thrust obtained from the bypass flow increases. 


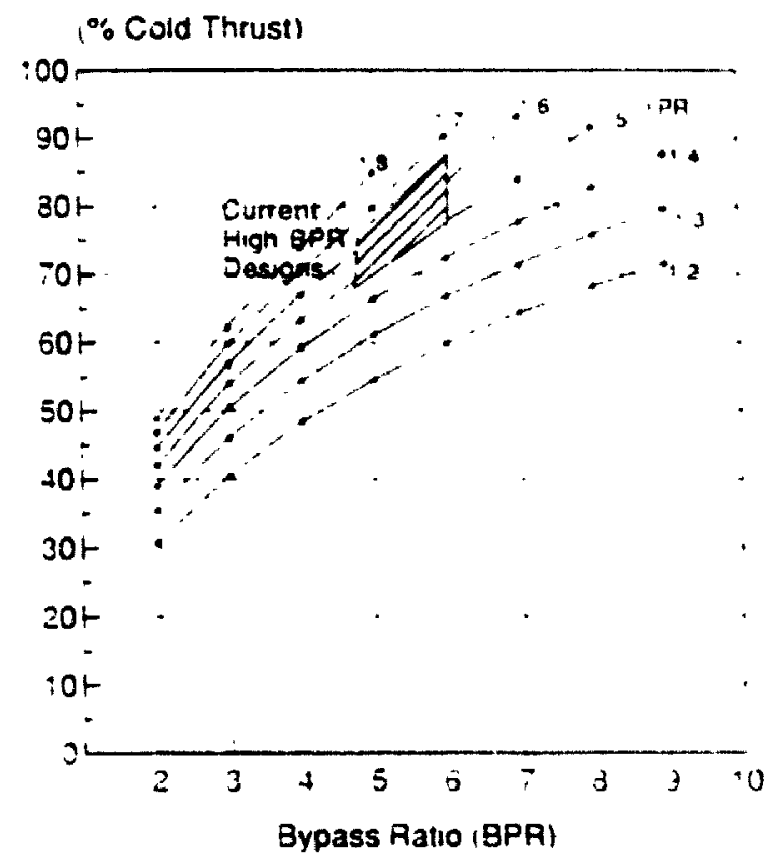

$T I T=1550 \mathrm{~K}$. OPR $=32.90 \%$ PolyiropIC Efficiencies

\section{Figure 6.2 Net Thrust Split for Advanced Cycles at SLS}

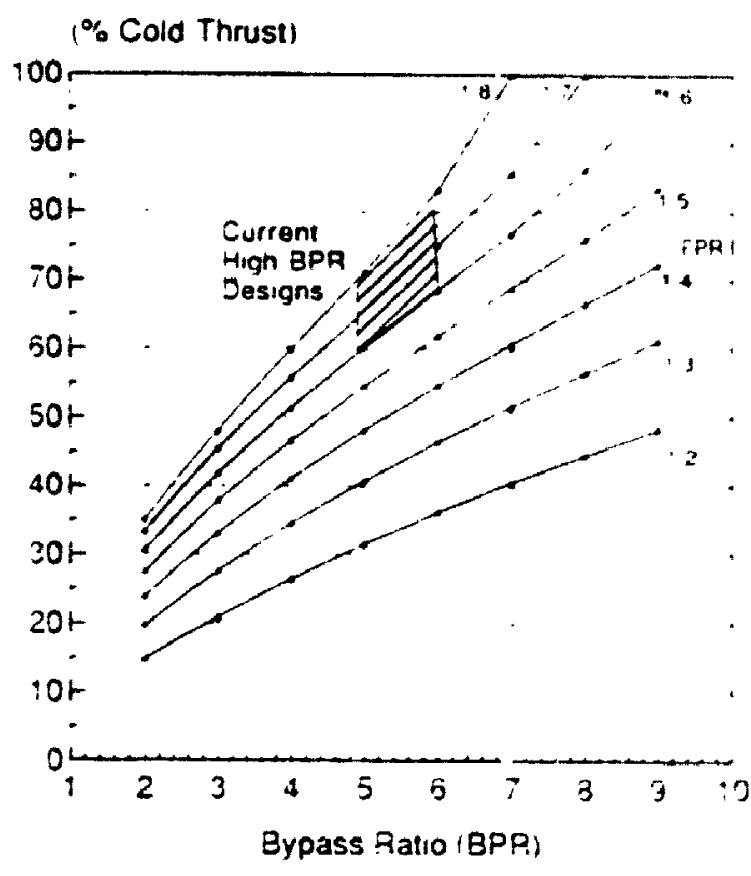

$T / T=1400 \mathrm{~K} . \mathrm{OPR}=35.30 \%$ Polytropic Elficiencies

Figure 6.3 Net Thrust Split for Advanced Cycles at TOC: 


\subsubsection{F.PR and IF.PR Variations}

The thrust splits for different cycles are interesting when they are compared with the trends for IER and IEPR for the same cycles. Figures 6.4 and 6.5 show the EPR for various cycles at standard SLS and TOC conditions, respectively. The trend for EPR is opposite to that observed for the thrust split, tending towards a value of 1.0 at high BPR and lilRs. These figures show that for current high bypass engines (with BPRs of 4.8 to 6), the IBPR at ISA SI.S will range from about 1.3 to 1.8 , whereas the range at TOC (assuming typical changes in OPR and TIT) will be slightly higher, 1.4 to 2.0. Figure 6.5 shows that as BPR is increased, such as is the trend with upcoming ultra-high bypass engines, I:PR drops below 1.5 and approaches 1.0. EPRs below 1.0 are possible for excessive IFPR/BPR combinations, though it is expected that lower FPR be used for ultra high bypass turbofans (BPRs of 9 or more) since these are optimum.

Similar graphs are shown for IEPR in Figures 6.6 and 6.7. The variation of IEPR for both design point choices is somewhat different from EPR. High BPR results in lower II:PR, whereas higher FPR in general results in higher IEPR except at high BPRs when II:PR starts to fall off agiin past a particular value of FPR. This is due to the IEPR being a weighted average of the PRs of both nozzles. The degree of IEPR variation is much lower than the corresponding change in EPR. showing the moderating effect of this averaging process. For lypical modern turbofans, the IEPR at sea level static conditions will vary from about 1.47 to 1.6.5. The equivalent engine at TOC conditions will have an IIEPR of leetween 1.6 and 1.75 . 


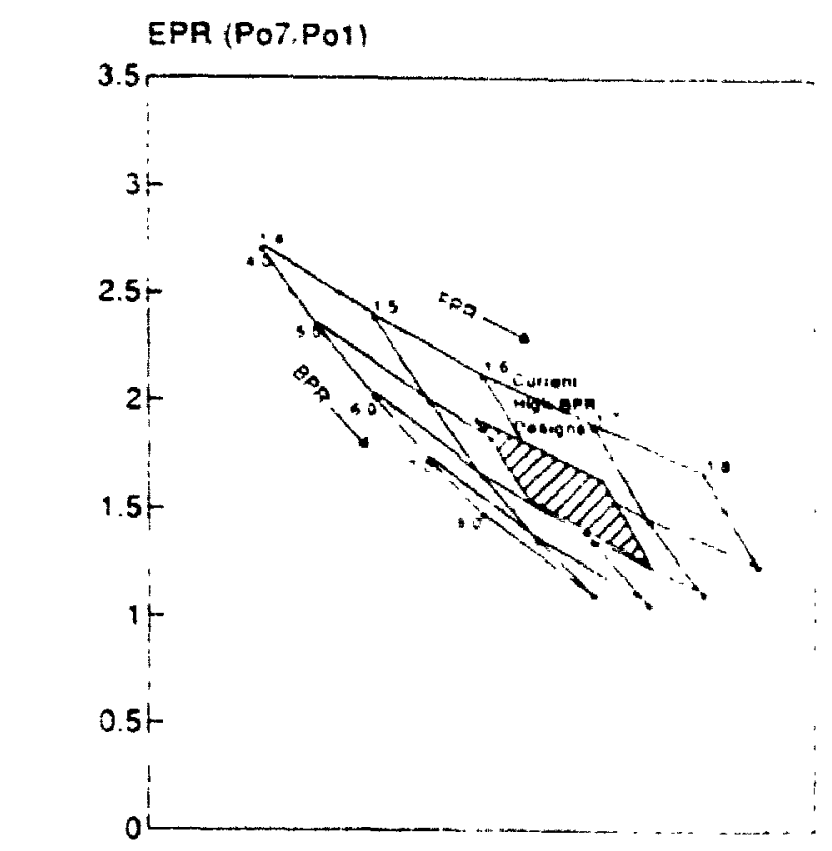

Advanced Twin Soool. OPA $=32 . T I T=1550.90 \%$ Polv

Figure 6.4 EPR Trend for Advanced Cycles at ISA SLS Design D'oint

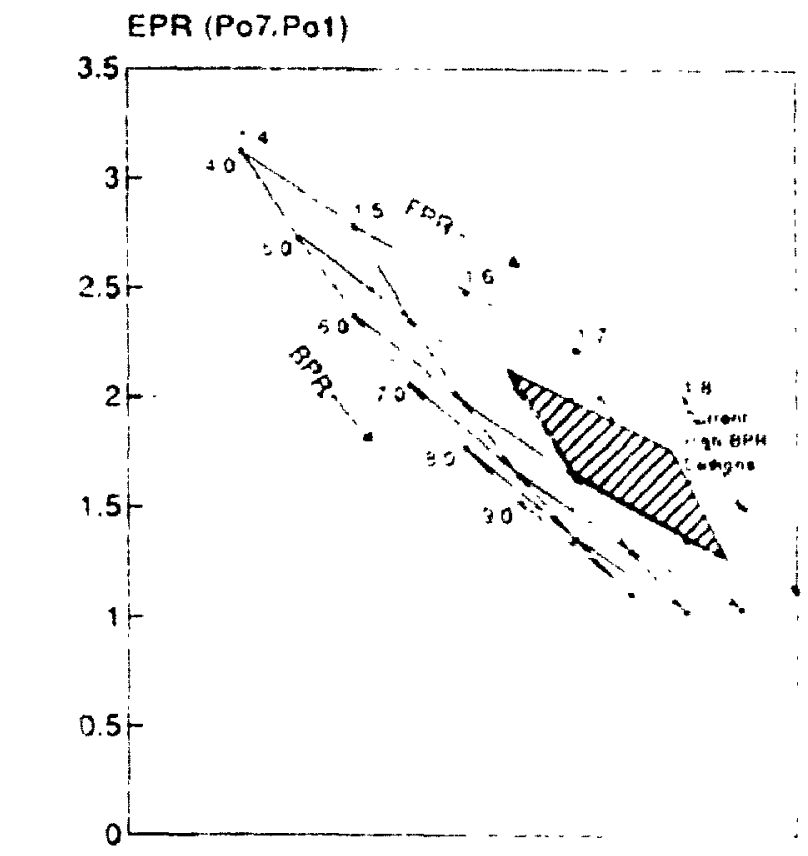

Advanced Twin Spool, OPR $=35$. IIT $=1400.50 \% \mathrm{PO} y$

Figure 6.5 EPR Trend for Advanced Cycles at TOC Design Point 
Chapter 6: Nominal Simulation Results

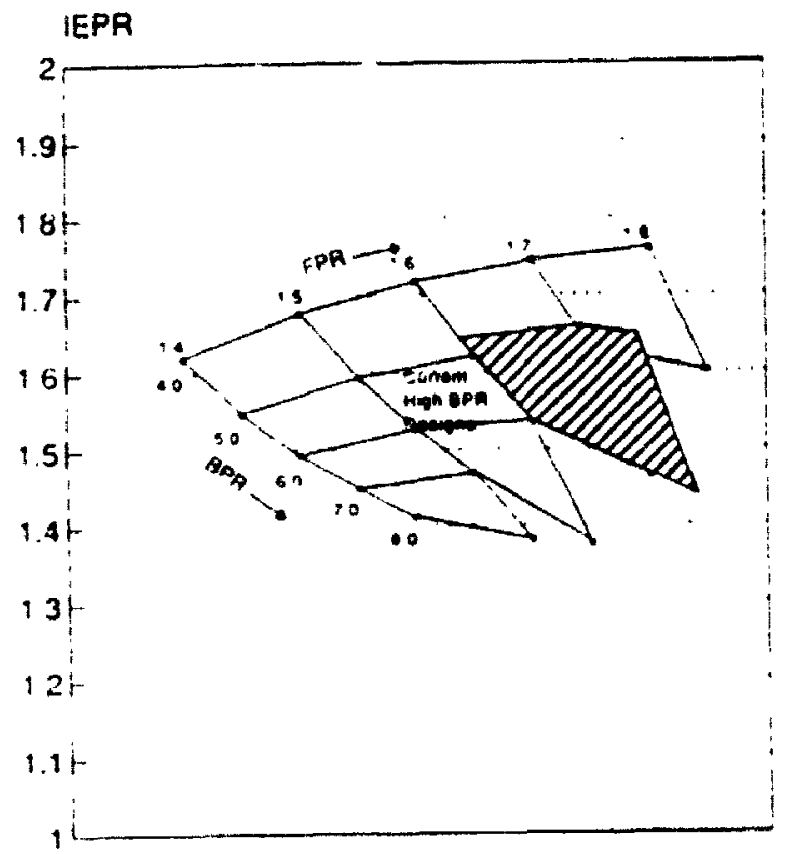

Advanced Twin Spool. OPR=32. TIT $1550.90 \%$ Paly

Figure 6.6 IEPR Trend for Advanced Cycles at ISA SLS Design Point

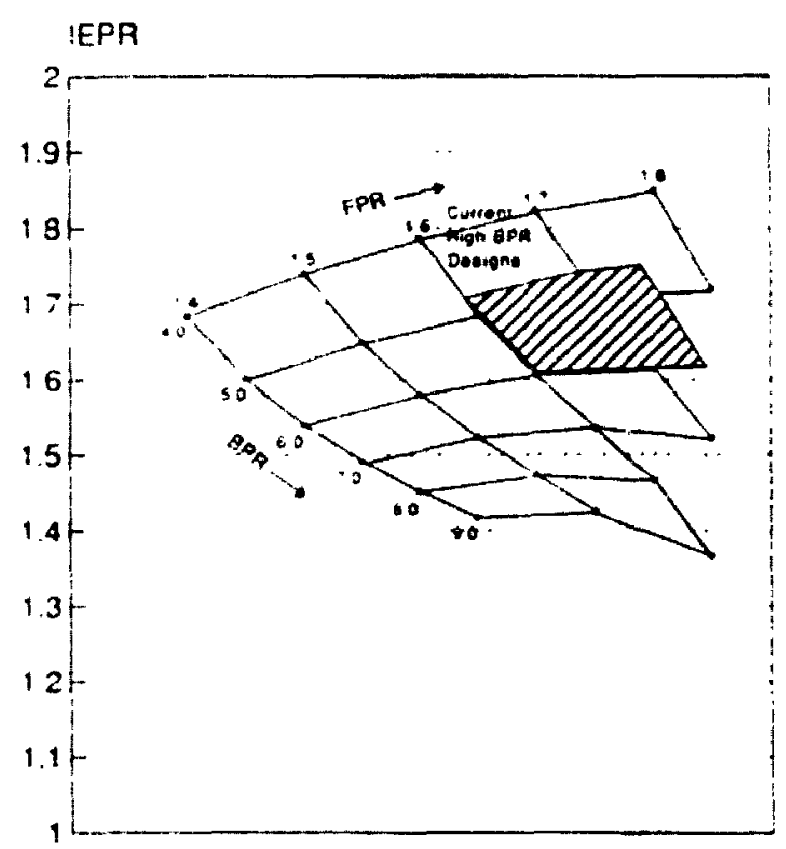

Advanced Twin Spoot, OPR=35. TIT $=1400 \mathrm{~K}, 90 \%$ Poly

Figure 6.7 IEPR Trend for Advanced Cycles at TOC Design Point 


\subsection{Advanced Cycle Design Choice}

To simulate the behaviour of a generic advanced cycle turbofan. the design point engine cycle had to be defined before conducting any off-design calculations. A typical modern turbofan design was selected at its aterodynamic design point, assumed to Ite at the Top-of-Climb (TOC) condition. The design details for this engine are given in Tahle 6.2. This combination of cycle parameters is very similar to the (19M156.5 fimily of engines, in particular the CFM56-5B1 engine, and was selected to give the same take aft performance as quoted in available engine brochures. The combination of ypusl speeds used at TOC results in approximately $100 \% \mathrm{~N}_{1}$ and $\mathrm{N}_{2}$ all III)T() conditions. The CFM56-5BI is flat-rated (up to ISA +15 C) to provide $133.5 \mathrm{kN}$ of SI.S Thrus, and has a $B P R=5.5$ and $m_{2}=428 \mathrm{~kg} / \mathrm{s}$ at ISA SLS conditions. (AN, CFMS6 Family of lingines Brochure, 1990)

Table 6.2 Design Data for Advanced Cycle Twin-Spool Turbofan

\begin{tabular}{|c|c|}
\hline Intake Efficiency & $95 \%$ \\
\hline Polytropic Efficiencies & $90 \%$ (Fan. Bomsters, III', III\%, I.1\%) \\
\hline Nozzle Efficiencies & $90 \%$ \\
\hline Spool/bearing Efficiencies & $99 \%$ \\
\hline Combustion Efficiency & $99 \%$ \\
\hline Combustion Pressure Drop & $6.5 \%$ of $\mathrm{Cl})$ \\
\hline HPT Cooling Bleed Flow & $10 \%$ Total (5\%. Stators, .5\% Rom,s) \\
\hline \multicolumn{2}{|c|}{ Cycle Conditions (2) TOC Design Point (Mach $0.8(w 3.5)(x)$ (1): } \\
\hline Fan Pressure Ratio & 1.7 \\
\hline Bypass Ratio & 5.3 \\
\hline Overall Pressure Ratio & 35.4 \\
\hline Turbine Inlet Temperature & $1.400 \mathrm{~K}$ \\
\hline Design Air Flow & $176 \mathrm{~kg} / \mathrm{s}$ \\
\hline Spool Mechanical Speeds & $N_{1}=95 \%, N_{2}=93 \%$ \\
\hline Nozzle Areas $\left(\mathrm{m}^{2}\right)$ & Cold $=1.023 \quad H$ Hot $:=(0.321$ \\
\hline
\end{tabular}


The off-design performance was simulated by running the engine detailed in Table 6.2 it a variety of flight conditions simulating typical take-off, climb and cruise pertonnance. Simulating climb performance required some knowledge of typical airliner climb procedures, particularly the True Airspeed (TAS) at different altitudes. A climb protile was constructed based on data for a DC-10 a'rliner. This profile can be seen in Figure 6.8. This profile is based on take-off rotation of $165 \mathrm{kts} .250 \mathrm{ksia}$ (knots, indicated airspeed) to $1(K(K)(\mathrm{ft}, 340 \mathrm{ksia}$ to 27000$) \mathrm{ft}$, and then a constant Mach number of 0.8 until a cruising altitude of $35000 \mathrm{ft}$ is reached. The latter Mach number was modified to accord with the choice of Mach number used in this study.

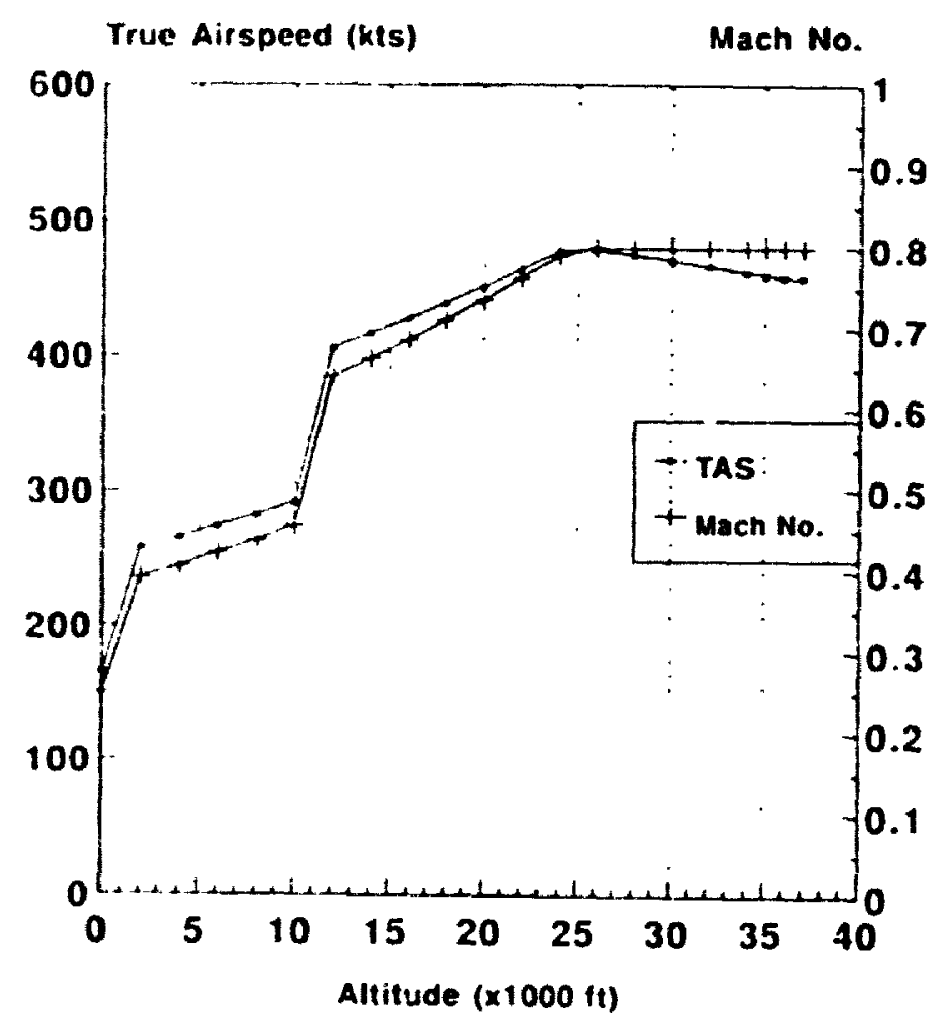

Figure 6.8 Typical Climb Profile for Modern Airliners (Shevell, 1989)

For simulations of clinb performance, a constant $N_{1}$ was assumed. Take-off perfomance simulation involved varying ambient conditions (all for SLS) and fan spool spects. Cruise performance was simulated by varying flight Mach number and throtte setting $\left(N_{l}\right)$ for a constant flight altitude $\left.(3500) \mathrm{ft}\right)$. 


\subsection{Off-Design Performance Estimates}

\subsubsection{Climb Performance}

The climb performance of the hypothetical advanced cycle engine wats determinted using the simulation software by conducting off-design calculations at disctete poims on the climb profile shown in Figure 6.8. It is important to note that for purposes of the study, a constant mechanical fan speed $\left(N_{1}=95 \%\right)$ was assumed during alimh. Also, a $\mathrm{N}_{1}$ of $100 \%$ was used at ISA SLS to simulate take-oft. This will over estim.lle the tathe off thrust since $100 \% \mathrm{~N}_{1}$ is likely to be used only on hot day take offs. This will ix. discussed in the section on take-off thrust.

\section{(a) Thrust and Fuel Flow}

Figures 6.9 and 6.10 show the variation of net thrust and fuel flow over the climb profile used. Figure 6.9 shows that the simulator is ahle to predict the expected trend, with gradual decrease in thrust with increasing altitude and Mach number. The effect ot throttle-back at the Top of Climb $\left(95 \%\right.$ down $\left.1090 \% N_{1}\right)$ is also evident. The finel fluw trend is predicted correctly, as shown in Figure 6.10, decreasing with increases in altitude and increasing with Mach number. The sinulator predicts that the S1:c at take wit will be $0.0334 \mathrm{~kg} / \mathrm{N} \cdot \mathrm{hr}(0.33 \mathrm{lb} / \mathrm{lb} \bullet \mathrm{hr})$ while the cruise SFC lassuming a throtlk iellung ut $\left.90 \% \mathrm{~N}_{1}\right)$ will be $0.0575 \mathrm{~kg} / \mathrm{N} \cdot \mathrm{hr}((0.564 \mathrm{ll} / \mathrm{lh} \cdot \mathrm{hr})$. The estimates are quite ratsonalile when compared with actual SFC values for current high bypass lurbolials. (c illins and Hill, 1991)

\section{(b) EPR and IEPR}

The variation of EPR and IIEPR during climb can be seen in leiguses 4.11 and 6 , I? respectively. Both parameters decrease with increasing forward speesl (i.e. Mis h mumber) but there is also an altitude effect for both indicators. The change: in I:PR appar w be more marked than corresponding changes in If:PR. The nature of the climb pustit: uned (gradually increasing Mach number and atritude) is such that up to $150 \mathrm{ft}) \mathrm{f}$, I:PR 
decreases to a minimum value of approximately 1.3 , but then starts to increase with further changes in altitude, reaching a maximum value of about 1.58 at TOC. The changes in EPR at constant Mach number (the vertical trend at Mach 0.8 ) is due to changes in ambient conditions with altitude, and the effect of throttle-back to cruise is quite evident, since this causes a reduction of EPR to 1.3. The variation of IEPR is less dramatic, starting at a take-of value of 1.62 , gradually decreasing to a value of 1.5 just under $1(N)(\%)$ ft, then increasing to 1.67 at TOC. Throttle-back to cruise $\left(90 \% \mathrm{~N}_{1}\right)$ causes a drop) in II:IRR to 1.52 .

\section{(c) Variation of Spool Speed:s}

While a constant LP spool speed was used, it is interesting to note how $\mathrm{N}_{2}$ changes during climb. Figure 6.13 shows the predicted variations of $N_{1}$ and $N_{2}$ during a lypcal climb. Followirg :ake-off (whon $N_{1}$ is assumed to be 100\%), the fan speed is reduced to 95\%, witt $\gamma_{2}$ dropping to $97 \%$ at $2000 \mathrm{ft}$. With $\mathrm{N}_{1}$ kept constant during climb $\mathrm{N}_{2}$ drops, eventu.ily reaching a value of $93 \%$ at about $25000 \mathrm{ft}$. From this altitude to the up of climb altitule of $350(6) \mathrm{ft}$, the simu! ator predicts that $\mathrm{N}_{2}$ will remain more or less constimt. When $N_{1}$ is throuled back at wruise, it can be seen that $N_{2}$ drops by a similar amount, such that a cruise $N_{1}$ of $90 \%$ gives a IIP Spool speed of $88 \%$. The choice of $N_{y} / N_{1}$ combination at the $T O C$ is highly dependent on the engine cycle (especially FPR and BPR), and a number of itcrations were necessary to find the right combination that fave the desircl cesult of $100 \% \mathrm{~N}_{1}$ and $\mathrm{N}_{2}$ at the hot day take-off condition while also providing reasmathle estimates of other take-off cycle parameters. The take-off $(0 \mathrm{ft})$ cindilix an on ligure 6.13 is for standard day, when $\mathrm{N}_{2}$ is slightly less than $100 \%$. 


\section{(d) Cycle Temperatures during Climb}

The variation of iycle temperatures has been shown in Figute 6.14. In gencral. all three hot end temperatures tend to decrease with increases in altituke, due to the decrease in ambient temperature with altitude. However, this effect is at least partially counteracted by increases in forward speed (i.e. Mach number). and in several points in the climb, the trends for TIT and ITT reverse. This happens to TIT and lil' between 10000 and $13000 \mathrm{ft}$. Another aspect which should not he ignored is that the corrected value of TIT is not decreasing. Indeed, following the throflle decreate at the start of climb, the corrected value of TIT increases steadily during climb, apant from lhe range of altitude mentioned when it drops (corresponding to the reversil of the llorrlt trend). At the TOC condition, the corrected TTl is approximately the same as the IIIT) value $(1635 \mathrm{~K})$ which supports the contention that the ToC and III)T() flight conditions represent two equivalent design points for the lurbofin cycle chusen. 
Thrust (kN)

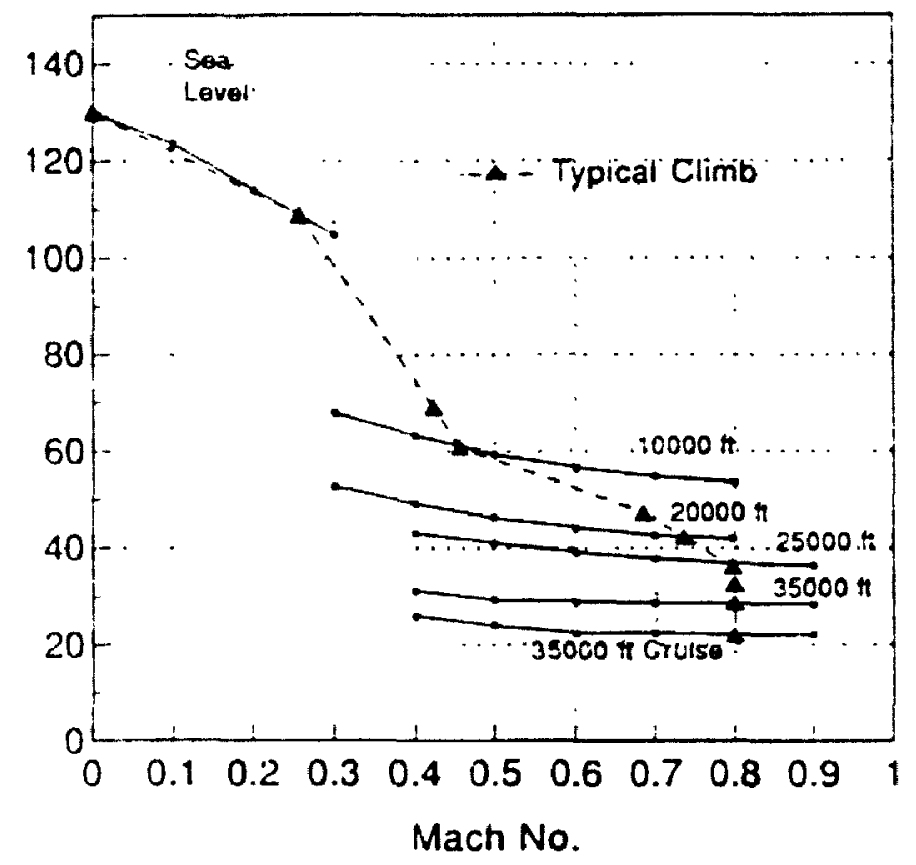

Figure 6.9 Thrust Trend during Climb

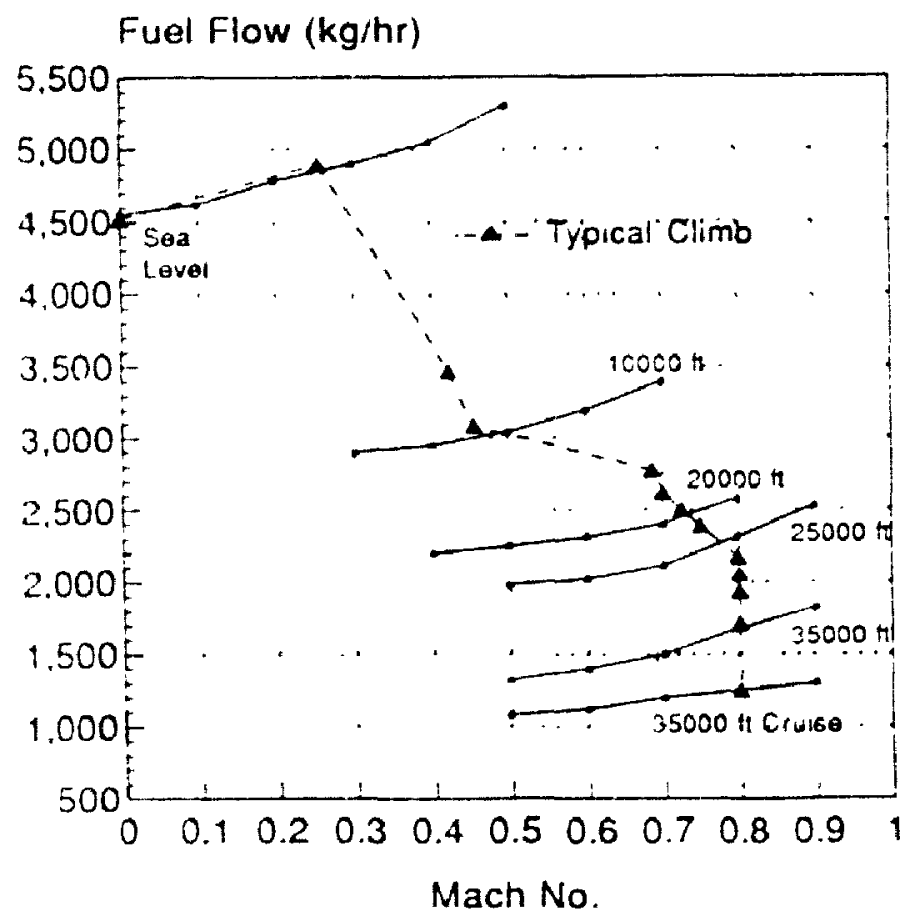

Figure 6.10 Variation of Fuel Flow during Climb 


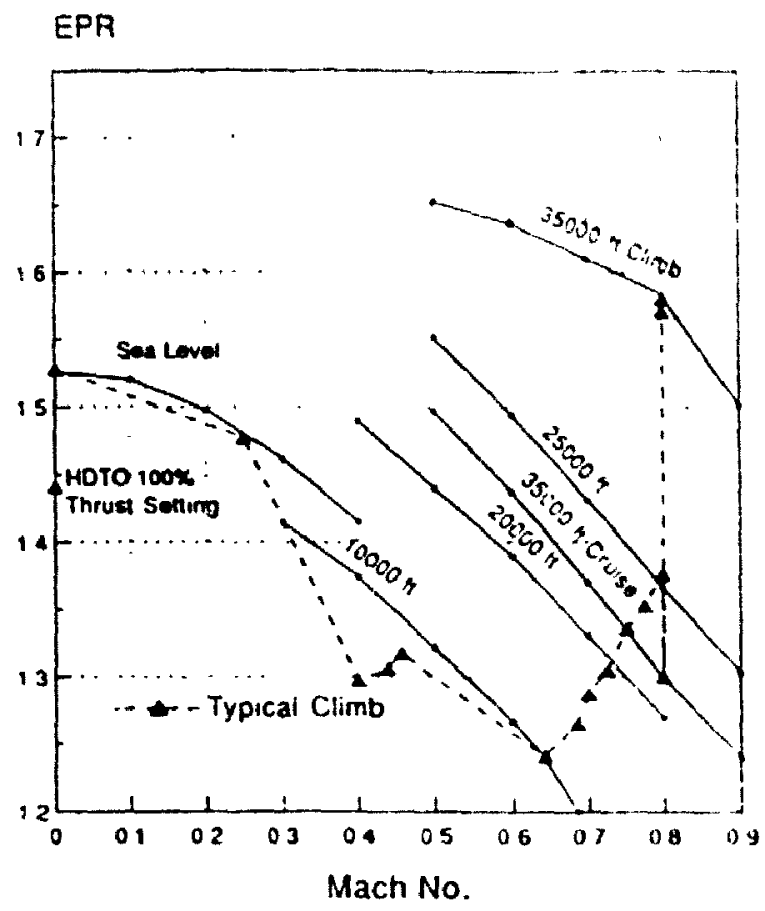

Figure 6.11 Variation of EPR during Climb

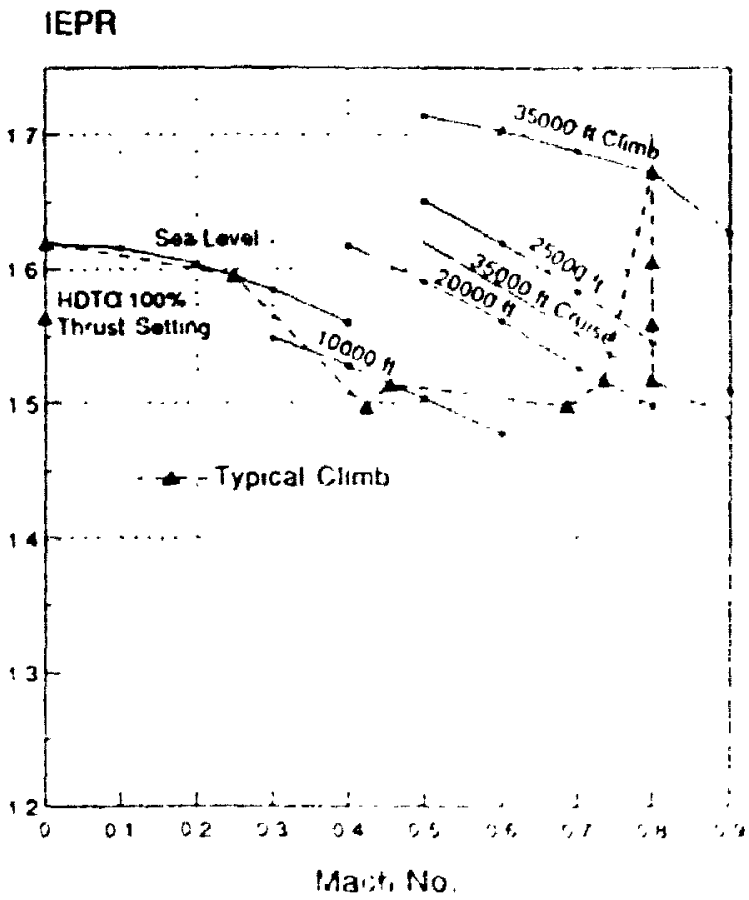

Figure 6.12 Variation of IFPR during (Iimb) 


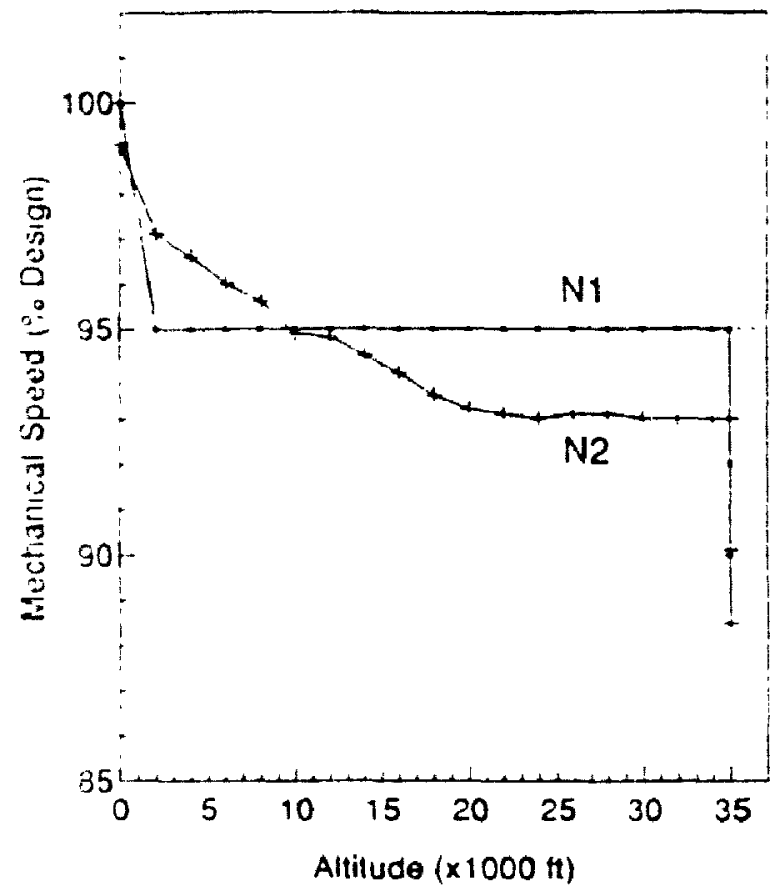

Figure 6.13 Variation of Spool Speeds during Climb

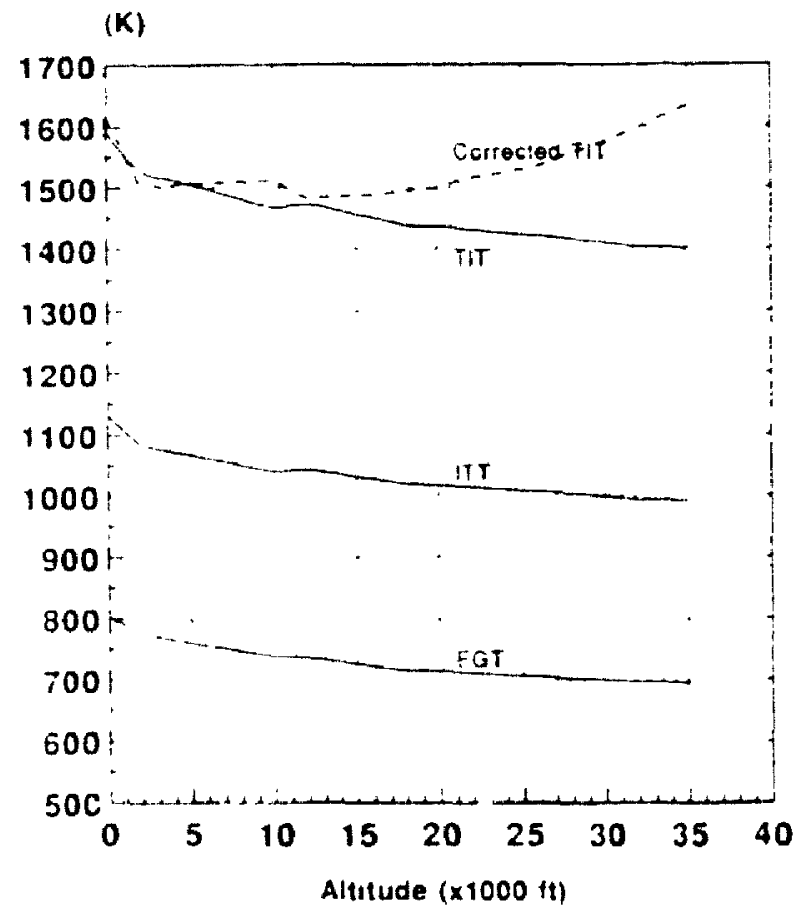

Figure 6.14 Change in Cycle Temperatures during Climb 


\subsubsection{Cruise Performance}

Cruise performance for the advanced turbofan was simulated for a typical thight level $(35000 \mathrm{ft})$ but at variable Mach numbers. The effect of throttle ialijustments at cruise were simulated by varying the fan spool speed $\left(N_{1}\right)$ from $88^{\prime} \%$ to $96 \%$, which also causes a proportional change in other thrust setting parameters. A setting of $N_{1} \cdot 1.5 \%$ is equivalent to the Top-of-Climb setting used as the design point, as was discussed in Section 6.2. The most important results from these simulations was the variation of thust when different thrust indicators were used. Of additional concern was the vatuiation of fuel flow with a desired flight speed.

\section{(a) $\quad \mathbf{N}_{1}$ as Thrust Setting}

Figure 6.15 shows that the variation of cruise thrust with fitn speced is approximately linear over the range of Mach numbers and spool speed somings considered. While increases in Mach number appear to give less thrust for a given $N_{1}$ setting, it can be seen that this effect is relatively minor, and the thrust variation can bi approximated by a single curve. The cruise thrust may thus be defined in terms of the fan speed setting, with a $1 \%$ change in spool speed yielding at difference of $1.25 \mathrm{kN} 128$ ! lb) craise thrust. Using the $90 \%$ setting, as the batse thrust $(22 \mathrm{kN})$, this increase or decrease in thrust is approximately $5.7 \%$.

\section{(b) Fuel Flow as Thrust Setting}

The variation of cruise thrust when fuel flow (lF) is used an a thrust mde atur may be seen in Figure 6.16. It can be seen that the effect of Mach number increates is mone pronounced when compared with Figure 6.15, with higher IF required in maintain the same thrust (or alternatively, less thrust being obtained for the same Hi). Hewever, the variation of thrust for each Mach number appears to be the same and linear, with an

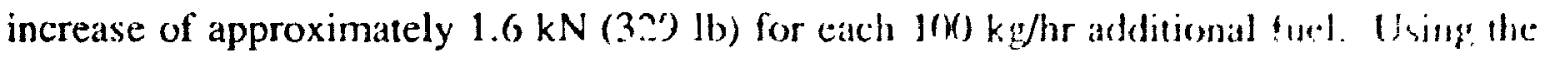
$90 \% \mathrm{~N}_{1}$ cruise condition $(\mathrm{FF}=1250 \mathrm{~kg} / \mathrm{hr}$ ) as the base cruise thrust, this meams an increase of $0.89 \%$ thrust per $1 \%$ of aduitional fuel flow. 
Figure 6.16 also serves to show the fuel flow required for a given cruise speed. If an increase in aircraft speed is desired (i.e. Mach number increase), more FF is needed just to maintain the same thrust level. However, higher cruise speeds will also require more thrust since drag will in general increase with Mach number. From the graph, it can Ix secn that these two effects are additive, contributing to an overall increase in the required fuel flow. For example, if it is desired that the aircraft accelerate from Mach 0.8 to (1.85, this will require approximately $50 \mathrm{~kg} / \mathrm{hr}$ extra fuel assuming the same thrust level. Illowever, drag is likely to increase proportionally to the square of the forward velocity. As a first approximation, this will mean approximately $13 \%$ more drag or about $2.8 \mathrm{kN}$ more thrust. This increase would require another $170 \mathrm{~kg} / \mathrm{hr}$, for a net increase of approximately $220 \mathrm{~kg} / \mathrm{hr}$, or $17.6 \%$ more FF to cruise at Mach 0.85 rather than Mach 0.8 .

\section{(c) EPK and IEPR as Thrust Settings}

Figures 6.17 and 6.18 show the variation of net thrust when EPR or IEPR is used as the thrust setting parameter. These appear to indicate that iricreases in Mach number will result in more net thrust for the same EPR or IEPR setting, quite contrary to what happens when $N_{1}$ or Fuel Flow are used. This appears to be due to the effect of increased Ram Pressure Ratio (RPR) which will cause a decrease in EPR or IEPR. In each case, the vatiation of thrust appears to be linear once again, especially in the case of IEPR. The change in net thrust with an adjustment to IEPR appears to be approximately twice the change if $1: P R$ is used. For the engine simulated, a 0.1 EPR increase will yield $2 \mathrm{kN}$ more thrust $(+9.1 \%)$, while the sime IFPR increase will give $4 \mathrm{kN}$ additional thrust $(+18.2 \%)$

Table 6.3 summarizes the results obtained for each thrust setting indicator when used to set cruise thrust. 
Table 6.3 Summary of Cruise Thrust Setting Parameters

\begin{tabular}{|l|l|l|l|}
\hline $\begin{array}{l}\text { Thrust Setting } \\
\text { Parameter }\end{array}$ & $\begin{array}{l}\text { Base Cruise } \\
\text { Setting (22 kN } \\
\text { thrust) }\end{array}$ & $\begin{array}{l}\text { 1\%o Change in } \\
\text { Parancter at } \\
\text { Cruise }\end{array}$ & $\begin{array}{l}\text { Change in } \\
\text { Thrust (kN) } \\
(\%)\end{array}$ \\
\hline $\mathrm{N}_{1}$ (fan speed) & $90 \%$ & $1 \%$ & $\begin{array}{l}1.25 \mathrm{kN} \\
(5.7 \%)\end{array}$ \\
\hline FF (kg/hr) & 1250 & 12.5 & $\begin{array}{l}0.196 \mathrm{kN} \\
(0.80 \%)\end{array}$ \\
\hline EPR & 1.3 & 0.013 & $\begin{array}{l}0.26 \% \mathrm{~N} \\
(1.2 \%)\end{array}$ \\
\hline IEPR & 1.52 & 0.01 .52 & $\begin{array}{l}0.62 \mathrm{kN} \\
(2.8 \%)\end{array}$ \\
\hline
\end{tabular}

From Table 6.3, it appears that $N_{1}$ is the most sensitive parameter for setting cruise thrust, while FF seems to be the least sensitive in terms of percentige change. Ilowever, it should be appreciated that the $1 \%$ change in EPR or HIPR is quite small, especially when changes in flight conditions are comsidered, in particular Mach numlx.r. $N_{1}$ (as predicted by the simulator) seems less likely to be influenced by external flight conditions at cruise, as evidenced by the slight change due to forward aircraft speed (Mach number). Thus, setting thrust at cruise is likely to be more critical when either IIIR or $\|$ II $R$ ate used, while not quite as critical if $N_{1}$ is $u$,ed. FF is rarely used as the main thrust sening: parameter in actual airline practise, though it is used (in conjunction with (ias (icnerator EGT and $\mathrm{N}_{2}$ ) to indicate the relative health of the engine and the economy of the cruise condition. This latter consideration is of prime impertance for commencial airlunes (Kenward, 1976) 


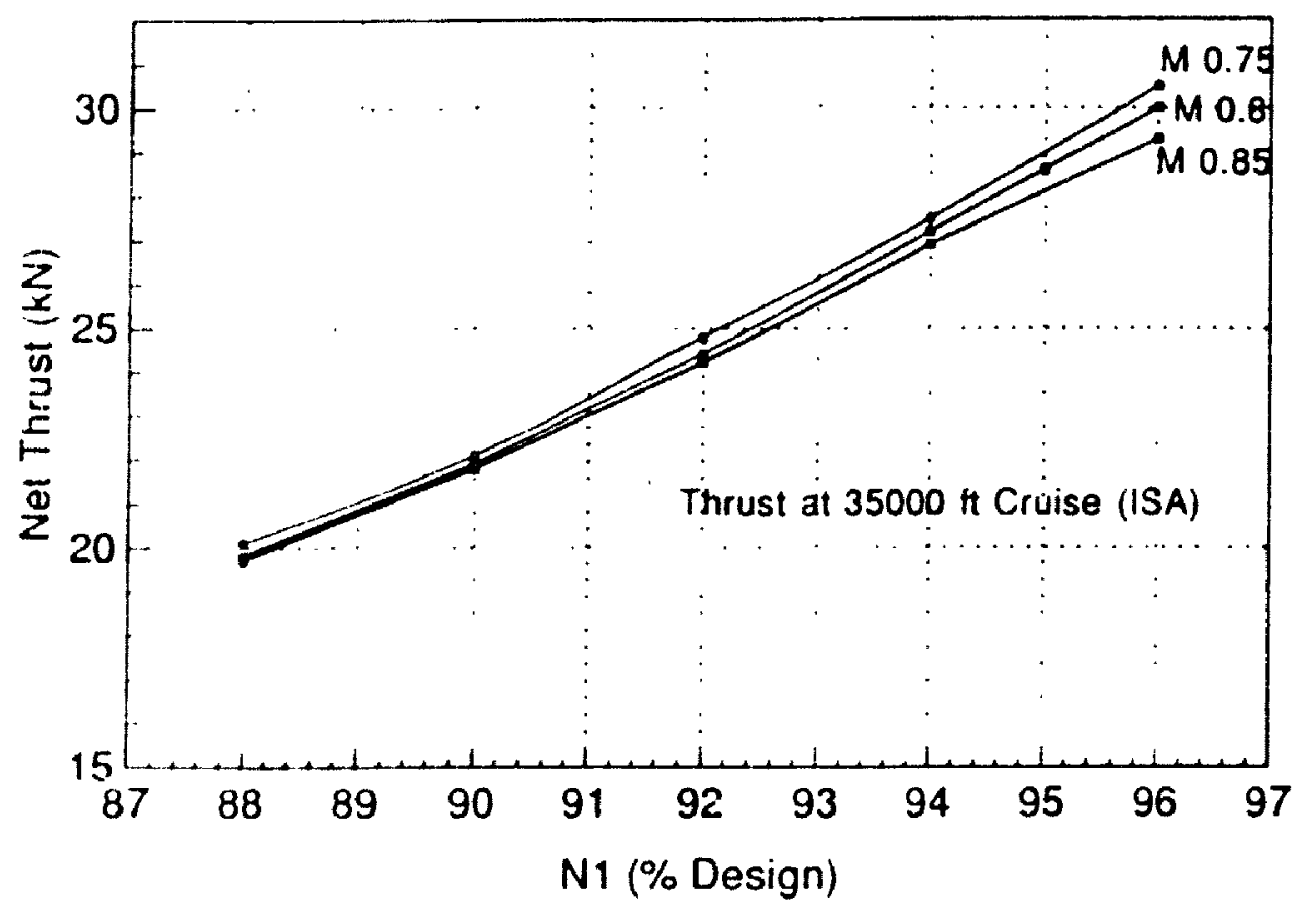

Figure 6.15 Cruise Thrust vs. $\mathbf{N}_{\mathbf{l}}$

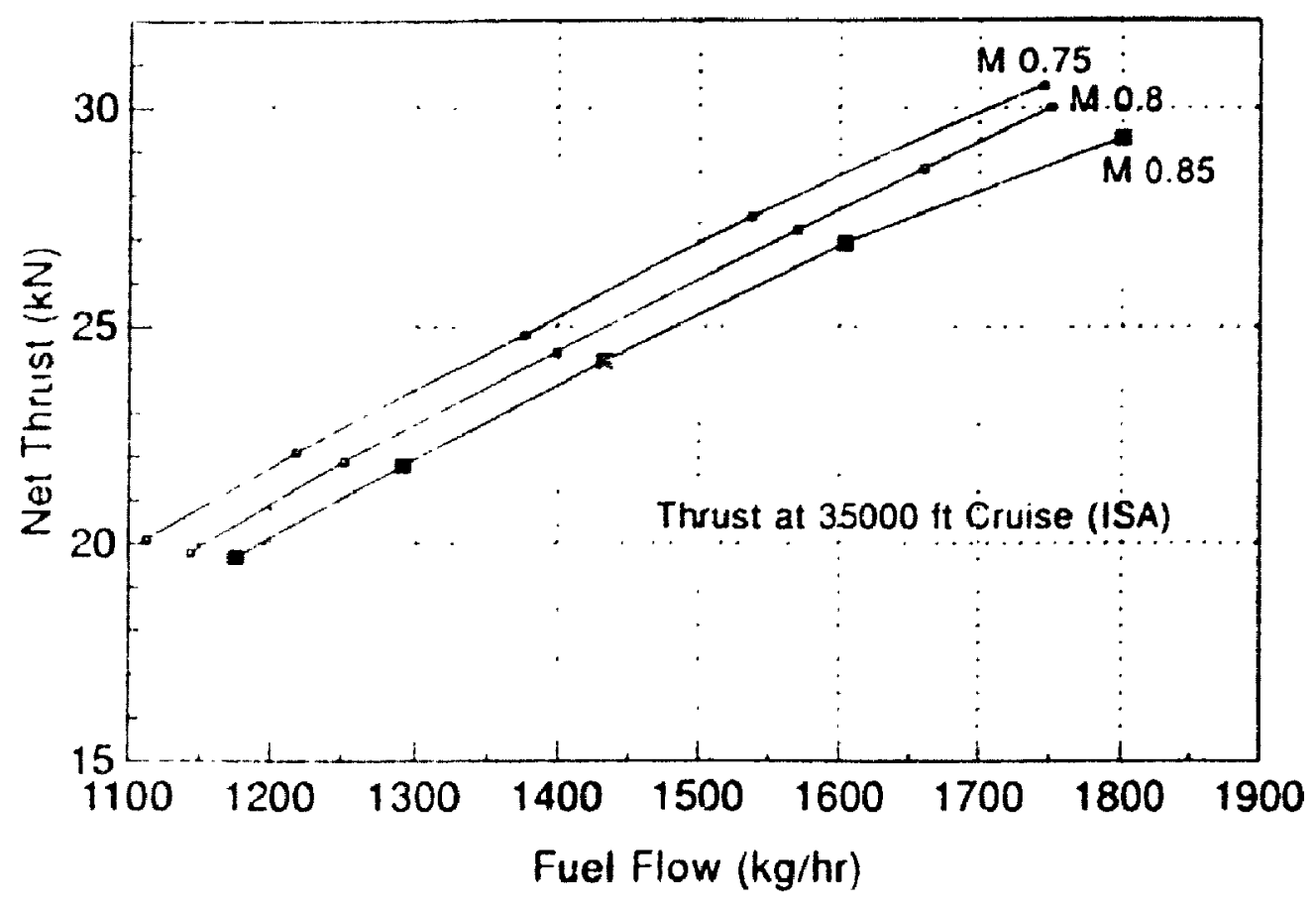

Figure 6.16 Cruise Thrust vs. Fuel Flow 


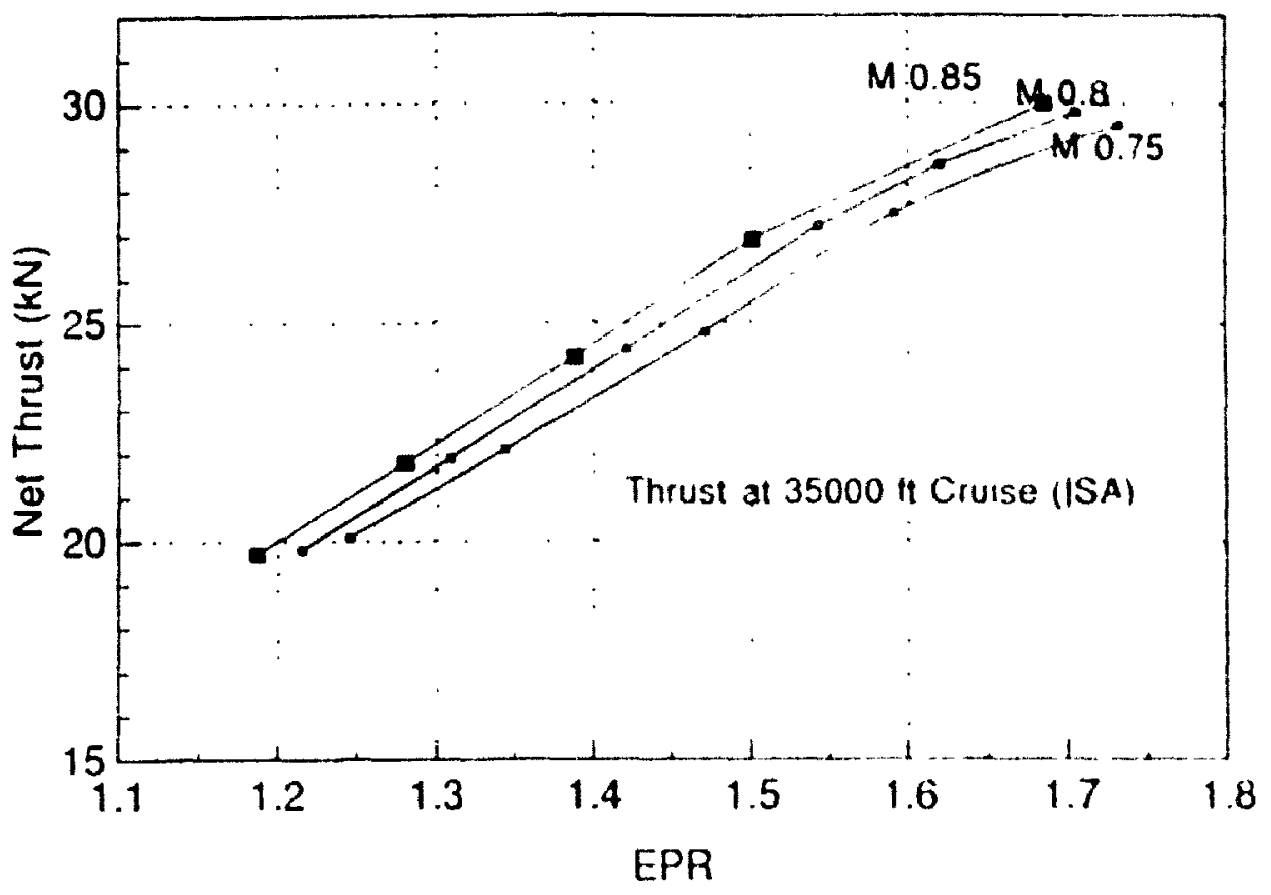

Figure 6.17 Cruise Thrust vs. EPR

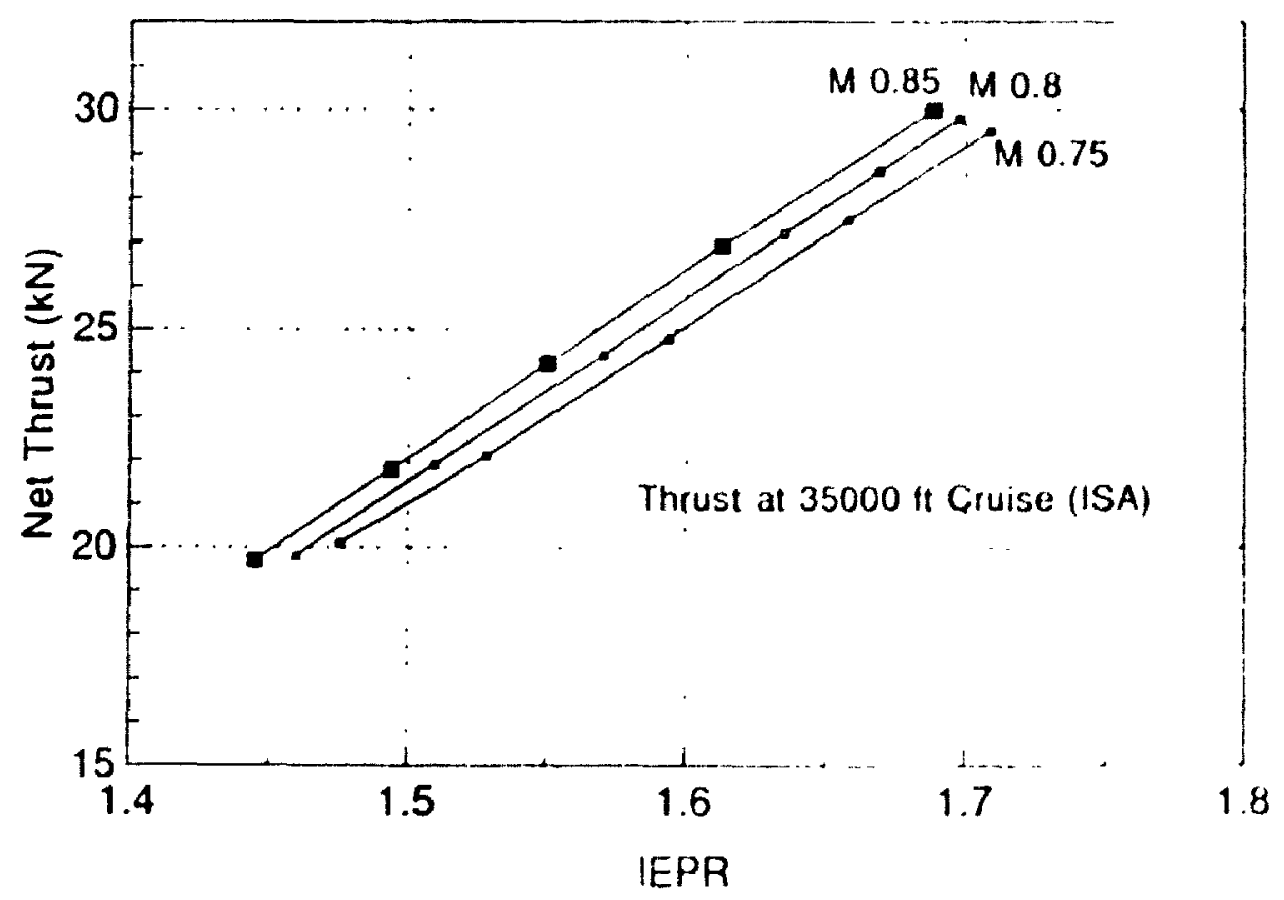

Figure 6.18 Cruis: Thrust vs. IEPR 


\subsubsection{Take-off Performance}

Since the issue of adequate thrust is likely to be of concern during take-off, delailed simulations of the take-off performance of the engine were conducted for various lake off conditions. Three typical take-off conditions were used:

(i) Hot Dav Take-off (HDTO): Sea level static condition, but with an elevated ambient tcmperature (ISA $+15^{\circ} \mathrm{C}$ ), simulating a hot day condition (ambient pressure was still assumed to be the standard sea level value).

(ii) Standard Day Take-off (ISA SLS): Standard ISA sea level static conditions 1288.16 $\mathrm{K}$ ambient tcmperatture, 1.01325 Bar ambient pressure, Mach 0.0). Equivalent 11) take-off when ambient temperature is $15^{\circ} \mathrm{C}$.

(iii) Coll Day Take-off (CDTO): Sea level static conditions, but with a lower ambient temperature (ISA $-15^{\circ} \mathrm{C}$ ).

The engine was simulated by using a range of Fan spool speeds $\left(\mathrm{N}_{1}\right.$ from $88 \%$ to $10.1 \%$ ). This simulates different throttle settings at take-off for each of the take-off conditions listed above. The results of these simulations were then analyzed to determine the effiet of using various types of thrust measurement pa.ameters for setting thrust at take-oft.

\section{(a) The Flat-rated Thrust Concept}

It is important to realize that for almos all modern turbofans, the sea level (Takeoff) thrus is held constant by a control system up tos some limiting ambient temperature $\left(I S A+15^{\circ} \mathrm{C}\right.$ is typical). This control is usually accomplished by atomatic control of the fuel thow into the engine, most likely through sens ng the GG exhaust temperature (ITT), which in turn controls the speed at which the engire runs. This can be simulated with the present model by adjusting $\mathrm{N}$, to hold thrust constant for a wide range of SLS ambient luperatures. but for purposes of showing the baseline engine performance this will he onilled. 


\section{(b) Delivered Thrust versus Various Thrust Setting Parameters}

Figure 6.19 shows how net thrust varies with fan speed for a range of SI.S conditions. Note that the HDTO thrust at a fin speed $N_{1}=1(0), r$ wass used as the nat rated thrust. From this graph, the speed setting needed to obtain low thrus cin the determined for each set of take-off conditions. It is clear that ambiem condutions hiare an effect on the thrust delivered for a given $N_{1}$ setting. On a cold day $\left.N_{1}-4\right)$ required, whereas on a standard (ISA) day $\mathrm{N}_{1}=97.5 \%$ is needed to produce the flat ralled thrust. A $100 \% \mathrm{~N}_{1}$ setting will yield 100 ) $\%$ thrust in the case of het day tahe offis. One may conclude that increased ambient temperature has a deleterious cflect on delwered thrust for a given $N_{1}$ setting, recuiring higher L.P spool speeds to compens.te for the decreased thrust performance. Also, the variation of thrust with $N_{1}$ is approsimantly linear (for the range $90 \%$ to $100 \%$ ) for the three take off conditions, with a 5 . 6 incleate in $N_{1}$ providing an additional $14 \%$ delivered thrust.

Figure 6.20 shows what happens when fuel flow (1F) is used as the thrust relling parameter. In general, the same trend as observed in Figure 6.19) may le sern. Incteases in ambient temperature mean that more fuel how is neded to give the same thrus. Fon $100 \%$ of flat-rated thrust a FF setting of $4520 \mathrm{hg} / \mathrm{hr}$ is needed for III Th(). For wandand day take-offs, a FF setting of $4360 \mathrm{~kg} / \mathrm{hr}$ is required whis $+210 \mathrm{~kg} / \mathrm{hr}$ is requincol on cold days. Once again, the variation of thrust with IF appears to be linear with the siture lrend for all three SLS conditions. From Figure 6.20, an additional $100(6) \mathrm{kg} / \mathrm{hr}(22 \%$ of the $100 \%$ HDTO fuel flow) will give $17.5 \%$ more take-off thrust.

It is interesting to compare ligures 6.19 and 6.26 with ligsuses 6.21 and 622 ,

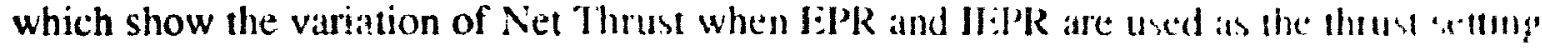
parameters. Figure 6.21 shows that the net threst varsation for all ance condations, lalls

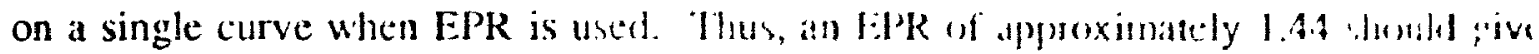
$100 \%$ of the flat-rated thrust for the sange of ambiemt temperature comdition, sudud als $-15^{\circ} \mathrm{C}$ to ISA $+15^{\circ} \mathrm{C}$ ). When IIEPR is used as the thrust setting paranceter, at sumlan

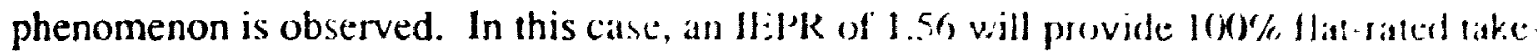
off thrust for the range of SLS conditions studied. H:PR and IIEPR bence appear w have

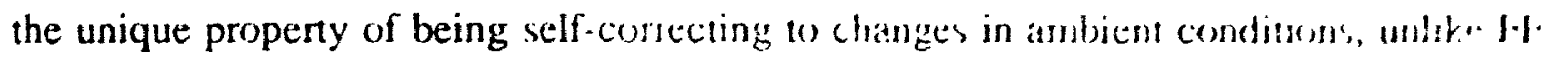


and $N_{1}$. The variation of thrust with IEPR appears linear, while the variation with EPR can be approximated fairly accurately by a straight line over the range 1.35 to 1.55 . A 0.1 variation in EPR (6.8\% change relative to the HDTO $100 \%$ thrust setting) will deliver $13 \%$ more thrust. A similar variation of IEPR (6.8\% of the HDTO $100 \%$ setting) will result in 17.5\% more thrust. These properties of EPR and IEPR may explain why they are still popular choices for thrust setting parameters with some engine manufacturers, since then take-off thrust could be expressed by a simple curve-fit equation allowing direct calibration between EPR/IIER and delivered thrust. Whether this is valid when an engine deteriorates is another matter.

Tahle 6.4 below summarizes the results of simulating take-off performance, and the relative perfomance of the thrust measurement parameters when setting take-off thrust for the most critical case (IIDTO).

Table 6.4 Summary of Take-off Thrust Setting Parameters

\begin{tabular}{|c|c|c|c|}
\hline $\begin{array}{l}\text { Thrust Sctting } \\
\text { Parameter }\end{array}$ & $\begin{array}{l}100 \% \text { HDTO } \\
\text { Thrust Setting }\end{array}$ & $\begin{array}{l}1 \% \text { Change in } \\
\text { Parameter at } \\
\text { Cruise }\end{array}$ & $\begin{array}{l}\text { Change in } \\
\text { Thrust (\%) }\end{array}$ \\
\hline$N_{1}$ (fin speed) & $100 \%$ & $1 \%$ & $2.8 \%$ \\
\hline $1 \%(k g / h r)$ & 4520 & 45.2 & $078 \%$ \\
\hline I:PR & 1.44 & 0.0144 & $1.91 \%$ \\
\hline II:i'R & 1.56 & 0.0156 & $2.57 \%$ \\
\hline
\end{tabular}

As with the cruise performance, $N_{1}$ again appears to be the most sensitive parameler while fli: is the least. Note, however, that the relative sensitivity of EPR and II:PR is not much lower than for $N_{1}$, unlike the results for cruise. The absolute changes in I:PR or IIPR are still quite low. but in theory will not be as sensitive to ambient icmperature conditions as $N_{1}$ and FF. This is quite different from the situation predicted for setting cruise thrust by these four par:meters. 


\section{(c) Variation of Cycle Temperatures at Take-off (Temperature I.imiting)}

The concept of flat-rating take-off thrus is closely connected with the variation of cycle temperatures at iake-off. As was expected, the highest eycle temperatures aciur during hot day take-offs, and thus represent the most critical conditions. The viriation of the hot-end temperatures (TIT, ITT, and EGT) with the Iwo mos commonly used thrust setting parameters (EPR and $N_{1}$ ) shows similar trends. These may le secoln in Figures 6.23 and 6.25 for the case of using $N_{1}$ and EPR respectively. Figure 0.24 shows the same information when ploted against the gas generatur spece $\left(N_{2}\right)$.

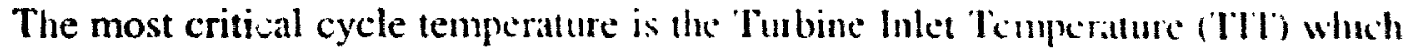
must be limited so that the themai linit of the HP Turbine rotor material is not enceded. In practise, TIT is difficult to measure so the gals generator exhaust gats Icmperature (called ITT in this thesis) is usually used instead. The results shown in Ingutes 0.2. through 6.25 indicate that there is in gencral a geod correlatum in the variation of $\mathrm{ll}$. and TIT. In practical terms, an ITT limit will be specilied which is deemed the hest compromise between delivered performance (hrust) and bot end overhatul lite which

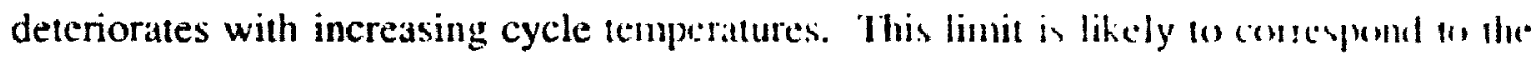
$100 \%$ thrust level for the fat-rate temperature, ypically ISA $15^{\circ}($, which is the III)I(I) condition used in this study. (Philpet, 1992) from the praph, the lit limit is

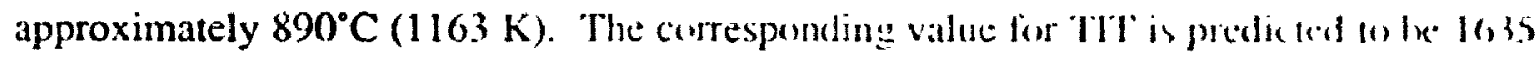

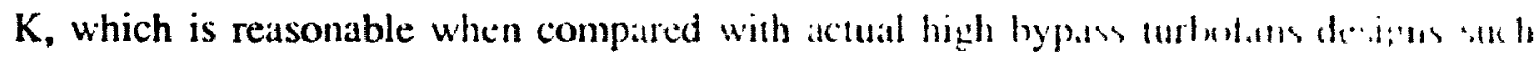
as the CFM56-5B engines (AN, C1M56 Famly of fingince, 1WM). 

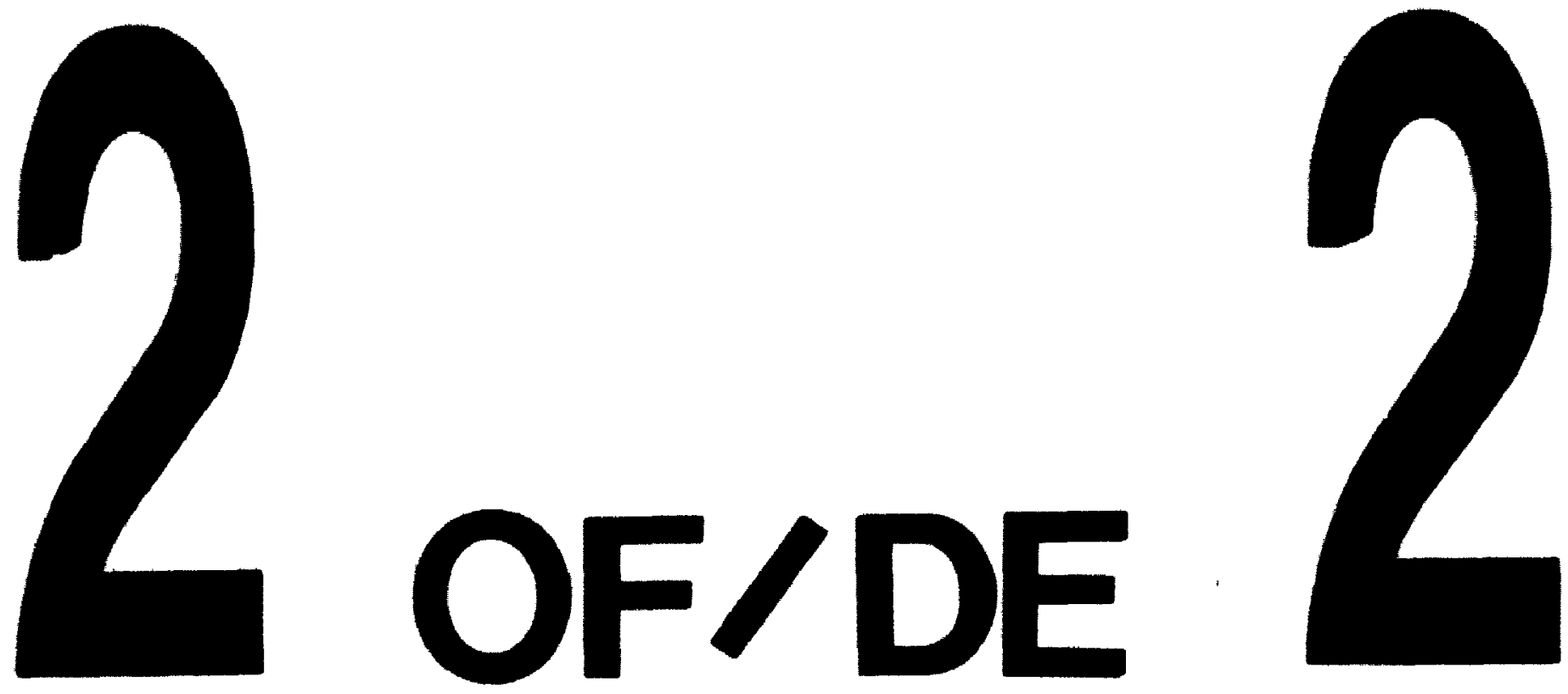

PM-1 $31_{2}^{\prime} \times 4$ " PHOTOGRAPHIC MICAOCOPY TARGET NBS 10 IGA ANSI/ISO "2 EOUIVALENT

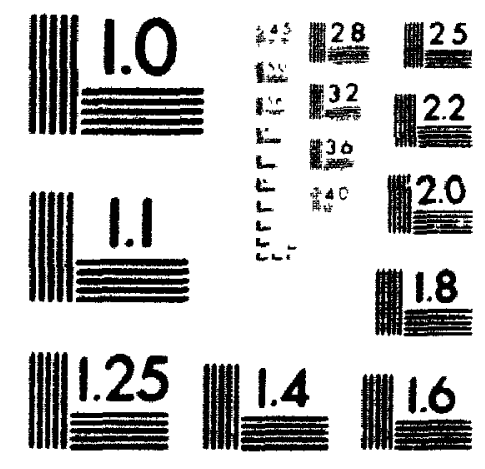




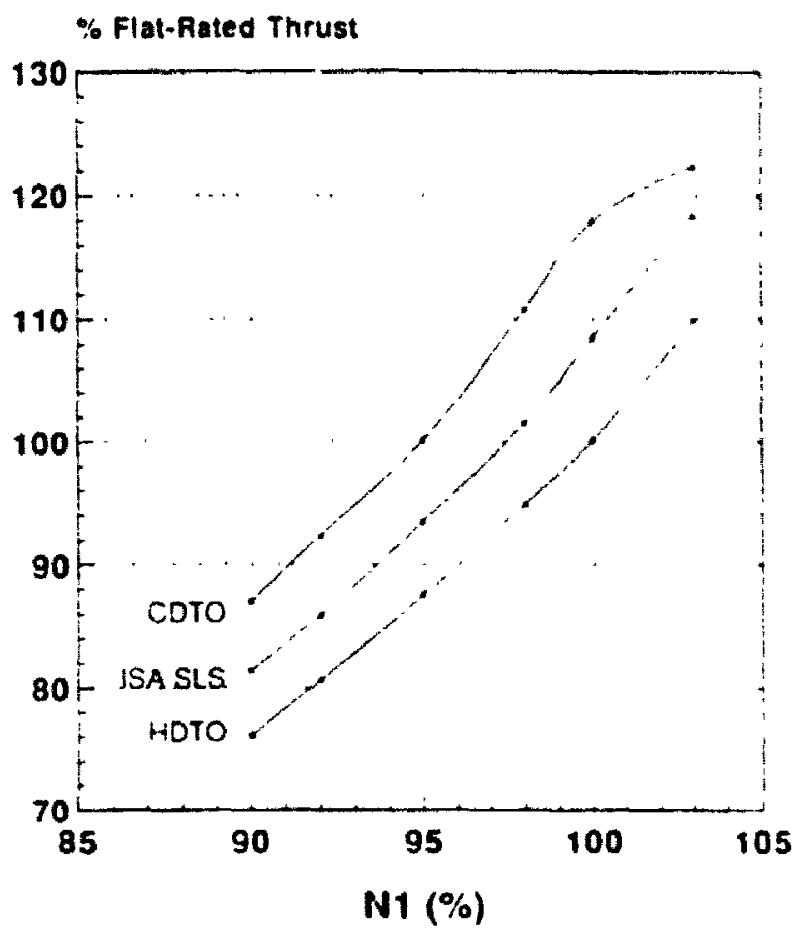

Figure 6.19 Take-off Thrust Variation vs. $N_{1}$

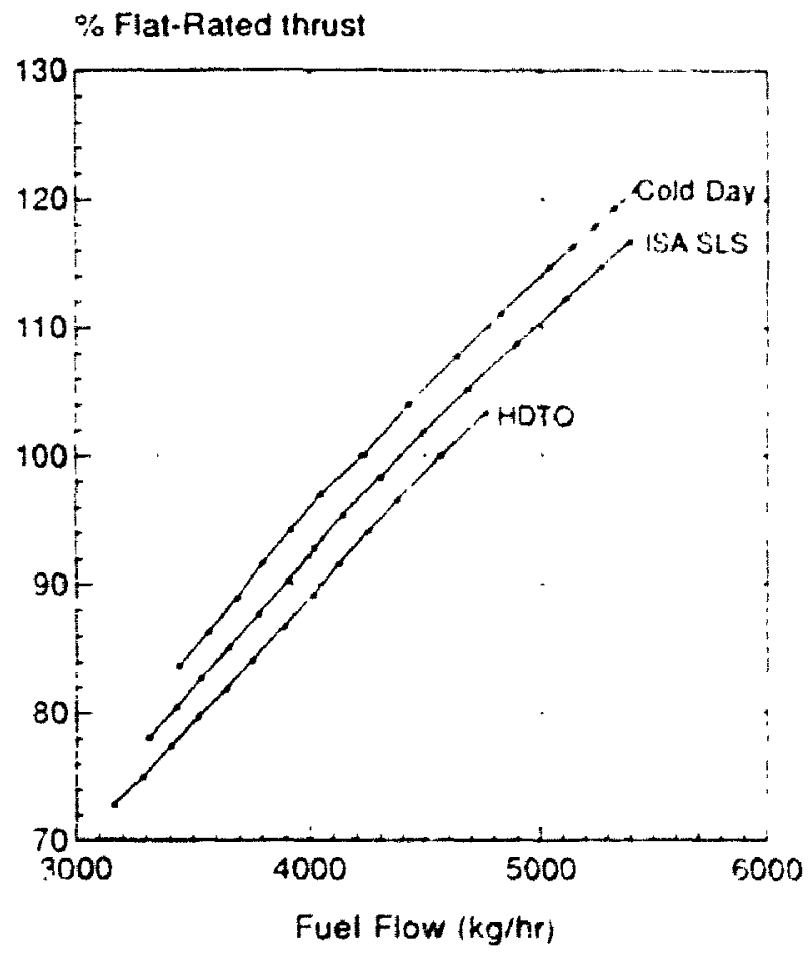

Figure 6.20 Take-off Thrust Variation vs. Fuel Flow 


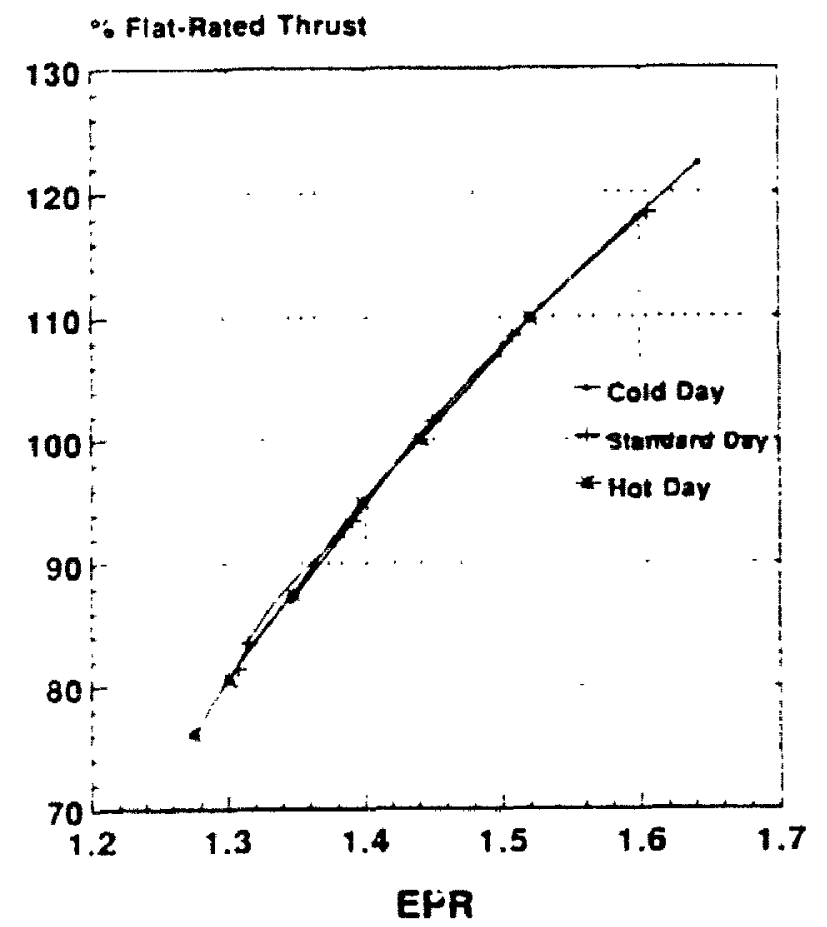

Figure 6.21 Take-of Thrust with EPR as Thrust Setting

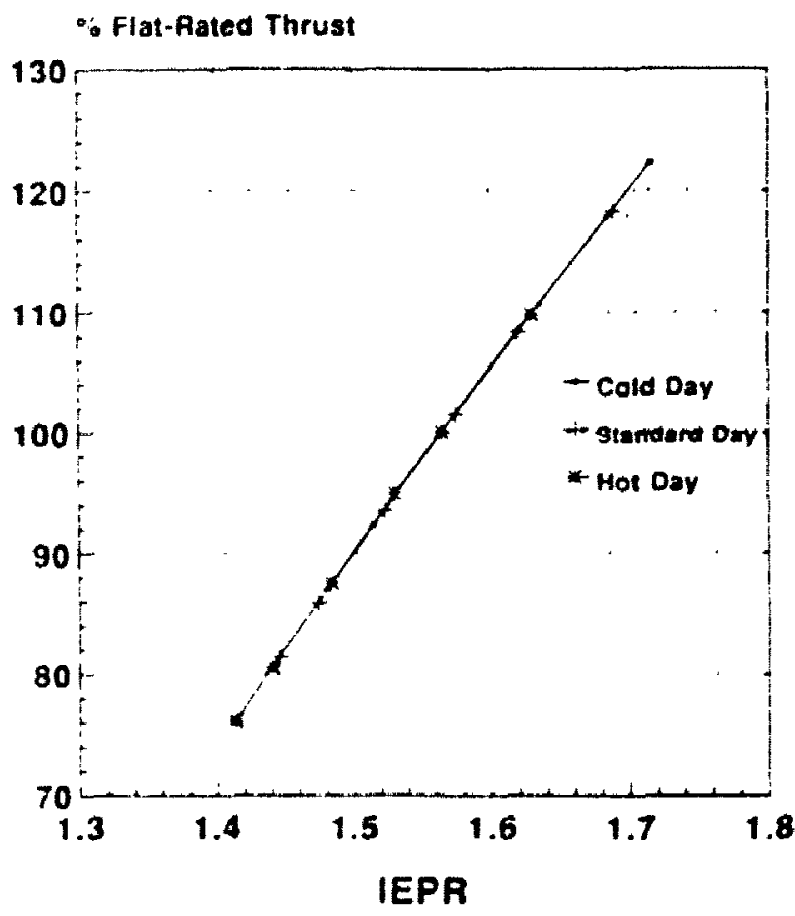

Figure 6.22 Take-off Thrust with IEPR as Thrust Setting 


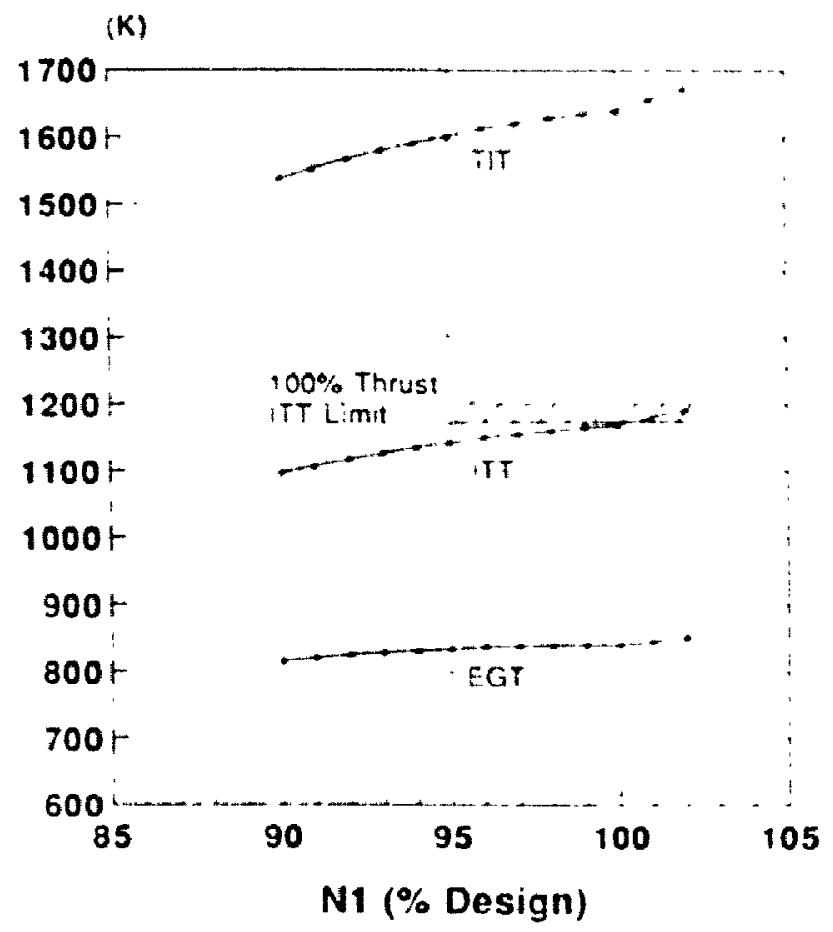

Figure 6.23 Variation of HDTO Cycle Temperatures vs. $N_{1}$

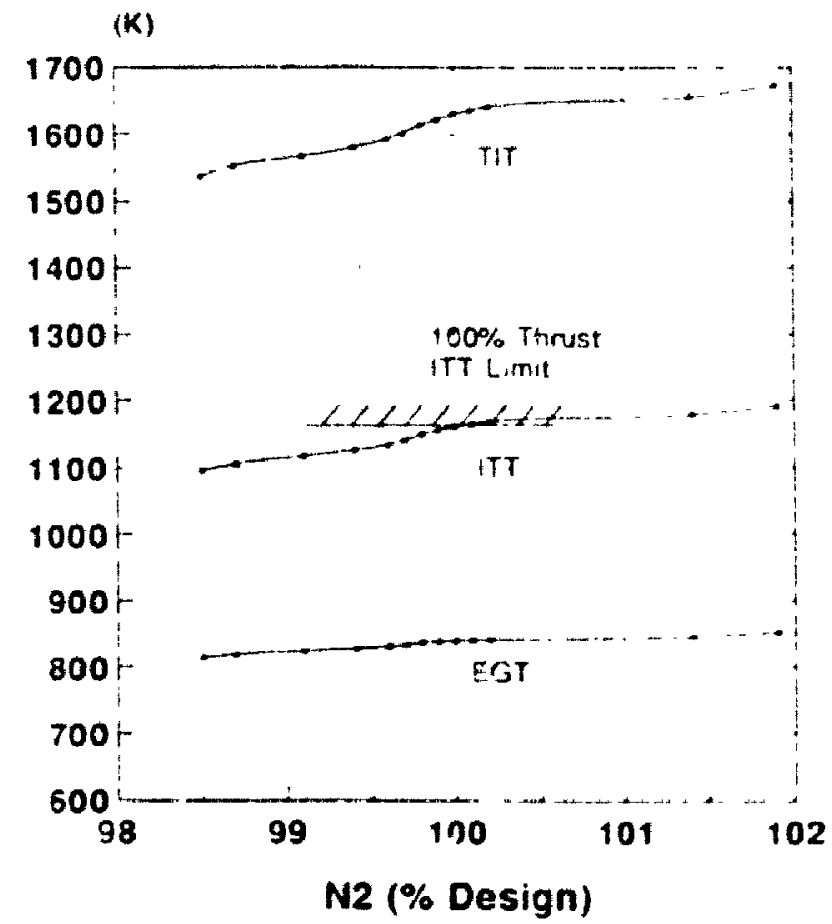

Figure 6.24 Variation of HDTO Cycle Temperatures vs. $\mathrm{N}_{2}$ 


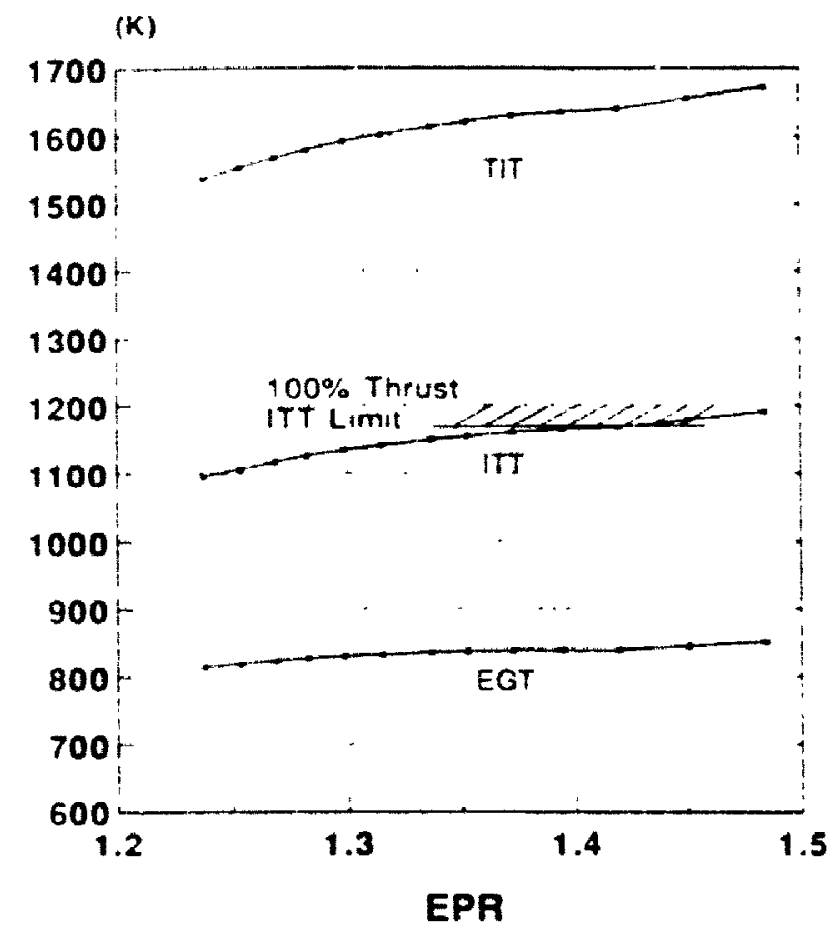

Figure 6.25 Variation of HDTO Cycle Temperatures vs. EPR 


\subsection{Validation of Turbofan Simulator}

\subsubsection{Simulation of the JT9D-7A}

The ability of the simulator to accurately predict both overait performance and the various indirect thrust measurement systems such at: EPR and IFPR has to he demonstrated, and the simplest way is to attempt to simulate the performance of an actual engine. Unfortunately, information on typical waltee for IPPR, IIPPR, or spowl speeds ane rare for a specific engine. However, some data is availahle for the JTy), from data collected from actual B747 flight decks (Saravanamuttoo, 1977-1985). In most cases this data is for stabilized cruise, and there is some scatter in the I:PR and F:(ill value's duc to different ambient conditions. Fairly good information is available for the cycle comditions and overall derign of the JT9D-7A, the engine nost common for the B7.17 flight dittat that is available (Borger, 1981). Table 6.5 summarizes what is known about the JI91) $7 \mathrm{~A}$.

Table 6.5 JT9D-7A Cycle and Uperation Dala

\begin{tabular}{|c|c|c|c|}
\hline Engine Cycle & ISA Take-off & Climb (1)OC) & Cinises \\
\hline BPR & 5.1 & & \\
\hline FPR & 1.52 & & \\
\hline OPR & 22.5 & & \\
\hline TIT & $1469 \mathrm{~K}$ & & $1,3,1 \mathrm{k}$ \\
\hline Mass Flow & $699 \mathrm{~kg} / \mathrm{s}$ & & \\
\hline \multicolumn{4}{|c|}{ Performance and Indicatory } \\
\hline Max Thrust (lbs) & $205.5 \mathrm{kN}(461.50)$ & & $4.1 \mathrm{kN}(989)(1)$ \\
\hline $\mathrm{SFC}(\mathrm{kg} / \mathrm{N} * \mathrm{hr})$ & 0.040 & & 0.0708 \\
\hline EPR (flight data) ${ }^{6}$ & $1.46(\max )$ & $1.45 w 1.55$ & 1.4 (avg) \\
\hline $\mathbf{N}_{1}$ & $100 \%$ (ISA SLS) & $95 \%, 1098 \%$ & $90 \%$ (avy) \\
\hline
\end{tabular}

5. Mach 0.85 at $35000 \mathrm{ft}$.

6. The Cruise settings shoun are the average values for Mach $0.85,350(\%)$ ft. 
Blank entries in Table 6.5 indicate that no definite information is known for that parameter. Unfortunately, this lack of information includes most of the TOC and cruise cycle parameters which are necessary to define the design point for the JT9D.

The simulation program was used to try and simulate JT9D-7A performance as closely as possible to the values given in Table 6.5. Attempts at using the ISA SLS conditions as the design point were unsatisfactory, since the off-design performance at the TOC and cruise conditions were under-estimated by a large margin. Using the cruise condition as the design point was hampered by the lack of information on other cycle conditions such as FPR, OPR and BPR. When reasonable values were used, the take-off turbine inlet temperature was greatly over-estimated. Therefore, based on similar findings for the Advanced CYCLE/CFM56 design, the top of climb (TOC) was used as the design point. Successive iterations were necessary, but eventually a design was found that adequately simulated the JT9D at other known operating points.

It was noticed that the effect of using different "design" values for the mechanical speeds of the I.P and HP spools was quite important, especially for accurate simulation of the TIT at take-off. Also, extensive iterations were needed to find the right combination of TOC cycle conditions that gave the known conditicns at SLS, while also providing the same thrust for the right air mass flow. When $95 \%$ was used as the design speeds for both spools at TOC, it was noted that a LP Speed of $98 \%$ at SLS conditions gave the best take-off match, which suggests a reduced power take-off for standard takeoff conditions. Of course, another factor may be the influence of the LM-2500 HPC Map that was used as the basis for the simulator, most particularly the shapes of the speed lines (fairly steep near the $100 \%$ non-dimensional speed line).

Table 6.6 summarizes the simulation results, and where possible the errors present in the simulations. It is evident that the simulation results are quite good apart from the slight under-prediction of the cruise thrust, EPR and TIT. These predictions may be improved somewhat if a slightly faster fan speed setting was used as the maximum cruise condition, or if a different set of TOC spool speeds was defined. 
Chapter 6: Nominal Simulation Results

Table 6.6 Simulation of the JT9D-7A

\begin{tabular}{|c|c|c|c|}
\hline \multicolumn{4}{|c|}{ Top-of-Climb (Mach $0.85,350(\mathrm{ft}$ ) Engine Design Details } \\
\hline Intake Efficiency & $95 \%$ & $\begin{array}{l}\text { Nozzle } \\
\text { Efficiencies }\end{array}$ & $99 \%$ \\
\hline $\begin{array}{l}\text { Spool/Bearings } \\
\text { Efficiencies }\end{array}$ & $99 \%$ & $\begin{array}{l}\text { Combustion } \\
\text { Efficiency }\end{array}$ & $99 \%$ \\
\hline $\begin{array}{l}\text { Polytropic } \\
\text { Efficiencies }\end{array}$ & \multicolumn{3}{|c|}{ Fan/LPC: $87 \%$ HPC: $89 \%$ Turbines: $88 \%$} \\
\hline Cooling Bleed & $\begin{array}{l}10 \% \text { Compressor } \\
\text { Air }\end{array}$ & $\begin{array}{l}\text { Combustion } \\
\text { Pressure Drop }\end{array}$ & $4.4 \%(\mathrm{CI}) \mathrm{P}$ \\
\hline $\begin{array}{l}\text { Design Point } \\
\text { Engine Cycle }\end{array}$ & \multicolumn{3}{|c|}{$\begin{array}{l}\text { FPR }=1.58 \quad \mathrm{BPR}=5.3 \quad \mathrm{OPR}=25.0 \quad \mathrm{TTT}=13 \times 0 \mathrm{~K} \\
\text { Mass flow }=300 \mathrm{~kg} / \mathrm{s}\end{array}$} \\
\hline \multicolumn{4}{|c|}{ ISA Take-off Engine Cycle and Performance } \\
\hline & Predictions & Known Values & $\%$ I:rror \\
\hline BPR & 5.27 & 5.1 & +3.3 \\
\hline FPR & 1.52 & 1.52 & 10.0 \\
\hline OPR & 22.6 & 22.5 & +0.4 \\
\hline TIT & 1507 & 1469 & +2.5 \\
\hline Mass flow $(\mathrm{kg} / \mathrm{s})$ & 691.6 & 699 & -1.1 \\
\hline Thrust $(\mathrm{kN})$ & 203.9 & 20.5 .5 & -0.8 \\
\hline EPR & 1.475 & 1.46 & +1.0 \\
\hline \multicolumn{4}{|c|}{ Cruise Cycle and Performance } \\
\hline BPR & 5.5 & $\mathrm{n} / \mathrm{a}$ & $n / a$ \\
\hline FPR & 1.52 & $\mathrm{n} / \mathrm{a}$ & $n / a$ \\
\hline OPR & 22.3 & $n / \mathrm{a}$ & $\mathrm{n} / \mathrm{at}$ \\
\hline TIT & 1325 & 1361.1 & -2.7 \\
\hline Mass flow $(\mathrm{kg} / \mathrm{s})$ & 285.1 & $\mathrm{n} / \mathrm{a}$ & $\mathrm{n} / \mathrm{a}$ \\
\hline Thrust (kN) & 38.1 & 44 & -13.4 \\
\hline EPR & 1.388 & 1.4 (avg) & -0.85 \\
\hline
\end{tabular}


The variation of cruise EPR and $N_{2}$ with fan speed $\left(N_{1}\right)$ was also simulated since actual flight data was available for these, allowing the accuracy of the simulator to be checked. The variation of $N_{2}$ with cruise $N_{1}$ setting (for approximately the same cruise condition as used for the simulations presented in Table 6.5) can be seen in Figure 6.26. For interest, similar information has been plotted for the CF6-80 engine as installed on the Boeing 767 airliner. The turbofan simulation program was then used to simulate cruise thrust settings of $N_{1}=88 \%$ to $N_{1}=95 \%$ for constant aititude and Mach number. As can be seen from Figure 6.26, the correlation between the predicted values of $\mathrm{N}_{2}$ and actual engine data is quite good, with a maximum error of about $1 \% \mathrm{~N}_{2}$

Similar results for EPR were obtained, and these may be seen along with actual JTOD-7A flight data in Figure 6.27. Where possible, EPRs for other types of aircraft/engine combinations have been shown in addition to the B747 flight deck information. The accuracy of the JT9D simulation is evident with a maximum error in EPR of about 0.05 (which is only $3.2 \%$ of the TOC EPR used as the design value). The take-off values for the JT9D and JT3D have been shown for comparison. It is interesting to note that in the much earlier JT3D (and JT8D) turbofans, which were basically just modified turbojets, EPRs approaching (or exceeding) 2.0 were normal. Since the advent of higher bypass P\&W engines, EPRs of about 1.5 at take-off have become more common. Unfortunately, comparison with other modern (non-P\&W) high BPR engines is not possible since it appears that only Pratt \& Whitney high BPR designs use EPR. However, can be expected that those engines with similar engine cycles would have approximately the same EPR trends. The simulated take-off EPR for the JT9D-7A is quite close to actual maximum take-off EPR, with an error of about $1 \%$. 


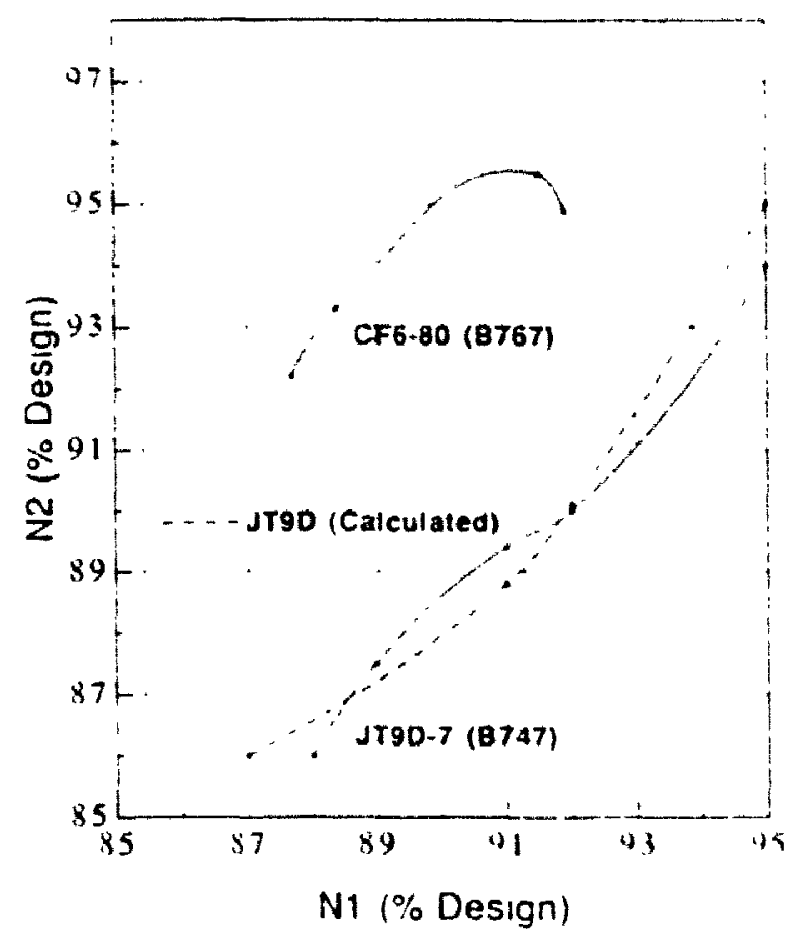

Figure 6.26 Variation of Spool Speeds at Cruise (JT91) and (F6-80)

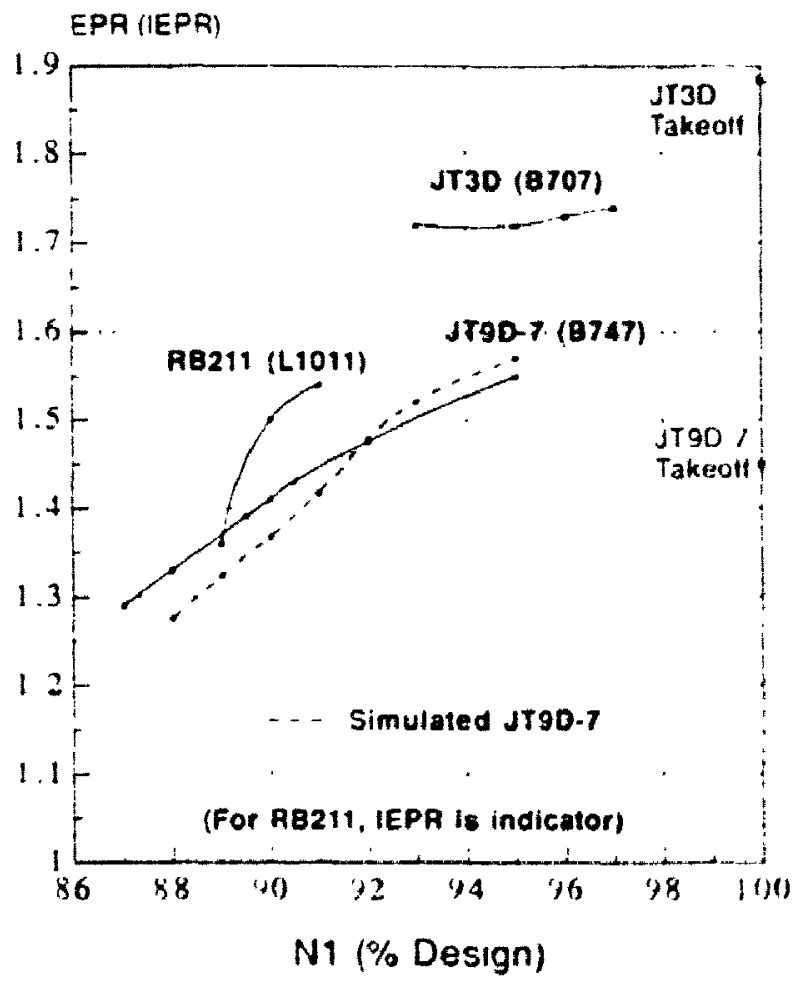

Figure 6.27 Variation of Cruise EPR (IEPR) for Several Engines 


\subsubsection{Simulation of the JT15D-4}

Detailed information on the climb performance of modern high bypass turbofans is rare. Fortunately, information was available for the JT15D-4 engine which is of molerate BPR. Despite the fact that the JT15D-4 has a centrifugal HPC compressor (with some axial stages upstream) with a much lower PR than the LM-2500 HPC, the turbofan simulator was able to predict fairly accurate take-off and climb performance for this engine. The simulations were performed using state-of-the-art assumptions for unknown design point parameters for the engine and the assumption that the JT15D-4 has the TOC condition as its aerodynamic design point. Part of this success is most likely due to the fact that the JT15D-4 fan was used as the base for the generalized fan map used by TURBOFN4. The design point parameters which provided the best match with published performance and design information to simulate the JT15D-4 are as listed in Table 6.7.

Table 6.7 TOC Design Point Data used to Simulate the JT15D-4

\begin{tabular}{|l|c|}
\hline Parameter & $\begin{array}{c}\text { TOC Design Value } \\
\text { (Mach 0.8 @35000 ft) }\end{array}$ \\
\hline \hline BPR & 2.7 \\
\hline FPR & 1.75 \\
\hline OPR & 11.5 \\
\hline TrT & $1150 \mathrm{~K}$ \\
\hline Mass Hlow & $15 \mathrm{~kg} / \mathrm{s}$ \\
\hline Polytropic Efficiencies & Fan $=88 \%$ HPC $=81 \%$ Turbines $=87.5 \%$ \\
\hline $\begin{array}{l}\text { Mechanical Details and } \\
\text { Efficiencies }\end{array}$ & $\begin{array}{c}\text { Intake }=95 \% \text { Nozzles }=99 \% \text { Spools }=99 \% \\
\text { Combustion }=95 \% \Delta \mathrm{p}_{\mathrm{b}}=9 \% \text { Cooling }=\text { nil }\end{array}$ \\
\hline Spool Speeds (TOC) & $\mathrm{N}_{1}=95 \%, \mathrm{~N}_{2}=96 \%$ \\
\hline
\end{tabular}

Take-off thrust performance was predicted by carefully adjusting the $N_{1}$ setting over the range of take-off ambient conditions considered. Climb performance was 
similarly predicted by varying Mach number at each tlight altitude considered and adjusting $N_{1}$ as required. The best climb thrust and FF correlation. occurred when $N_{1}$ was increased gradually with Mach number and altitude. This would appear to indicate that the JT15D-4 is operated such that the fan speed is allowed to change during climb. Accurate FF simulations were obtained only when a reasonable TOC turbine inlet temperature was used, along with a reduced combustion efficicncy and with insignificant HPT cooling bleed. The accuracy of the simulator in predicting known values for the take-off cycle conditions was also checked, as detailed in Table 6.8. It is clear that the simulated JT15D-4 is quite close to actual engine data, with the worst error heing a $7.2 \%$ over-estimate of take-off thrust.

The performance predictions for the JT15D-4, compared with Pratt \& Whitney data sheets, may be seen in Figures 6.28 through 6.30. It is evident from these graphs that the simulations are quite accurate, especially when one considers the mumler of assumptions that were required to establish a reasonable TOC design cycle.

Table 6.8 Predicted JT15D-4 Take-off Performance and lingine (yycle?

\begin{tabular}{|l|c|c|c|}
\hline & Predictions & Krown Values" & \% I:rror \\
\hline BPR & 2.70 & 2.70 & $+(1.0$ \\
\hline FPR & 1.75 & $\mathrm{n} / \mathrm{a}$ & $\mathrm{n} / \mathrm{a}$ \\
\hline OPR & 10.4 & 10.1 & +3.0 \\
\hline TIT & 1287.4 & 1288 & $<0.1$ \\
\hline Mass flow (kg/s) & 36.5 & 35.3 & +3.4 \\
\hline Thrust $(\mathrm{kN})$ & 11.9 & 11.1 & +7.2 \\
\hline SFC $(\mathrm{kg} / \mathrm{kN} * \mathbf{h r})$ & 0.0564 & 0.0573 & -1.6 \\
\hline
\end{tabular}

7. Assuming a standard day take-off with $\mathrm{N}_{1}=97 \%$. Similar performance is sir: ulated for HDTO (ISA $+15^{\circ} \mathrm{C}$ ) if $100 \% \mathrm{~N}_{1}$ is used, but TIT is then increased to $1348 \mathrm{~K}$.

. From JT15D-4 engine data sheet (AN, Pratt \& Whitney Canada Inc.). 


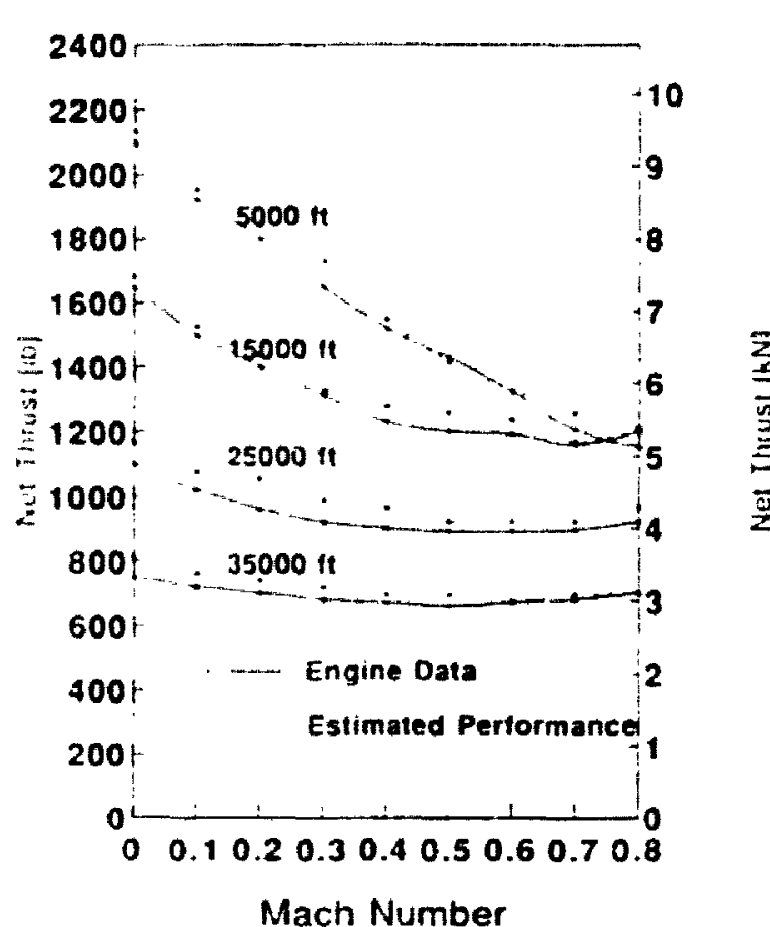

Figure 6.28 JT15D-4 Climb Thrust

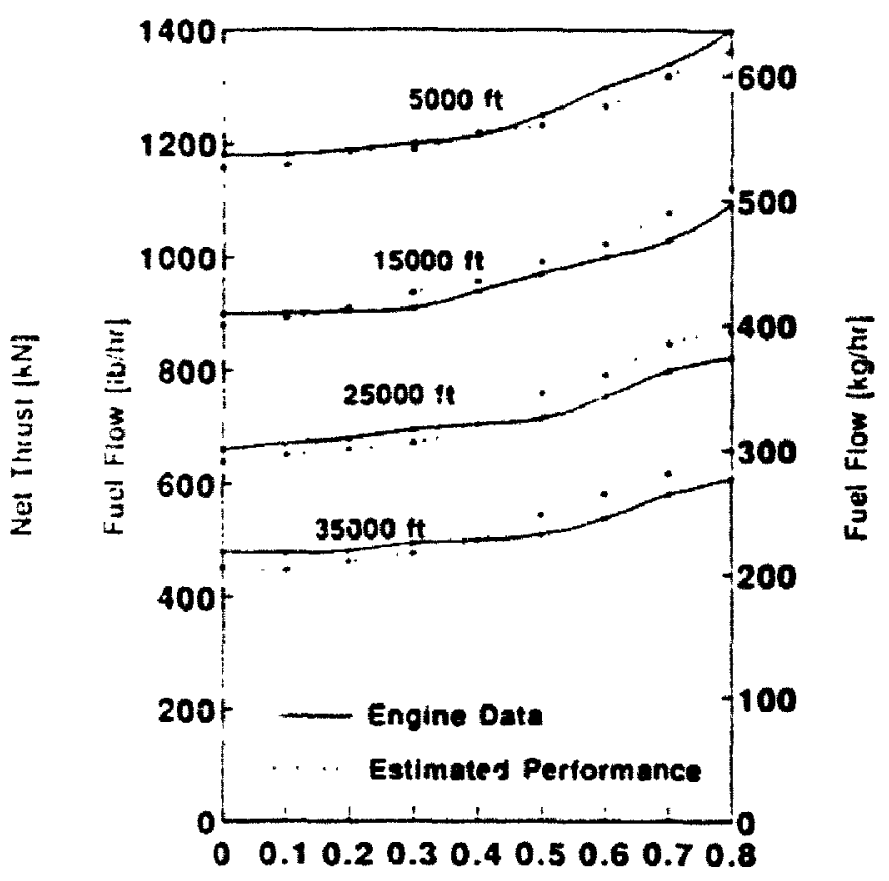

Mach Number

Figure 6.29 JT15D-4 Climb Fuel Flow

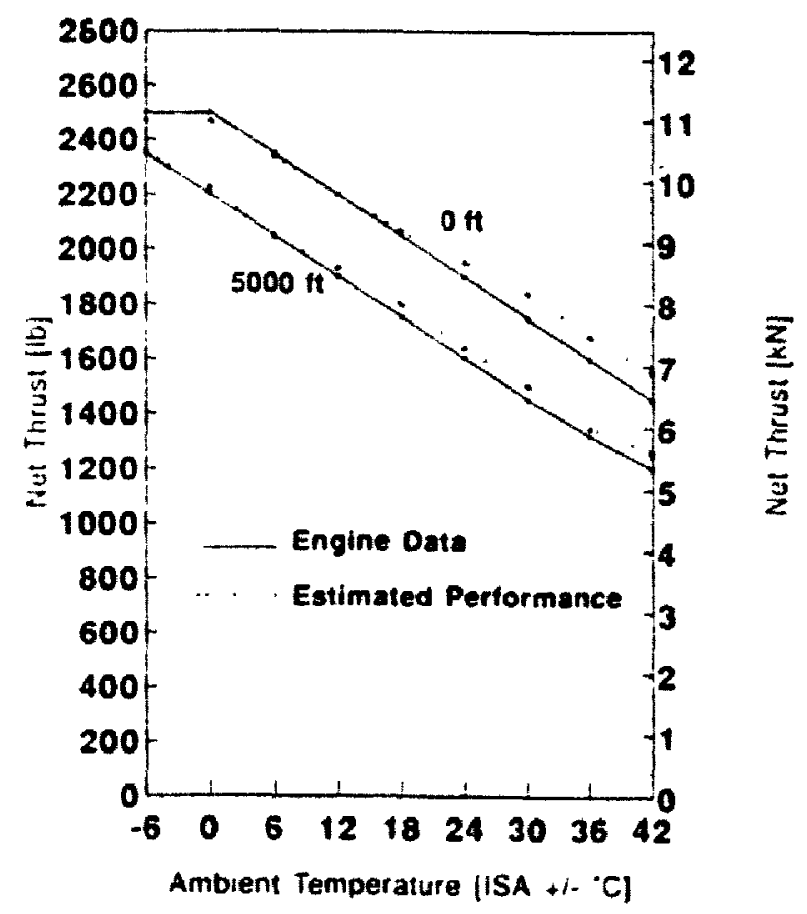

Figure 6.30 JT15D-4 Take-off Thrust 


\section{Chapter 7 Deteriorated Engine Performance Simulation}

\subsection{Fault Simula'. on Methods}

The purpose of this study was to investigate the effect that various kinds of turbofan engine faults had on the delivered performance and also the intluence that the se faults had on the various indirect thrust indicators commonly used in modern turlxufans. The goal was to determine the relative effectiveness or accuracy of ane indirect measurement method over the others. Before this could be acomplished it was first necessary to decide on the types of engine deterioration to lec comsidered, and the metlux to be used to simulate them.

\subsubsection{Types of Engine Faulls Considered}

Given the wide variety of engine faults possible, it was necessary w limil the scope somewhat to include only those faults considered to be most likely 10 (x) in in practice. Also, since the principal aim was to determine the effects of faults on severa' indirect thrust indicators using a thermodynamic turbofin simulation program, lhest faults had to be specified in a manner which the computer progrann could use. $\therefore$ list of the types of faults that were considered in this study is shown in Table 7.1.

Table 7.1 Probable Turbofan Faults

\begin{tabular}{|c|c|c|}
\hline Types of Faults & Probable Cause(s) & Simulation Methen! \\
\hline Fan Deterioration & Fore,gn Object Damage & $\eta_{\infty}$ Drop \\
\hline LPC Deterioration & $\begin{array}{l}\text { Foreign Object Damage } \\
\text { (FOD) }\end{array}$ & $\eta \infty 1$ 1)rol \\
\hline HPC Deterioration & Tip Rubs, FOD, fouling & $\begin{array}{l}\text { Пro and/or } O \\
\text { Drops }\end{array}$ \\
\hline HPT Deterioration & Overheat/Erosion & nos Drop \\
\hline LPT Deterioration & Erosion & $\eta \infty$ Drop \\
\hline
\end{tabular}


Other kinds of engine damage and deterioration are possible, including various kinds of mechanical damage such as wom bearings, broken seals, nozzle blockages or erosion, but the deterioration of aerothermal components is seen to have a much greater impact on overall engine performance and efficiercy. (Collins and Hill, 1991) Another serious fault in modern turbofans is a fault in the control system(s), especially in engines which employ variable geometry technology such as variable position stators or nozzles. Variable geometry can not be simulated by the present turbofan simulation software since this would require very specific knowlerge for a given engine to be simulated properly. Since overall trends are the goal in this study, the simulation of variable geometry engines or their conuol systems were not considered.

\subsubsection{Simulation Methods Applied}

It is believed that the engine falts listed in Table $\% .1$ may be simulated $\cdots$ ith a fair degree of accuracy by imposing decrements to the design point operating parameters, specifically the efficiency, non-dimensional mass flow or pressure ratios. The precise effect of various kinds of gas turbine damage or deterioration is not known definitely, and is the current subject of ongoing research by other investigators. However, previous studies into various kinds of gas turbine faults have shown that the faults listed in Table 7.1 may be sinulated quite adequately by altering the polytropic efficiency only, while keeping the other operating purameters unchanged. (Dupuis, Saravanamutton, and Rudnitshi, 1986) In the case of the compressor components (Fan, LPC or HPC) this has the effect of causing a shift in the component characteristic which has a direct impact on the iwin spool match.

Other effects such as an increase or decrease in the design PR or non-dimensional How rate $(Q)$ were not considered in this study, except in the case when HPC fouling was simulated. The details concerning each type of fault simulated will now be described. 


\section{(a) Fan and Booster Deterioration}

Foreign Object Damage (FOD) is of primary concern in modern high bypass turbofans, causing (in general) a decrease in the performance of the LP Compression system, and can lead to an In Flight Shutdown (IFSD) of the engine in the event of major blade damage (such as a severe bird strike). This decrease in performance is due to damage to the fan or booster blades in the form of splitting, cracking, dents or actual blade sections missing (in the case of savere damage). FOD is less likely to occur in the LPC, since ingested foreign material tends to be centrifuged out the hypass duct. However, events of this type of damage (and general erosion damage) have been recorded on recent high bypass designs. (lovey, 1990) Ian or booster deterioration was simulated by a $\mathbf{0 - 5 \%}$ drop in the polytropic efficiency in either the lan or I.PC, while keeping other parameters unchanged. It was noted during simulations that an excessive drop in Fatn efficiency could result in an unsolvable twin-spool match. For the turbofan cycle under consideration, this was found to be a decrease of more than $3 \%$ for the same nozzle sizes, which forced the HP Spool to run faster than the highest speed available on the HPC characteristic. A standard drop of $2 \%$ in polytropic efficiency was used 'or comparisons with other faults.

\section{(b) HPC Deterioration and Fouling}

Two kinds of deterioration were considered. The first kind of IIPC dekerionation was damage to the rotor or stator blades either from ingestion of forcign objects, crosion of blade surfaces from finer materials, or tip clearance increases from blade tip rubs. Major damage to the HPC due to ingestion is fairly rare in high bypass engines due th the tendency of the LP Compression System (Fan) to centrifuge large objects ow the outer casing and out the bypass duct. However, wear of rotor blade seals (from rubs) or airfoil erosion will cause slight changes in tip clearances or blade geometries and hence will alter the performance of the HPC. This kind of damage was simulatiet by a drop in polytropic efficiency, and the design point isentropic efficiency was then re-calculated based on the design value of $\mathrm{PR}_{\text {tpc }}$ and the faulted polytropic efficiency. It was noted that 
excessive drops in efficiency (5\% or greater) again resulted in unsolvable twin-spool matches. A standard drop of $2 \%$ was found to give the mos, reasonable results and allowed comparisons with other engine faults.

Another kind of deterioration, HPC fouling, was also simulated since this phenomenon is a common problem with modern gas turbine units and has the potential of causing major changes in performance. Following the suggestion of previous investigators, HPC fouling was simulated by imposing a decrease in polytropic efficiency coupled with a decrease in the design point non-dimensional flow rate $Q_{3}$. (Aker and Saravanamuttoo, 1988) Several combinations of efficiency and flow drops were used and were shown to have a marked effect on the HP versus LP spool speed matches and hence overall performance. A decrease in polytropic efficiency of $2 \%$ and a decrease in $Q_{3}$ of $5 \%$ were used for comparison with simple efficiency drops, since from what limited information is available, percent changes in $Q$ tend to be $\mathbf{2}$ to $\mathbf{4}$ times more than the drop in efficiency. Fortunately, this level of HPC fouling is rarely seen in modern turbofans, quite unlike advanced ground-based gas turbine units.(Aker and Saravanamuttoo, 1988)

\section{(c) HPT and LPT Deterioration}

Deterioration in either turbines was simulated by imposing decreases in the design point polytropic efficiencies only. HPT deterioration is likely to result due to the effect of thermal cycles. This in general causes erosion or wear of the HP Turbine blades or annulus seals. Another source of deterioration is corrosion which is accelerated in the high thermal stress environment. Damage or deterioration of the LPT is less likely since the rotation speeds and temperatures are lower. Of course, severe wear can occur in both turbines if abrasive foreign material (such as sand) is ingested by the engine and passes through the hot end components. Severe damage will most likely cause an engine failure but less severe damage/deterioration will likely cause a drop in performance; this deterioration was simulated by using a polytropic efficiency drop of $2 \%$ to allow comparison with other component faults. 


\subsubsection{Implementation of Fault Simulation in TURBOFN4}

The organisation of TURBOFN4 was discussed in Chapter 5, including the menu structure used for fault modelling. A small program called FAULTSET is used to define the current engine fault to be used. This set of data defines the changes to be imposed on design point values of the polytropic efficiency or non-dimensional flow rate for each of the components, in terms of a percentage increase or decrease. This data is automatically saved upon exiting FAULTSET in a file called FAULT.DAT. While within FAULTSET, the faulted condition definition may be saved to a user-named file or previously saved sets of fault data may be recalled from other user-defined files.

From TURBOFN4, the simulation of faults is initiated by selecting Option (3) which calls the subroutine FAULTED. This routine initializes the simulator for simulation of a faulted engine, before passing control to OFFDFS. FAULTIED uses the set of defined component efficiency or Q changes contained in FAULT.DAT to change the appropriate design point parameters while the unfaulted parameters are temporarily stored during the subsequent off-design calculations for later recovery. Then, the design point isentropic efficiencies of the components are recalculated before calling OIFIDES.

OFFDES conducts a full off-design matching procedure for the faulted engine, using the set of flight conditions defined in the file FLIGHT.DAT. Output from OIIDES may be stored in three ways (screen output only, printer, or to a data file) but the engine name normally contained in the header information is replaced by the name of the engine fault being simulated.

Following the completion of OFFDES, control is returned to FAUITILI) to allow the nominal (unfaulted) engine to be restored. This is accomplished easily since the unfaulted design-point parameters of the five components were stored before conducting the fault modelling. Once the nominal engine is restored, control is returned to the Main Menu of TURBOFN4. 
It is important to note that OFFDES calculates a new HPC operating line based on the faulted component parameters, at the start of the off-design matching procedure. However, on-design calculations are not conducted using the modified components, so all design point values not directly affected by the fault definition in FAULT.DAT will be unchanged. This is important, since the engine must still satisfy the flow conditions for the same nozzles which were calculated for the nominal (unfaulted) engine. Excessive changes in the component design point operation could result in unsolvable twin-spool matches due to this fact and the limited range of speeds on the compressor characteristics. 


\subsection{Take-off Performance with Faults}

The faults discussed in the previous section were each imposed on the advanced cycle design used in Chapter 6. TURBOFN4 was then used to simulate the variation of take-off thrust with different throttle settings, for cold day (ISA $-15^{\circ} \mathrm{C}$ ), standard day (ISA) and hot day (ISA $+15^{\circ} \mathrm{C}$ ) take-offs. The performance of the engine with each of the single faults was compared with the unfaulted performance discussed in Chapter 0.

\subsubsection{Take-off Thrust for Different Ambient Conditions}

Figures 7.1 and 7.2 show what happens when $N_{1}$ or I:PR are used to set thrust at take-off when one of the worst faults (Fan deterioration) is present. In ligure 7.1 it is evident that at each take-off condition, the fan fault actually results in a slight $(+1 \%)$ increase in thrust for the same $N_{1}$ speed setting. Similarly, IPR still appears to correct itself for the three different ambient conditions as evident in Figure 7.2, with the delivered thrust still falling on a single line. The delivered thrust for a constant IiPR appears to the slightly lower in the case of the fan fault, but this drop is very slight (less than $(\%)$.

It was noted that in most cases, a $2 \%$ reduction in polytropic efficiency in the live main aerodynamic components results in minor changes in the net delivered thrust, and in some cases even resulted in a slightly higher thrust! This seems to contradict what one weuld expect, but it is important to realize that in general, lower efficiency in the compressor components results in higher TIT which can lead to higher thrust. In actual engines, the presence of temperature limiting control systems will prevent higher hot end cycle temperatures and would generally impose a limit which would result in lower takeoff thrust. 


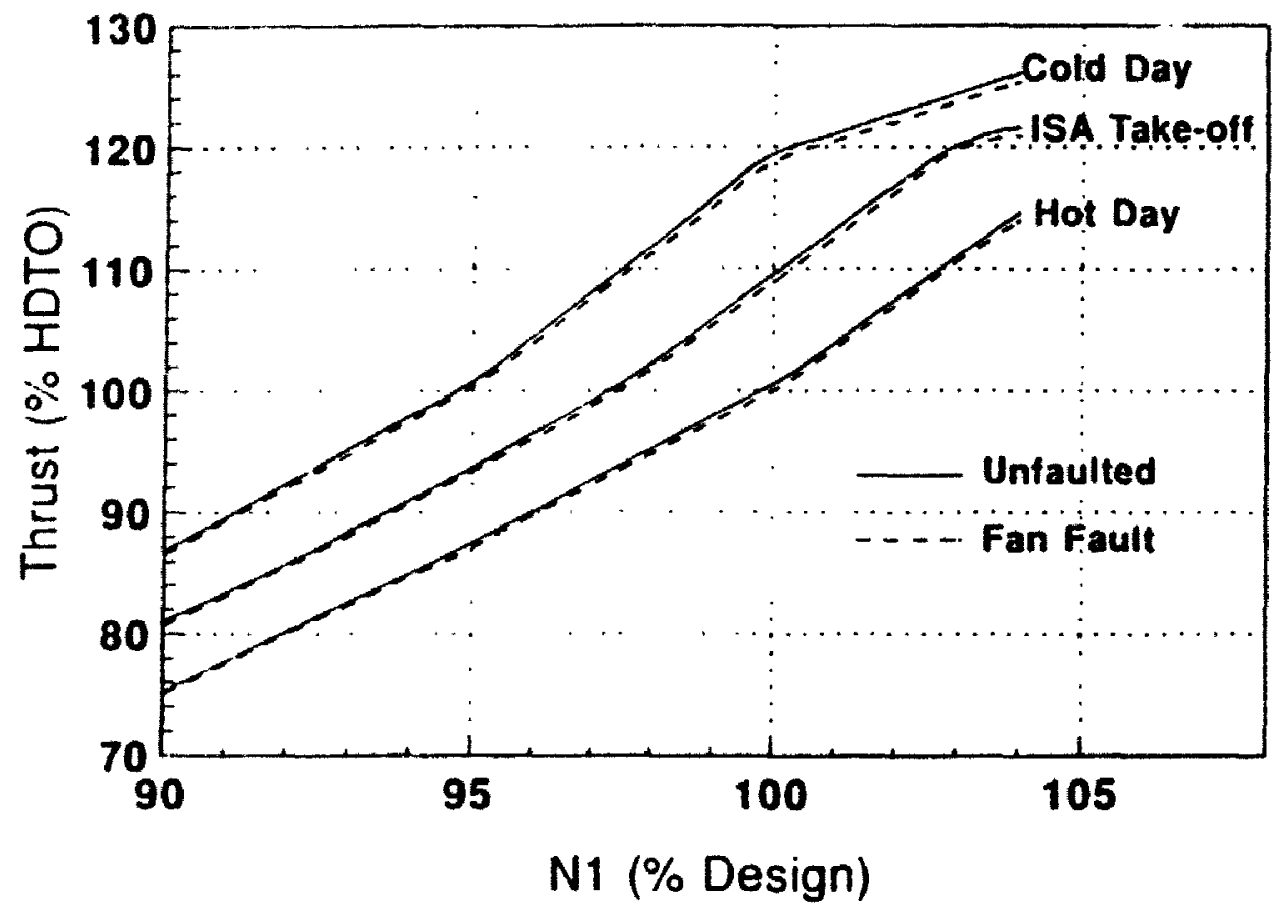

Figure 7.1 Take-off Thrust with Fan Fault using $\mathbf{N}_{\mathbf{1}}$ as Setting

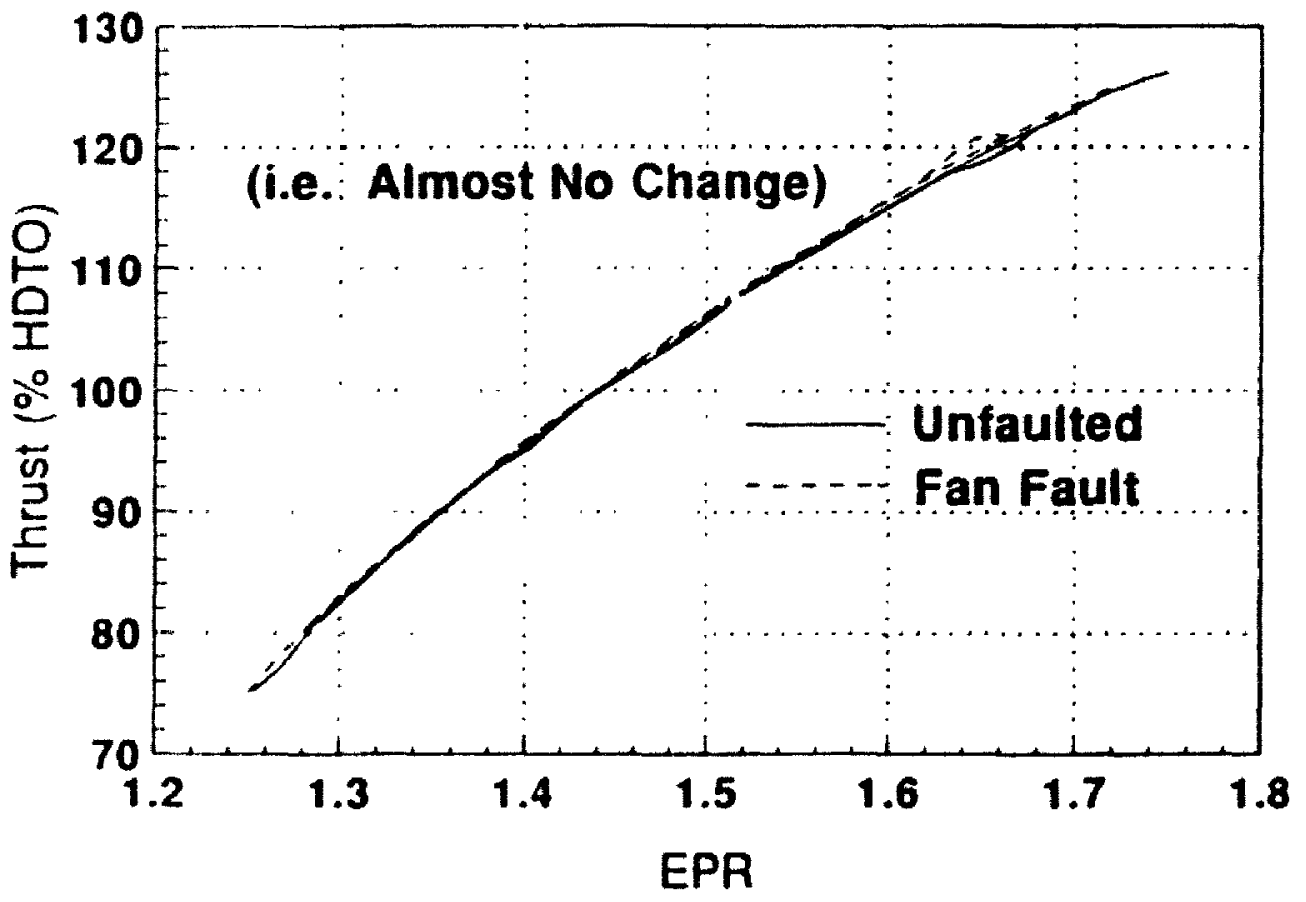

Figure 7.2 Take-of Thrust with Fan Fault using EPR as Setting 


\subsubsection{HDTO Thrust without Temperature Limiting}

Since the concept of temperature limiting is likely to the critical at the flat-rated temperature limit (typically ISA $+15^{\circ} \mathrm{C}$ ) the effect of various faults on the hot day take-off (HDTO) thrust was examined. The effect of using $N_{1}$, fuel flow (FF), EPR, or IIIPR to set thrust when faults are present may be seen in Figures 7.3 through 7.6. For clarity only the most severe fault effects have been shown on cach graph. The worst variations of HDTO thrust that were obtained using $2 \%$ efficiency faults have been summarized in Table 7.2.

Table 7.2 Setting HDTO Thrust (No Temperature limits)

\begin{tabular}{|l|c|c|c|c|}
\hline \multirow{2}{*}{ Fault Type } & \multicolumn{4}{|c|}{ Maximum Change in Thrust with Constant Sctring: } \\
\cline { 2 - 5 } & $\mathrm{N}_{1}$ & $\mathrm{FF}$ & EPR & IIIPR \\
\hline Fan $\eta_{\infty}-2 \%$ & $+1 \%$ & $-5 \%$ & $<-1 \%$ & $<+1 \%$ \\
\hline Booster $\eta_{\infty}-2 \%$ & no effect & $<-1 \%$ & no effect & no cffect \\
\hline HPC $\eta_{\infty}-2 \%$ & $<+1 \%$ & $-4.5 \%$ & $+1 \%$ & no effect \\
\hline $\begin{array}{l}\text { HPC } \eta_{\infty}-2 \%, \mathrm{Q}_{3}-5 \% \\
\text { (fouling) }\end{array}$ & $<+1 \%$ & $<-1 \%$ & $+1 \%$ & no cffect \\
\hline HPT $\eta_{\infty}-2 \%$ & no effect & $-2.5 \%$ & no effect & no effect \\
\hline LPT $\eta_{\infty}-2 \%$ & $+2 \%$ & $-4.5 \%$ & $-1 \%$ & $<+1 \%$ \\
\hline
\end{tabular}

When $N_{1}$ is used as the thrust setting parameter (Figure 7.3) it can be seen that the net thrust against $N_{1}$ falls along a line, with faults shifting this line upwards slightly (such that a slightly increased thrust results in the faulty engine when compared with the nominal engine at the same $\mathrm{N}_{1}$ setting). The maximum increase, however is of the order of $2 \%$ for the case of the I.PT fault and $1 \%$ for Fan fault. This latter effect is mainly due to increased hot end cycle conditions which may not be permissible at III)T() conditions. 
Figure 7.4 shows that using FF to set take-off thrust will result in lower thrust when faults are present for the same FF setting (or alternatively, more FF for the same thrust). The worst fault appears to be when the Fan efficiency is dropped, which results in a drop in delivered take-off thrust of about 5\%. LPT and HPC efficiency decreases also appear to have a fairly major impact (4-5\% thrust decrease). HPT efficiency drops appear to result in 2-3\% less thrust for the same FF setting, while LPC efficiency diops and IIPC fouling appear to have only minor effects.

Figures 7.5 and 7.6 show what happens when either EPR or IEPR are used to set HDTO thrust. It is evident from Figure 7.6 that IEPR appears to be a slightly more accurate indicator. With faults, the thrust curves appear to fall along a single curve, with a maximum increase of less than 1\% thrust in the case of Fan or LPT faults and negligible changes from the other faults. Figure 7.5 shows that faults make EPR a slightly less precise thrust setting parameter, with HPC fouling and HPC efficiency drops resulting in maximum increases of $1 \%$ in delivered thrust versus the unfaulted engine at the same EPR setting, and LPT faults resulting in a $1 \%$ decrease in thrust. Fan and HPT faults appear to have only minor effects on the delivered thrust when EPR or IEPR are used. 


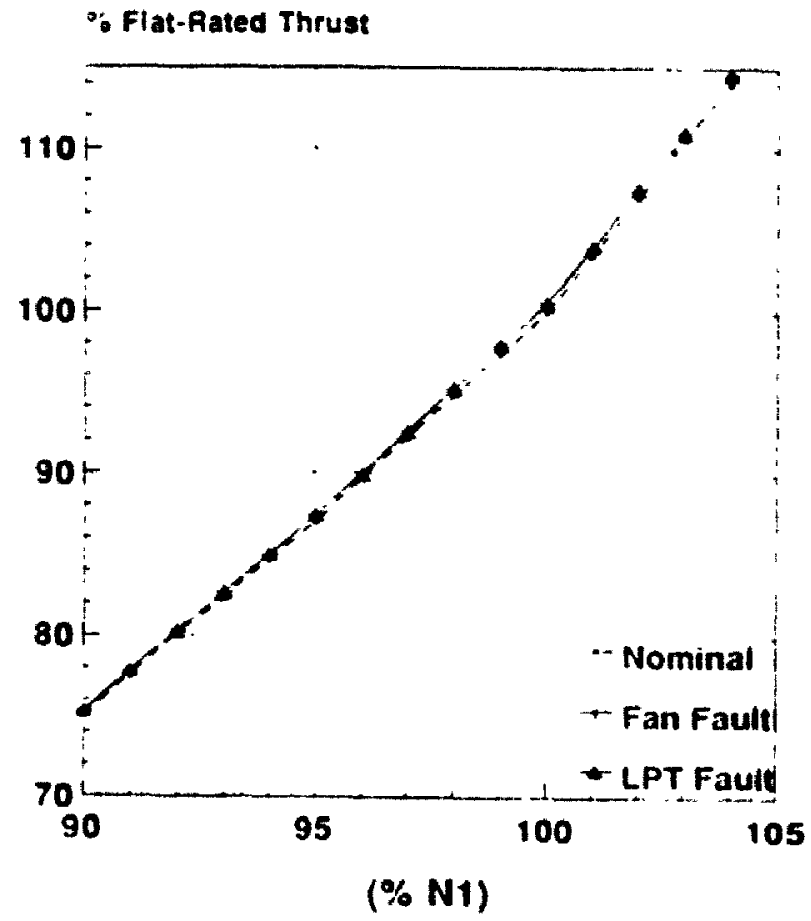

Figure 7.3 HDTO Thrust Variation with $\mathrm{N}_{1}$ for Different Faults

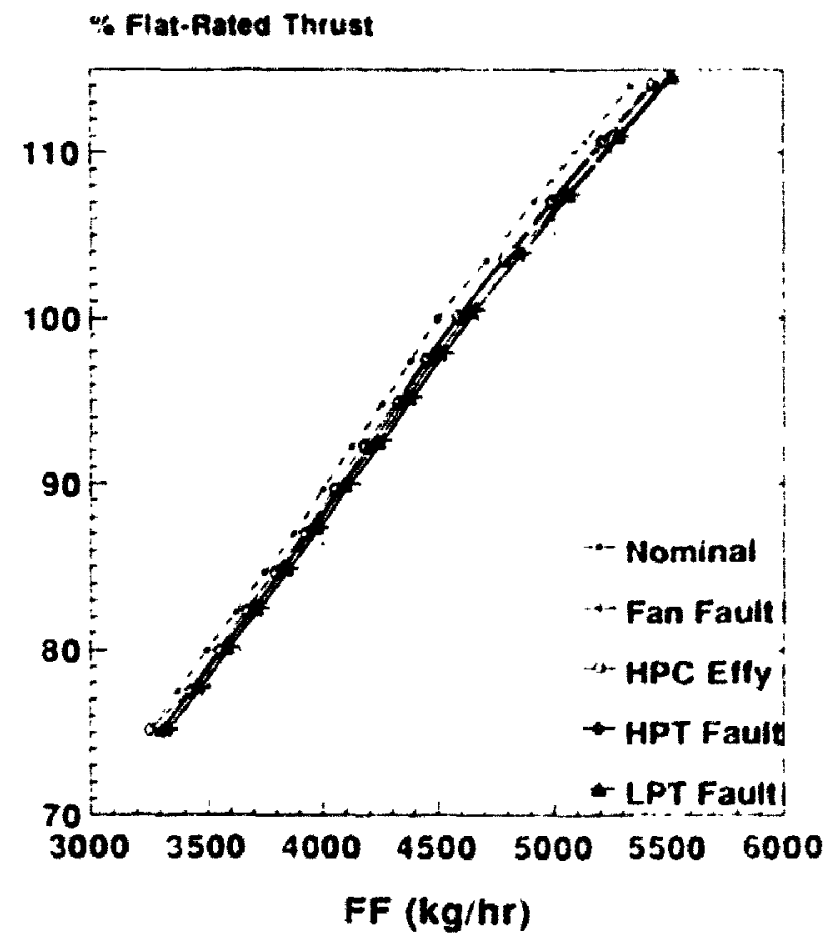

Figure 7.4 HDTO Thrust Variation with Fuel Fluw for Different Faults 


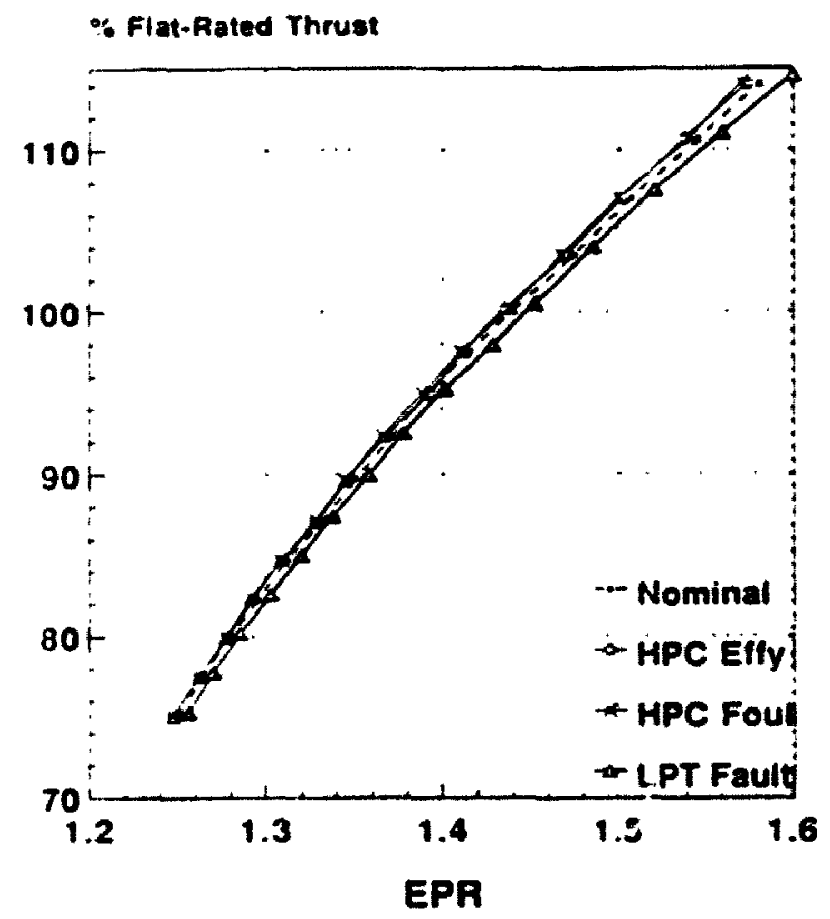

Figure 7.5 HDTO Thrust Variation with EPR for Different Faults

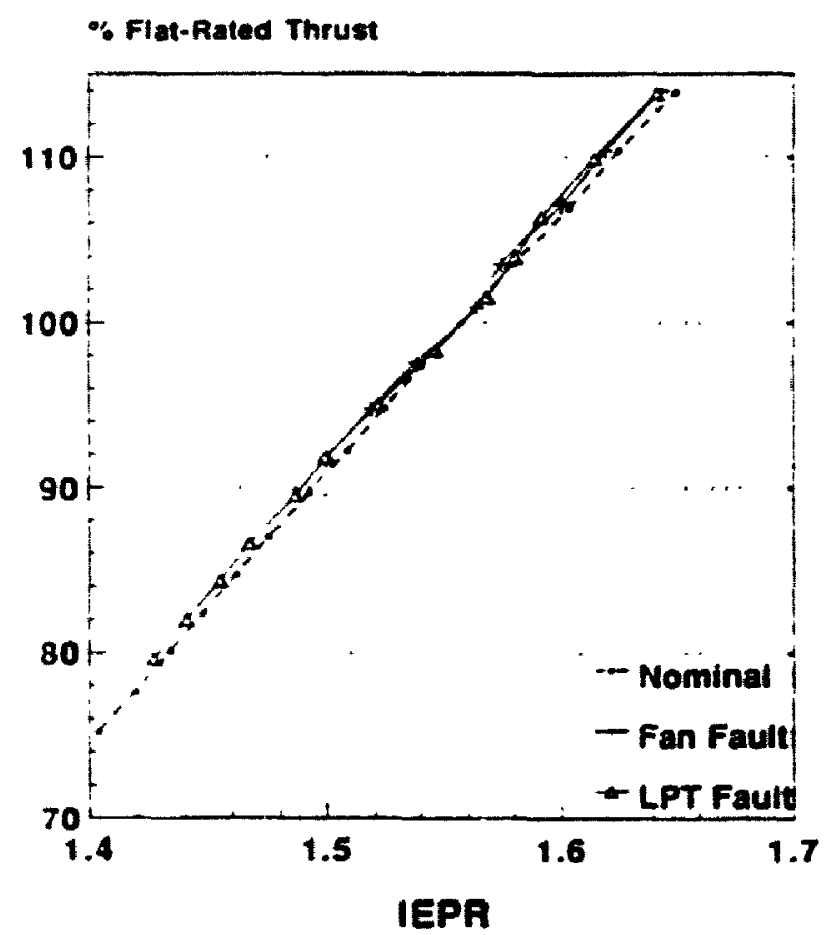

Figure 7.6 HDTO Thrust Variation with IEPR for Different Faults 


\subsubsection{HDTO Thrust when Temperature Limiting is Applied}

The engine faults modelled cause an increase in the hot end cycle temperatures, particularly the TrT and ITT. This was the reason that net delivered thrust actually increased with some kinds of faults. However, modern turbofins control the hor end temperatures in such a manner that they are limited to some level, usually the flat-rated temperature (ISA $+15^{\circ} \mathrm{C}$ was used in this study). As mentioned in Chapter 6, TIT' is rarely monitored in high bypass turbofans due to measurement difficulties. A more common approach is to monitor the gas generator exhaust gas temperature, or liTr, which provides a good indirect indicator of the TIT. This ITT is limited to some hot rating, and for purposes of this study the ITT which gives $100 \%$ thrust at IIDTO conditions has Ixen used as the limit. This was found to be approximately $890^{\circ} \mathrm{C}(116.3 \mathrm{~K})$ which correlates fairly well with quoted ITT red-lines for the CFM56 family of engines ( $A N, \operatorname{SNICM} A$ CFM56 Family of Engines Brochure, 1990).

The mean ITT iricreases observed when faults were imposed have been summarized in Table 7.3 pelow. It can be seen that the effects are virtually identical for either constant $N_{1}$ or EPR.

Table 7.3 Mean ITT Increases with Faults at HDTO Conditions

\begin{tabular}{|l|c|c|}
\hline \multirow{2}{*}{ Fault } & \multicolumn{2}{|c|}{ Increase ('C) over Nominal IID'TO IIT at Constimt } \\
\cline { 2 - 3 } & $\mathrm{N}_{1}$ & EPR \\
\hline Fan $\eta_{\infty}-2 \%$ & +25 & +22.5 \\
\hline Booster $\eta_{\infty}-2 \%$ & +5 & +5 \\
\hline HPC $\eta_{\infty}-2 \%$ & +20 & +25 \\
\hline $\begin{array}{l}\text { HPC } \eta_{\infty}-2 \%, Q 3-5 \% \\
\text { (fouling) }\end{array}$ & +30 & +32.5 \\
\hline HPT $\eta_{\infty}-2 \%$ & +15 & +18.8 \\
\hline LPT $\eta_{\infty}-2 \%$ & +12 & +15 \\
\hline
\end{tabular}


Figures 7.7 and 7.8 show the effect that faults have on the ITT at HDTO conditions, when using $N_{1}$ or EPR as the thrust setting parameter. HPC faults appear to cause the greatest increase, with HPC Fouling having the greater effect. This result is reasonable when one considers that the majority of the OPR is due to the HPC, and that high efficiency is most critical in this component in high BPR/OPR engines to limit the HPC exit temperature. Fan faults also appear to cause a rather large increase in ITT, while turbine faults have about half the effect. Booster efficiency drops seem to have very little effect on ITT, due to the small contribution they make to OPR.

The horizontal shaded line in Figures 7.7 and 7.8 represent the hot day take-off ITT limit (corresponding to the $100 \%$ thrust condition for the unfaulted engine) which is approximately $890^{\circ} \mathrm{C}(1163 \mathrm{~K})$. If this limit is imposed on the engine, it is evident that engine faults will actually cause the control system to limit the take-off thrust to a lower value than would otherwise result due to increased ITT (and hence TIT). This modifies the finding of the previous section, where some faults were found to actually cause an increase in take-off thrust. The maximum thrust at HDTO that would be available in the case of a faulty engine appears to be dependent on the choice of the thrust setting parameter. The greater the increase in ITT due to faults, the lower will be the maximum thrust setting ( $N_{1}$ or EPR) and therefore the lower the thrust. The results shown in Figures 7.7 and 7.8 may be used in conjunction with the previous results (Figure 7.3 for faulted HDTO Thrust using $N_{1}$. Figure 7.5 for faulted HDTO Thrust using EPR) to determine the actual maximum HDTO thrust that would be permitted by ITT limiting control. These are summarized in Table 7.4. 
Table 7.4 Maximum HDTO Thrust with ITT Temperature limiting

\begin{tabular}{||l|c|c||c|c|}
\hline \multirow{2}{*}{ Fault Type } & \multicolumn{4}{|c|}{ Maximum Thrusts Permitted (\% Flat-rated Thrust) } \\
\cline { 2 - 5 } & Max $\mathrm{N}_{1}(\%)$ & Max Thrust & Max EPR & Max Thrust \\
\hline No Fault & 100 & 100 & 1.4 & $1(0)$ \\
\hline Fan $\eta_{\infty}-2 \%$ & 96 & 89.8 & 1.352 & $9(1.3$ \\
\hline Booster $\eta_{\infty}-2 \%$ & 98 & 97.5 & 1.42 & 97.8 \\
\hline HPC $\eta_{\infty}-2 \%$ & 96 & 89.8 & 1.345 & 84 \\
\hline $\begin{array}{l}\text { HPC } \eta_{\infty}-2 \%, Q_{3}-5 \% \\
\text { (fouling) }\end{array}$ & 94.3 & 85.8 & 1.32 & 86 \\
\hline HPT $\eta_{\infty}-2 \%$ & 96.7 & 91.5 & 1.36 & 92.5 \\
\hline LPT $\eta_{\infty}-2 \%$ & 96.7 & 91.5 & 1.375 & 92.6 \\
\hline
\end{tabular}

Both indicators appear to give approximately the same maximum III) TO) thrus when faults are present. The worse fault conditions appear to be those affecling the IIIr: with HPC fouling apparently causing the worse decrement in take-off thrust. It should be appreciated, however, that such a high degree of HPC fouling is unlikcly to occur from external contaminants due to the high cruise altitudes where lurbofans operate, with the notable exception of flying through volcanic plumes when fouling of most engine components is much more serious! (Grove, 1992) Fan faults appear to cause a faurly major decrease in HDTO thrust when ITT limiting is applied. This is of greater concern since Fan deterioration from FOD is quite common in high bypass turbofans. (Ifoves", 1990) One may also conclude that turbine or booster faults will not have as major an impact on HDTO thrust. 


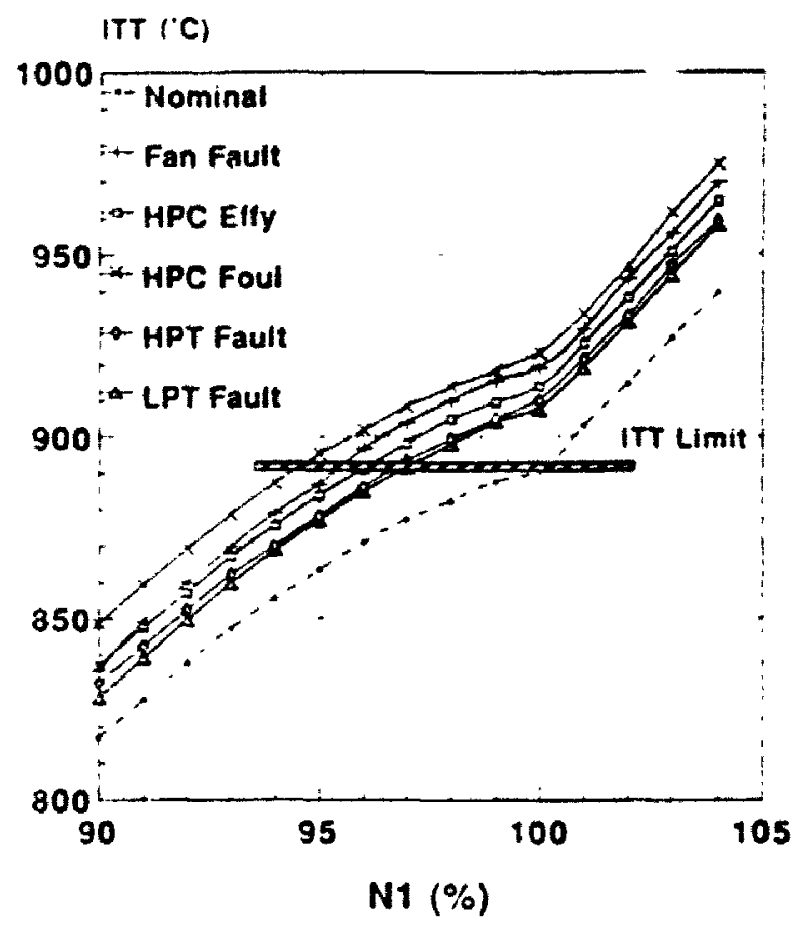

Figure 7.7 Increases in HDTO ITT with Faults when N, is Thrust Setting ITT ('C)

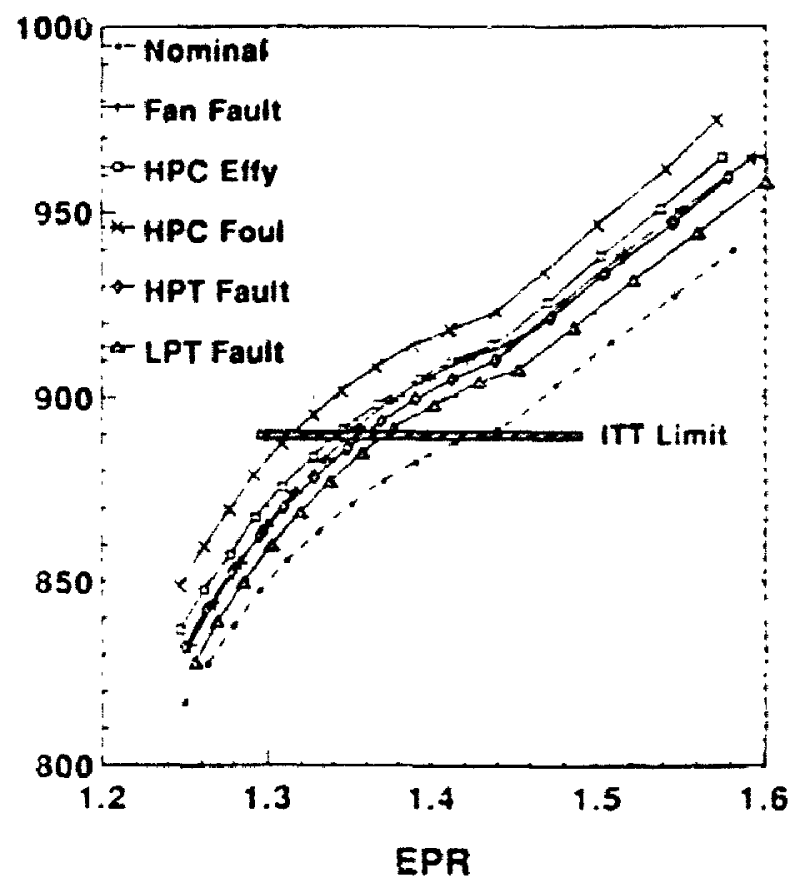

Figure 7.8 Increases in HDTO ITT with Faults when EPR is Thrust Setting 


\subsection{Cruise Performance with Faults}

Of secondary importance is the effect that faults have on the accuracy of setting cruise thrust using one of the four thrust setting parameters being examined. The matter of sufficient cruise thrust is not necessarily one of safety, but rather economics. Of particular concern to commercial airline operators is fuel burn, which should the as low as possible for a given cruise flight condition. This requires obtaining the optinum specific fuel consumption (SFC) which means getting the most thrust for the least fucl expended. Inefficient operation of turbofans (higher SFC) leads to increased fucl burn (and hence cperating costs) and can cause a reduction in cruise range. Minimizing St:C is of such concern that it has led one airline to switch engine types when guaranted SF( estimates proved optimistic. (Bailey, 1991)

This leads one to the issue of how to set cruise thrust, since once again an indirect measurement will be required. A brief study was conducted to examine the accuracy of $\mathrm{N}_{1}, \mathrm{FF}, \mathrm{EPR}$ and IEPR as cruise thrust setting parameters, when engine faults are present. The faults simulated were those listed in Table 7.1, and the methods used to simulate these were the same as done for the take-off thrust analysis. The performance at a typical cruise condition (Mach $0.8 @ 35000 \mathrm{ft}$ ) was then simulated for a range of thrust settings, hy varying $\mathrm{N}_{1}$ from 85 to $98 \%$. This was done witt each fault condition, and the results were then compared with the nominal cruise performance generated in the previous chapter.

The first thing evident from the simulations is that the faults impored result in minor changes in cruise thrust, similar to the situation at take-off. lijgure 7.9 shows the effect of using $N_{1}$ as the thrust seting parameter. The thrust at cruise for the fathly engine falls pretty well on the same line as for the unfaulted enginc. Careful cxamination of the plot does show that, like HDTO thrust, the most severe faults cause a slight increase in cruise thrust, amounting to approximately $+2 \%$ more thrust (versus a meminal thrust rating of $22 \mathrm{kN}$ at $90 \% \mathrm{~N}_{1}$ ) for a given $\mathrm{N}_{1}$ setting if either a Fan or $1.1 \%$ fault is present. HPC and HPT appear to cause very slight increases, while the LPC fault appears to have almost no effect. 
Figure 7.10 shows the situation when fuel flow (FF) is used to set cruise thrust. It appears that engine faults cause a decrease in thrust for a constant setting, or more fuel for the same thrust. This seems reasonable since polytropic efficiency decrements will have a direct impact on the overall propulsive efficiency of the turbofan. Fan faults appear to have the greatest impact, with $2 \%$ efficiency deductions causing a similar reduction in thrust for a given FF. HPC faults appear to be almost as bad, with a drop in thrust of 1.8 to $2.0 \%$. Turbine faults appear to have a smaller effect, with the $2 \%$ reductions in efficiency causing a $1.8 \%$ reduction in thrust with the LPT fault, and $1.5 \%$ reduction with the UPT fault. Once again, LPC faults appear to have little or no effect.

III is rarely used as a primary thrust setting parameter but is monitored to give an indication of engine health and cruise economy. If seen from the point of view of maintaining the same thrust (based on another indicator) more fuel will be required depending on the severity of the fauit. This is summarized in Table 7.5 below.

Table 7.5 Effect of Faults on Cruise Fuel Flow

\begin{tabular}{|l||c|c|}
\hline \multirow{2}{*}{ Fault Type } & \multicolumn{2}{|c|}{$\begin{array}{c}\text { Changes in Cruise FF at } \\
\text { Constant Thrust }\end{array}$} \\
\cline { 2 - 3 } & $(\mathrm{kg} / \mathrm{hr})$ & $\%$ Increase \\
\hline \hline Fan $\eta_{\infty}-2 \%$ & +40 & +3.2 \\
\hline Booster $\eta_{\infty}-2 \%$ & $\begin{array}{c}\text { slight } \\
\text { increase }\end{array}$ & $\begin{array}{c}\text { slight } \\
\text { increase }\end{array}$ \\
\hline HPC $\eta_{\infty}-2 \%$ & +35 & $+2.8 \%$ \\
\hline HPC Fouling & +38 & $+3 \%$ \\
\hline HPT $\eta_{\infty}-2 \%$ & +20 & $+1.6 \%$ \\
\hline LPT $\eta_{\infty}-2 \%$ & +30 & $+2.4 \%$ \\
\hline
\end{tabular}


Figures 7.11 and 7.12 show the effect of engine faults on setting cruise thrust using either EPR or IEPR respectively. Once again, IEPR appears to be the most stable indicator, with practically no deviation from the cruise thrust of the unfaulted engine. Figure 7.10 shows that the same is not true for EPR, which shows a slight deviation of thrust from the nominal curve. Fan. LPC and HPT efficiency drops appear wo have almost no effect on cruise thrust versus EPR. Both HPC faults appear to cause increased cruise thrust, $1 \%$ with efficiency decrease only, $2.3 \%$ with severe fouling. The L.YT efficiency fault appears to cause of $2.3 \%$ reduction in cruise tiinust.

The changes in setting cruise thrust to various thrust setting paramcters (when faults are present) have been summarized in Table 7.6. I'rom these results, one may conclude that IEPR appears to be the best thrust setting parameter at cruise, while fucl flow appears to be the least appropriate parameter as far as accuracy is concerned. $N_{\text {, }}$ and EPR are two of the more popular parameters (EPR being used by most Pratl \& Whitney Engines, $N_{1}$ by General Electric, SNECMA, Garrett and P\&W() despite the fact that both appear to be susceptible to inaccurate indications when various engine faults are present. The choice of one over the other does not appear to be clear, hut when one considers the probability of fauts actually occurring (with IAan, IIPC: and III'I' deterioration very likely), EPR appears to be the slightly hetler candidate provided instrumentation accuracy can be assured. LPR, however, still suffers from the problem of not giving a "feel" for its impact on delivered thrust, while the interpretation of Itan spool speed $\left(\mathrm{N}_{1}\right)$ is intuitive to most pilots. 
Table 7.6 Effect of Faults on Setting Cruise Thrust

\begin{tabular}{|l|c|c|c|c|}
\hline \multirow{2}{*}{ Fault Type } & \multicolumn{4}{|c|}{ Changes in Cruise Thrust at Constant Thrust Parameter } \\
\cline { 2 - 5 } & $\mathrm{N}_{1}$ & FF & EPR & IEPR \\
\hline Fan $\eta_{\infty}-2 \%$ & $+2.3 \%$ & $-2 \%$ & no effect & $\mathrm{n} / \mathrm{a}$ \\
\hline Booster $\eta_{\infty}-2 \%$ & no effect & no effect & no effect & $\mathrm{n} / \mathrm{a}$ \\
\hline IIPC $\eta_{\infty}-2 \%$ & $<+1 \%$ & $-1.8 \%$ & $+1 \%$ & $\mathrm{n} / \mathrm{a}$ \\
\hline $\begin{array}{l}\text { IIPC } \eta_{\infty}-2 \%, \mathrm{Q}_{3}-5 \% \\
\text { (fouling) }\end{array}$ & no effect & $-2 \%$ & $+2.3 \%$ & $\mathrm{n} / \mathrm{a}$ \\
\hline HIPT $\eta_{\infty}-2 \%$ & no effect & $-1.5 \%$ & no effect & $\mathrm{n} / \mathrm{a}$ \\
\hline L.PT $\eta_{\infty}-2 \%$ & $+2.3 \%$ & $-1.8 \%$ & $-2.3 \%$ & $\mathrm{n} / \mathrm{a}$ \\
\hline
\end{tabular}

9 At Mach 0.8 and $35000 \mathrm{ft}$ cruise. 


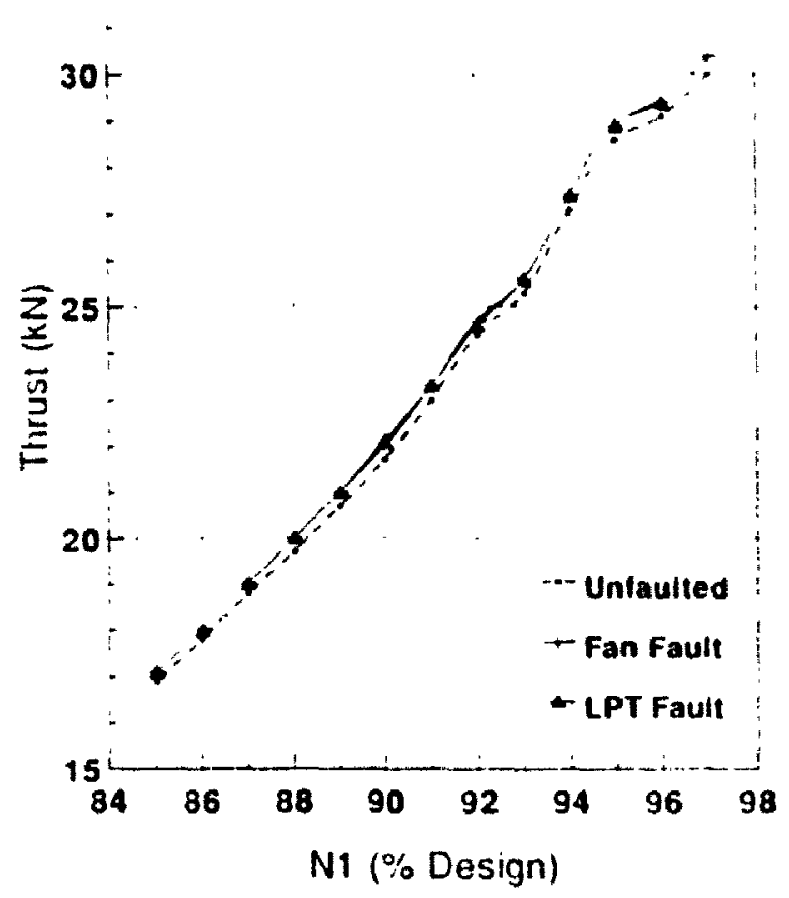

Figure 7.9 Cruise Thrust vs. $N_{1}$ for Faulty Engine

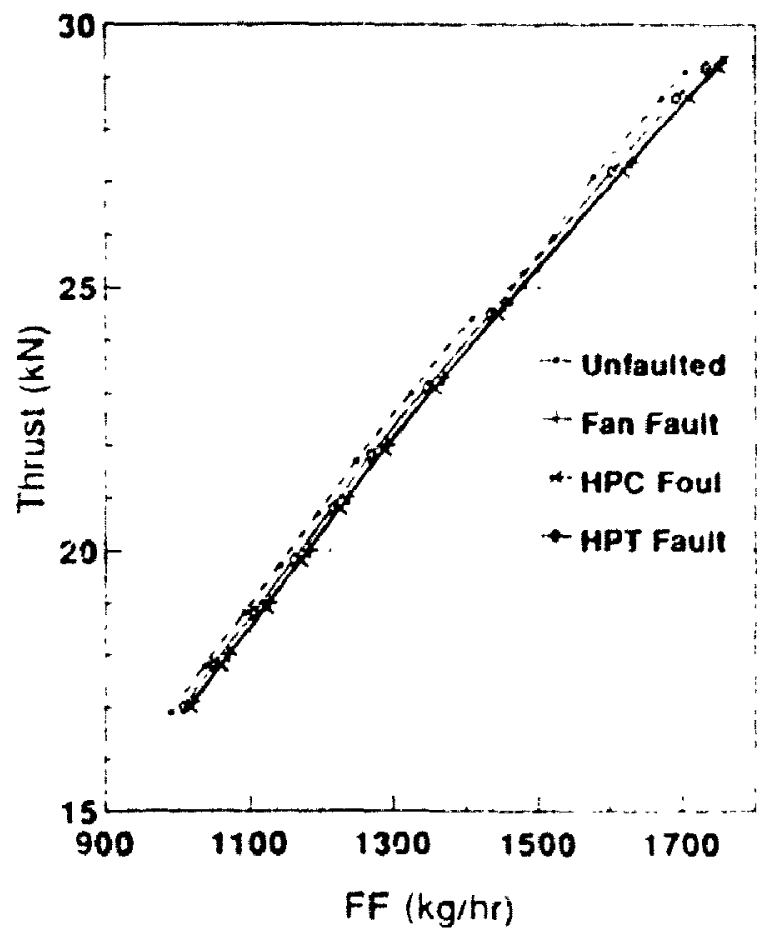

Figure 7.10 Cruise Thrust vs. Fuel Flow for Faulty Engine 
Chapter 7: Deteriorated Engine Performance Simulation

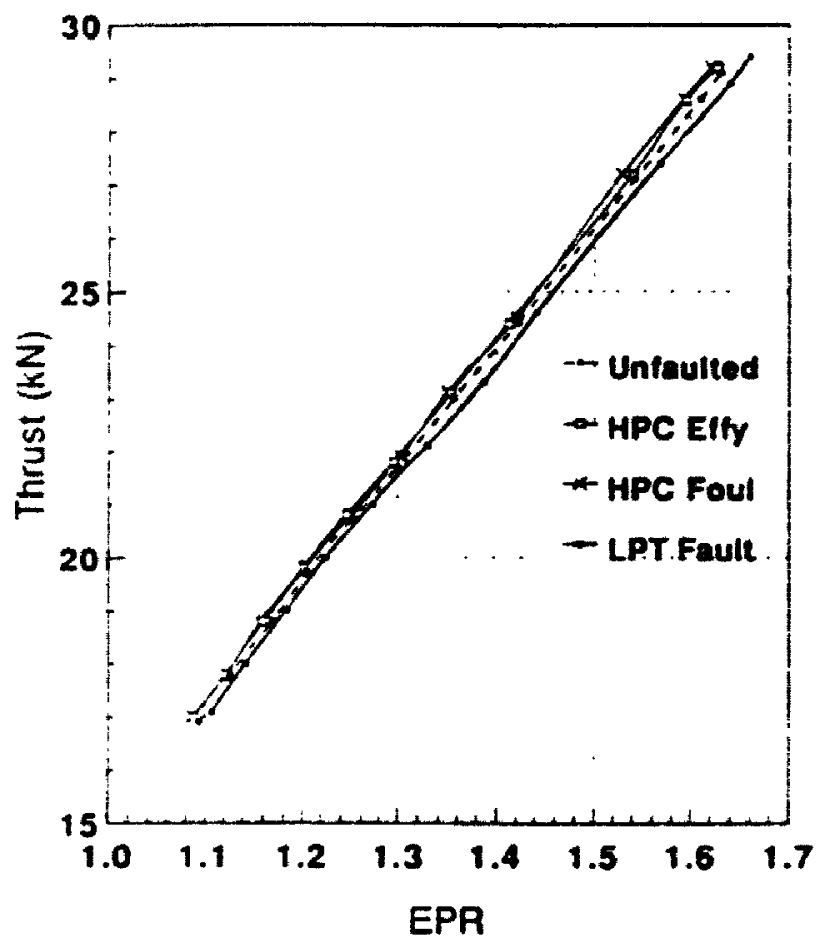

Figure 7.11 Cruise Thrust vs. EPR for Faulty Engine

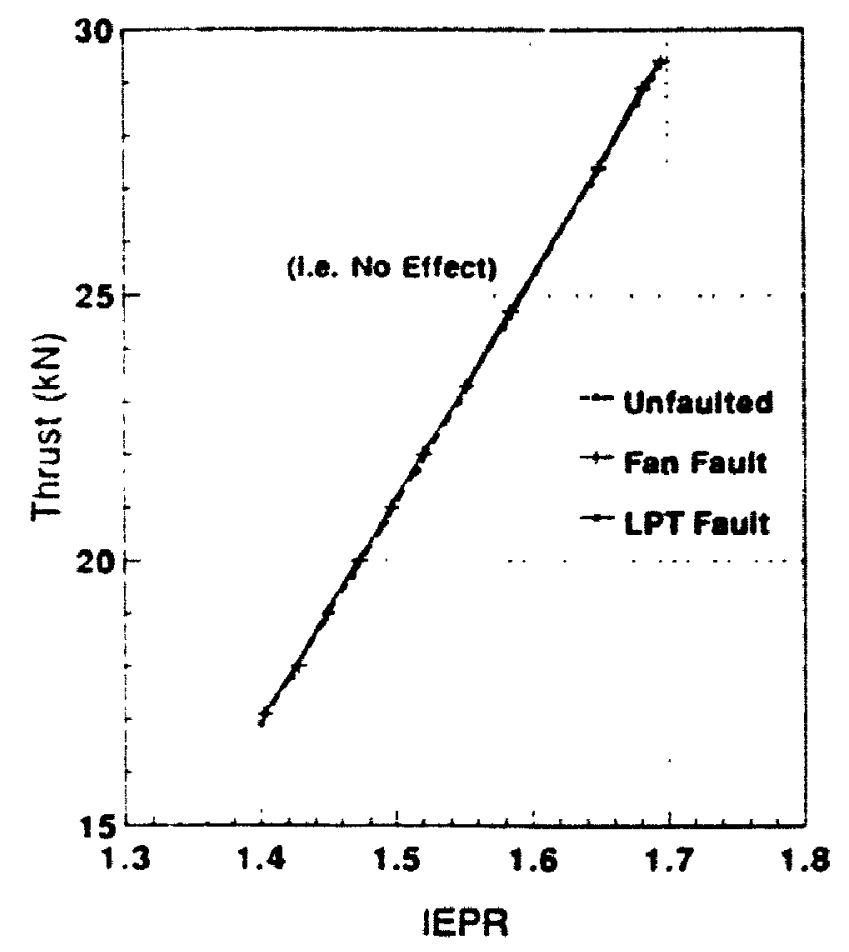

Figure 7.12 Cruise Thrust vs. IEPR for Faulty Engine 


\section{Chapter 8 Selection of Thrust Indicators}

\subsection{Observations Concerning Thrust Indicators}

It is clear from the results outlined in Chapters 6 and 7 that the selection of the "best" indirect thrust indication system is not simple. However, the following observations may be made concerning the various indicators studied:

\section{a) Fan Speed}

Fan spool speed $\left(\mathrm{N}_{1}\right)$ is a popular thrust indicator because it is easy to measure directly and accurately. It also has the unique advantage of having some physical meaning to pilots, quite unlike EPR or IEPR numbers which could seem arbitrary. Most people instinctively understand the concept of $100 \%$ speeds providing $10 \% \%$ power. However, manual setting of take-off thrusts will require additional calibrations. This latter concern is perhaps minor as modern engines become increasingly computerized. Fan spool speed therefore appears to be the most logical choice of thrust setting paraneter for current civil airline operations. $N_{2}$ should be used to monitor the engine core since engine faults can affect the cruise value of this parameter. Similarly, fucl flow should be used to monitor the cruise flight fuel economy.

\section{b) Engine Pressure Ratio}

In the absence of advanced computerized controls, I:PR seems a logical chesice for setting take-off thrust due to its unique property of being self-adjusting to different ambient temperature conditions. Engine faults do not appear wo destroy this characteristic. and temperature limiting (if applied to the ITT) has almost the same effect on J:PR thrusts as $\mathrm{N}_{1}$ thrusts. However, since EPR involves the measurcment of tola! pressures (and thus the -equirement of accurate total pressure probes) it may be more prone (o) instrument error than $\mathbf{N}_{1}$. In fact, there has been at least one fatal accident where failure in the 
intake tntal pressure ports (due to ice blockage) resulted in an inaccurate thrust setting during a foul weather take-off. It should be mentioned that while the EPR readings during this tragedy were erroneous, the other thrust indicators (especially $\mathrm{N}_{1}$ ) were consistent with a low thrust setting. ("NTSB Report Raises 737 Crash Issues", Aviation Week and Space Technology, October 18, 1982)

\section{c) Inteqrated Engine Pressure Ratio}

Of the indicators that were studied, IEPR appears to be the most stable indicator (even when faults were considered) though setting cruise thrust may still be a problem if a wide range of cruise conditions are considered as the normal operating regime of the engine. It should be realised that the accurate measurement of IEPR requires extensive pressure probe instrumentation in the fan exhaust. The theoretical basis of this indicator appears to be the most logical, however it is not the most practical (or easiest) to implement.

\subsection{Effect of Faults on Thrust Indication Accuracy}

When faults occur in the compression systems (Fan, boosters or HPC) they tend to cause a rise in downstream temperatures. If uncontrolled, this can actually lead to higher delivered thrust due to increases in TIT, but at the penalty of increased fuel consumption and decreased engine life. This tendency will be altered in actual turbofan operations when ITT limiting is used.

\section{a) Setting Take-off Thrust}

ITT temperature liniting is likely to be critical only when setting take-off thrust. When this was applied to the faulty engine simulations, it was noted that HPC faults have the greatest effect. Fan deterioration also has a fairly major impact on maximum allowable thrust levels, while turbine deterioration has less of an effect. Such deteriorations appear to affect $N_{1}$, EPR and IEPR settings for the same thrust level, but the difference between using the two most popular indicators ( $N_{1}$ and $\left.E P R\right)$ appears to be 
very minor when used with current advanced engine cycles. IEPK was the indicator least affected, which seems to suggest that it would make the hest candidate for setting take-off thrust.

\section{b) Setting Cruise Thrust}

If engine faults are present when setting cruise thrust (assuming a constamt cruise condition of Mach $0.8 @ 35000 \mathrm{ft}$ ), the maximum error is when Fan or L.PT faults are present. If $\mathrm{N}_{1}$ is used, either of these faults result in a slight increase in cruise thrust for the same $N_{1}$ setting. With a constant EPR setting, LPT faults result in reduced cruise thrust, while Fan deterioration has a minor effect. HPC faults appear to have grealter impact when setting cruise thrust with EPR.

The effect of faults appears to be very minor when using IIEPR to set cruise thrust. The same cannot be said for fuel flow, since in all cases, faults resulted in a decreased thrust for a given fuel flow setting. To maintain the same thrust level, assuming that some other thrust indicator is used, the result will be increased fuel flow. Fan and HPC: faults appeared to have the greatest effect on FF at cruise. FF theretore seems to be the least suitable primary thrust setting indicator. 


\section{Chapter 9 Conclusions and Recommendations}

\subsection{Conclusions}

\subsubsection{Thrust and Cycle Trends with Modern Turbofans}

Modern turbofans are not designed around a single design point, but rather are optimized to provide good performance at several key operating points. The primary concern at take-off is adequate thrust, while at cruise, fuel economy is more important. The Top-of-Climb condition appears to be the aerodynamic design point for the majority of modern engines, and using this as the overall "design point" provides the most accurate computer simulations of engine performance based on generalized component characteristics.

Current high bypass turbofans cierive a majority of net thrust (70-80\%) from the bypass nozzle. Higher BPR also means lower specific thrust resulting in the need for larger engines. This also provides improved SFC at cruise, and the trend for future high performance engines is towards lower specific thrust and increased BPR.

\subsubsection{Use of Indirect Thrust Selting Parameters}

Thrust from modern turbofans cannot be measured directly, so indirect thrust measurement schemes are required. However, the selection of the "best" indicator is not clear, since the results of this study has shown very little difference between the most popular methods used.

The dominance of Pratt \& Whitney in the civil jet engine industry in the 1960s and 1970)s has resulted in a large number of EPR-equipped engines (such as the JT8D and JTYI) in civil airliners. These engines, and more recent advanced Pratt \& Whitney designs, will continue to be used well into the next century. Most new entries into the civil engine market (such as General Electric or SNECMA engines) have tended to use 
$N_{1}$ (fan mechanical speed) as a prinary thrust setting parameter in civil airline engines. Meanwhile, Rolls-Royce uses IEPR in most of their high bypass turbofans. EPR continues to find wide use in most military engines where the low hypass ratio afterburning cycie is very similar to the pure turbojet.

The best choice of thrust setting parameter is not clear, as there are very minor differences when used in current high bypass engines, even when engine deterioration is considered. EPR and IEPR have the unique advantage of being self-correcting to a wide range of ambient take-off temperatures. Thus, only a single IEPR (or IIIPR) has wo lx specified to give a particular take-off thrust level. EPR and IFPR are affected by changes in altitude and forward speed (i.e. Mach Number) so selling cruise thrust is not as straight-forward. EPR and IEPR are also affected by engine cycle, particularly BPR and FPR, and this may influence whether these indicators will continue to be used. This is particularly true with the advent of Ultra High Bypass (UHB) lingines, whell extremely low values of EPR or IEPR make these values fairly meaningless as indicaturs.

$N_{1}$ appears to exhibit different behaviour at take-off and cruise operalion. Different ambient take-off conditions affect the $N_{1}$ required for a given thrust. This requires the added complication of determining the required thrust setting hy taking into account aircraft weight and ambient conditions. This is perhaps of less concern with recent engines as advanced thrust management systems find wider use. $N_{1}$ (and $N_{2}$ ) are: also fairly independent of engine cycle, with design values of these spreds lxeing the result of compromises between the rotational speeds of the acrothermal componients. Setting cruise thrust appears to be less involved when using $N_{1}$ since different hight Mach numbers and altitudes appear to have little effect. $N_{1}$ also has the advantage of lxeing: intuitive to pilots, unlike the sometimes arbitrary IEPR or HIPR settings.

Fuel flow is directly affected by different take-off and cruise conditions and hence is unreliable as a primary thrust setting parameter. Engine deterioration appears to have: a major effect at both take-off and cruise operating conditisns, generally resulting in increased fuel consumption. 


\subsection{Recommendations for Further Work}

\subsubsection{Simulation of Other Faults}

The fault simulations used during this study concerned changes to the polytropic efficiencies and non-dimensional mass flow for the HPC only. This was done to limit the scope of the study to orly those faults considered to be most likely to occur in high bypass engines. It would be instructive to examine the effect of several kinds of faults in combination. This could be done quite easily with the existing model, provided faults are simulated through changes in efficiency or non-dimensional mass flow.

The effect of various kinds of faults on component performance is not understood fully, though previous studies have shown that actual engine deterioration could be simulated fairly accurately using he methods shown in Chapter ?. It is likely that faults to the compressor components may affect the performance curves themselves and not just the pulytropic efficiency.(Saravanamuttoo and Lakshminarasimha, 1985) If this is correct. the faulted component would be changed to the extent that the original (unfaulted) component characteristic would no longer apply. However, assuming the component still functions in a manner similar to the present generalized maps, this could be simulated through changes in all three design parameters ( $Q$, efficiency and $P R$ ), which would cause the component map to be completely re-scaled. This kind of deterioration could be done with the current simulator, though changes to design point PR would necessitate the modification of the fault simulation sub-routines (FAULTSET and FAULTED) to include a third fault array.

\subsubsection{Enhancements to the Computer Model}

The current turbofian simulation package could be enhanced with the following additions. Detailed documentation of the program, including compilation information, source code listings and a variable catalogue may be found in the Users Manual that has been prepared for the program. Any changes to the program should be conducted after consulting this manual to avoid possible compiling problems. 
(a) Addition of Mixed Nozzles

The addition of mixed nozzles would be of secondary interest, since they are quite rare in high bypass engines. However, older low bypass engines (and most military engines) could be simulated by the present model with modified component characteristics and alterations to the on-design and off-design calculation procedures.

Mixed nozzles may be simulated through the use of momentum. enthalpy and mass balances between the core flow and bypass flows before the mixer, and the flow after mixing. There is an additional need to determine the Mach numbers wo chithle the calculation of static properties for these three flows, and this is assisted by the requirement that equal static pressures must exist at the mixing plane. For on design calculations, this procedure is fairly straight-forward, but the current on-design modules (such as CYCLE) would need modification to deal with a mixed single noryle.

The inclusion of a mixed nozzle during off-design calculations will recuire significant modification of the subroutine MATCH. This is necessary to allow the provision of inatching the conditions in the bypass duct with those at I.IT exil, particularly the mass, energy and momentum balances. This may include an additional iteration loop involving a search to find the most appropriate BPR since this parameter could no longer be determined using the methods for separate noz/le turlofims.

\section{(b) Graphical Display of Characteristics}

Limited time did not permit the inclusion of graphical outputs for the turistin simulation software. However, Microsoft FORTR AN version 5.6) deres have in extemive set of graphical commands which coukl be used to display the component maps in scaled form with operating points or lines indicated. Continusus displays of the fan and compressor maps during OFFDES and MATCH precedures could be used w seplace the present text screens and could provide some insight into the matching procedure. The digitized nature of the component maps as they presently exist lend thenselves to such graphical displays. Instructions on how to use such graphics may be found in the Microsoft FORTRAN Reference Manuals. 


\section{References}

AN, GE Product Brochure, 1980, "General Electric LM2500 Industrial Gas Turbine System", GEA-10523C, 4/80 (5M).

AN, Pratt \& Whitney (Canada) Inc., "JT15D Engine Data Sheet".

AN, SNECMA Sales Brochure, 1990, "CFM56 Farnily of Engines".

AN, "NTSB Report Raises 737 Crash Issues", Aviation Week and Space Technolugy, October 18, 1982, pp. 73-79.

Aker, G.F., Saravanamutwo, H.I.H., 1988, "Predicting Gas Turbine Performance Degradation due to Compressor Fouling Using Computer Simulation Techniques", Trans. ASME, Vol. 111, pp. 343-350.

Bailey, J., 1991, "The Cost of Broken Promises", Flight International, August 14-20, 1991, page 18.

Borger, J.G., 1991, "The Well Tempered Transport Aircraft Engine", Aeronautical Journal, November 1981, pp. 395.413.

Boyd, D.I., 1987. "Development of a New Technology Small Fan Jet Engine", Canadian Aeronauties and Space Journal, Vol. 33, No. 2, June 1987. 
Byworth, S. (Rolls Royce), "Turbine Cooling Technologies", Turbomachinery International, 1987.

Chappell, M.S., Cockshutt, E.P., 1974, Gas Turbine Cycle Calculations: Thermodvnamic Data Tables for Air and Combustion Products for Three Systems of Units, Aeronautical Report LR-579, NRC No. 14300, National Research Council, Ottawa, August 1974.

Cohen., H., Rogers, G.F.C., Saravanamuttoo, H.I.H., 1987, Gas Turbine Theory. 3rd edition, Longman Scientific and Technical.

Collins, A.G., Hill, R.J., 1991, "The Effects of Aerothermal Component Performance on Large Civil Turbofans", ASME Paper No. 91-(;'1-396.

Dupuis, R.J., Saravanamuttoo, H.I.H., Rudnitski, D.M., 1986, "Moxllling of Component Faults and Application to On-Condition Health Monitoring". ASMIE: Iaper No. 86-GT-153.

Grove, N., 1992, "Volcanoes: Crucibles of Creation", National Geographic, Vol. 182, No. 6, pp.31-34.

Hovey, R., Manager RB211/PW4())( Puopulsion (Air (anada), "()perattonal Experience with High Bypass Tubotan Engines", (Proceedings) C.A.S.I. Mecting, Toronto, 1990.

Kenward, J.R.D., 1976, "Thrust Management in Airline (operation", Shell Avialion News, no. 435, 1976.

Mirza-Baig, F.S., 1990, "Prediction of Off-Design Performance of 'Turbojets and Turbofans Using Gasdynamics", M.Eng Thesis, Carleton University, ()ttawa, ('anada. 
Peacock, N.J., Sadler, J.H.R., 1989, "Advanced Propulsion Systems for Large Subsonic Transports", AIAA Paper 89-2477, Monterey, CA, June 12-14.

Philpot, M.G., 1992, "Practical Considerations in Designing the Engine Cycle", A(jARI) Lecture Series LS.183, Paper 2.

Pickerell, D., 1984, "Civil Turbofan Technology to the Year 2000", Rolls-Royce North American Symposium Papers, Paper 3, San Francisco.

Reynolds, B., Etter, S., Torony, J., O’Connor, J., 1991, "Design of a Small Axial Compressor for High Efficiency over a Wide Range", ASME Paper 91-GT-195.

Rolls Royce Company, The Jet Engines, 4th Edition, 1986.

Saravanamuttoo, H.I.H., 1972, "A Rapid Matching Procedure for Twin-Spool Turbofans". Canadian Aeronautics and Space Journal, October 1972.

Saravanamuttoo, H.I.H., Lakshminarasimha, A.N., 1985, "A preliminary Assessment of Compressor Fouling", ASME Paper No. 85-GT-153.

Saravamamutioo, H.I.H., MacIsaac, B.D., 1983, "Thermodynamic Models for Pipeline Gas. Turbine Diagnostics", Trans. ASME, Journal of Engineering for Power, Vol. 105, no.4, Oct.1983, pp.875-884.

Shevell, R.S. 1989, Fundamentals of Flight, 2nd Edition, Prentice-Hall, Inc.

Williams, K., 1991, "Rolls-Royce RB211-24C Gas Turbine Computer Model", 4th Year Undergraduate Engineering project, Department of Mechanical and Aerospace Engineering, Carleton University, April 1991. 
Williams, M.R., 1984, "Large Turbofans to the Year 2000)", Aeronautical Journal, January 1984.

Wittenburg, H., 1976, "Prediction of Off-Design Performance of Turkojet and Turbofan Engines Based on Gasdynamics Relationships", Delft University of Technology. 


\section{Additional Readings}

Details on the program TURBOFN4 may be found in a separate document:

Stevenson, J., 1992, "TURBOFN4 Users Manual", Program Documentation, Carleton University, December 1992.

In addition, the following references are suggested:

MS DOS Version 5.1, USERS MANUAL, Microsoft Corporation, 1989-91.

MS FOR'TRAN Version 5.0, REFERENCE MANUAL, Microsoft Corporation, 1987-89. 

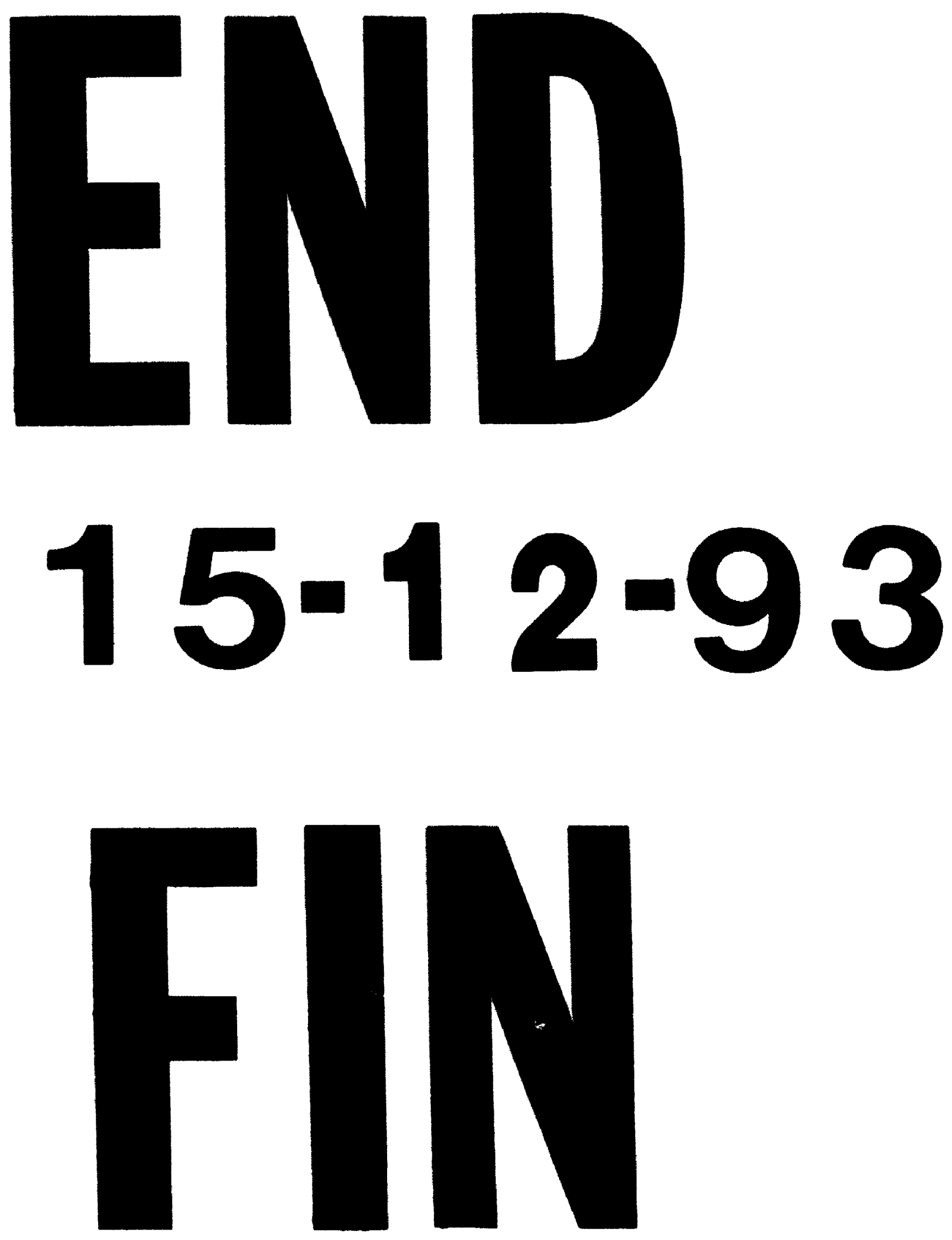